\title{
Pharmacology and Therapeutics of Bronchodilators Revisited
}

\author{
M. G. Matera, C. P. Page, L. Calzetta, P. Rogliani, and M. Cazzola
}

Unit of Pharmacology, Department of Experimental Medicine, University of Campania "Luigi Vanvitelli," Naples, Italy (M.G.M.); Sackler Institute of Pulmonary Pharmacology, Institute of Pharmaceutical Science, King's College London, London, United Kingdom (C.P.P.); and Unit of Respiratory Medicine, Department of Experimental Medicine, University of Rome "Tor Vergata," Rome, Italy (L.C., P.R., M.C.)

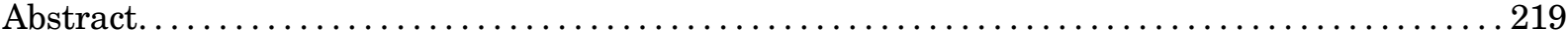

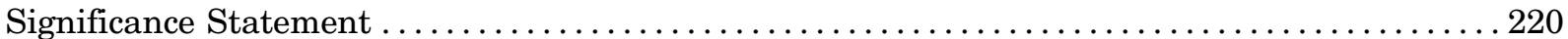

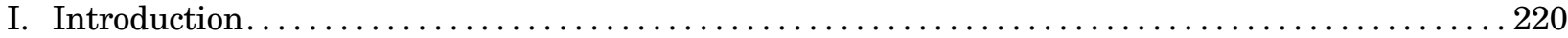

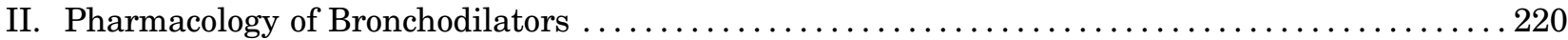

A. The Physiologic Rationale for Using Bronchodilators $\ldots \ldots \ldots \ldots \ldots \ldots \ldots \ldots \ldots \ldots \ldots 220$

B. The Pharmacological Optimization of Bronchodilation ........................ 221

1. Combining $\beta_{2}$-Adrenoceptor Agonists and Muscarinic Acetylcholine Receptor

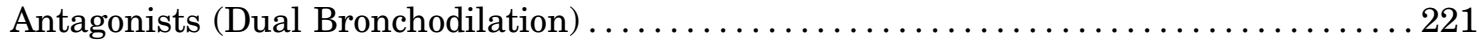

2. Combining $\beta_{2}$-Adrenoceptor Agonists and Inhaled Corticosteroids $\ldots \ldots \ldots \ldots \ldots \ldots \ldots 221$

3. Combining Muscarinic Acetylcholine Receptor Antagonists and Inhaled

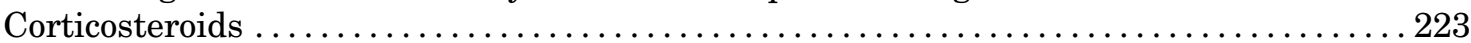

4. Combining $\beta_{2}$-Adrenergic Receptor Agonists, Muscarinic Receptor Antagonists, and

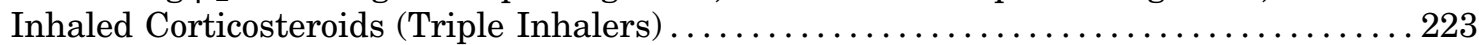

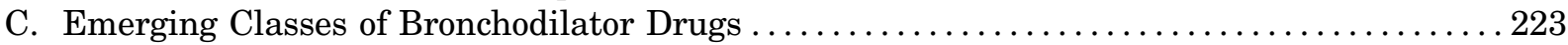

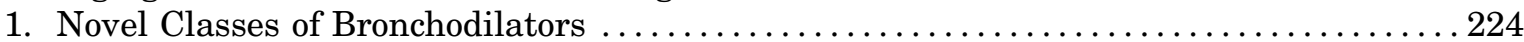

a. Bitter Taste Receptor Agonists ..................................... 224

b. E-Prostanoid Receptor 4 Agonists . . . . . . . . . . . . . . . . . . . . . . . . . . 225

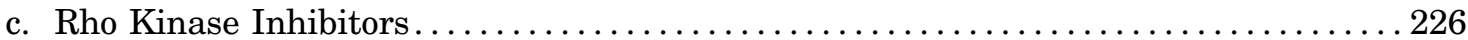

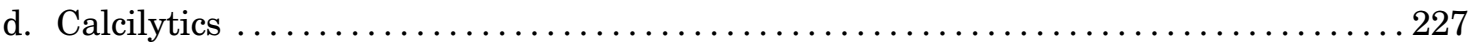

e. Agonists of Peroxisome Proliferator-Activated Receptor- $\gamma \ldots \ldots \ldots \ldots \ldots \ldots \ldots \ldots 227$

f. Relaxin Family Peptide Receptor 1 Receptor Agonists...................... 227

g. Soluble Guanylyl Cyclase Activators.................................. 227

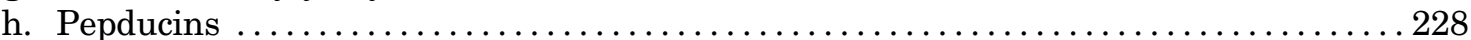

2. Improvements to Existing Classes of Bronchodilators $\ldots \ldots \ldots \ldots \ldots \ldots \ldots \ldots \ldots \ldots \ldots 228$

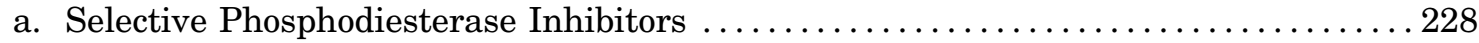

b. Novel $\beta_{2}$-Adrenoceptor Agonists . ................................. 229

c. Novel Muscarinic Acetylcholine Receptor Antagonists ........................ 229

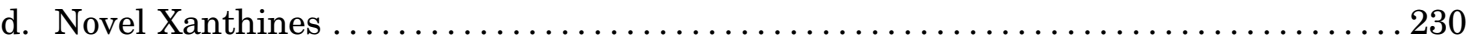

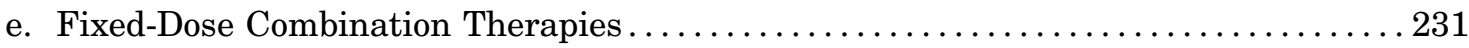

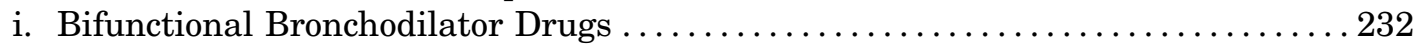

ii. Bifunctional Bronchodilator/Anti-Inflammatory Drugs ................. 232

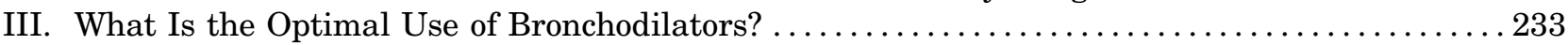

A. Is It Appropriate to Treat All Patients Suffering from Airway Obstruction with Long-

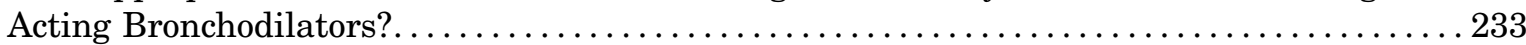

B. Is It Better to Start with a $\beta_{2}$-Adrenergic Receptor Agonist or with a Muscarinic

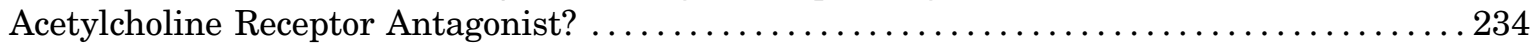

C. Is It Useful to Use a Bronchodilator with a Rapid Onset of Action? . . . . . . . . . . . . . . . . 234

D. Is Once-a-Day or Twice-a-Day Dosing Preferable? ............................235

E. When Should a Second Bronchodilator with a Different Mechanism of Action Be Added? . . 235

Address correspondence to: M. Cazzola, Dipartimento di Medicina Sperimentale, Università di Roma Tor Vergata, Via Montpellier 1, 00131 Rome, Italy. E-mail: mario.cazzola@uniroma2.it https://doi.org/10.1124/pr.119.018150. 
F. When Must an Inhaled Corticosteroid Be Added?.......................... 236

1. Combination Therapy of $\beta_{2}$-Adrenergic Receptor Agonists and Inhaled

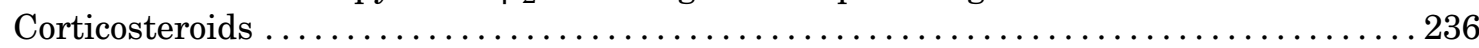

2. Combining Muscarinic Acetylcholine Receptor Antagonists and Inhaled

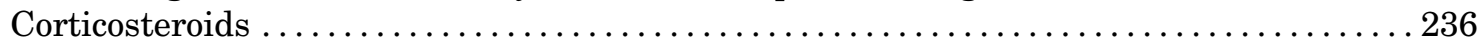

3. Combining Dual Bronchodilation and Inhaled Corticosteroids .................2237

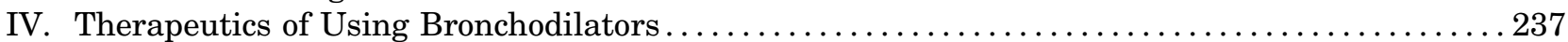

A. The Role of Bronchodilators in the Management of Asthma ......................237

B. The Role of Bronchodilators in the Management of Chronic Obstructive Pulmonary

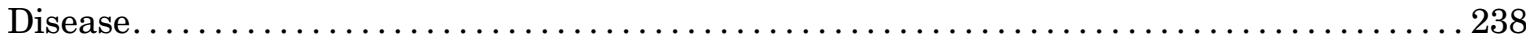

C. Use of Bronchodilators for Treatable Traits in Airway Diseases................... 240

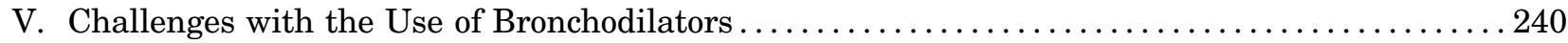

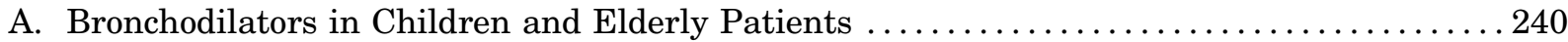

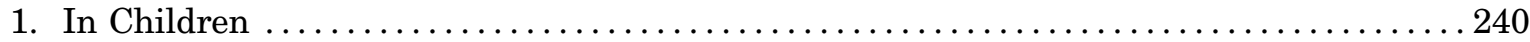

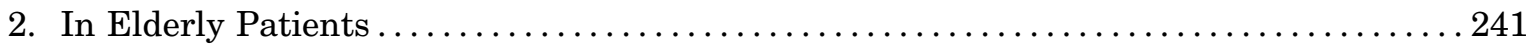

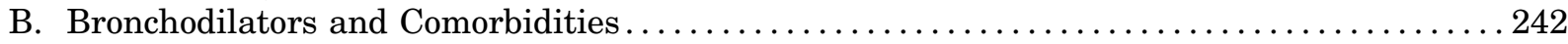

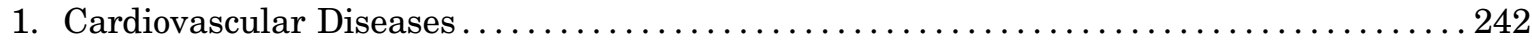

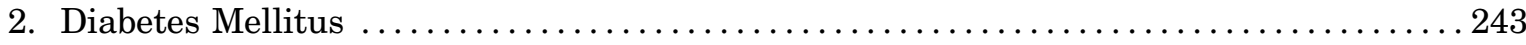

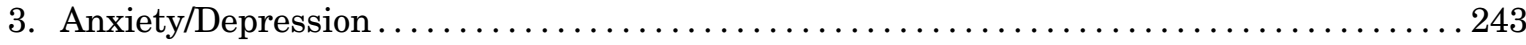

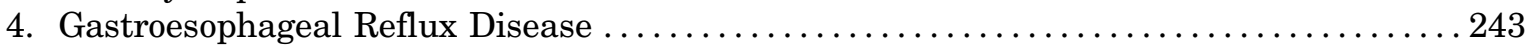

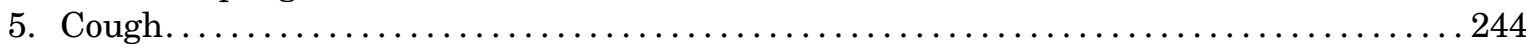

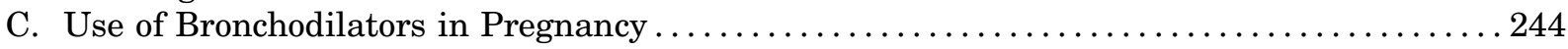

D. Pharmacogenetics of Airway Obstruction and Bronchodilators ................... 245

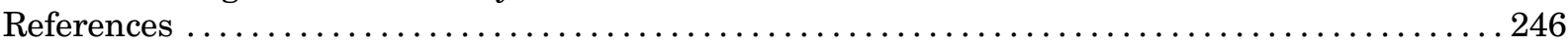

Abstract_-Bronchodilators remain the cornerstone of the treatment of airway disorders such as asthma and chronic obstructive pulmonary disease (COPD). There is therefore considerable interest in understanding how to optimize the use of our existing classes of bronchodilator and in identifying novel classes of bronchodilator drugs. However, new classes of bronchodilator have proved challenging to develop because many of these have no better efficacy than existing classes of bronchodilator and often have unacceptable safety profiles. Recent research has shown that optimization of bronchodilation occurs when both arms of the autonomic nervous system are affected through antagonism of muscarinic receptors to reduce the influence of parasympathetic innervation of the lung and through stimulation of $\beta_{2}$-adrenoceptors $\left(\beta_{2}\right.$-ARs) on airway smooth muscle with $\beta_{2}$-AR-selective agonists to mimic the sympathetic influence on the lung. This is currently achieved by use of fixed-dose combinations of inhaled long-acting $\beta_{2}$-adrenoceptor agonists (LABAs) and long-acting muscarinic acetylcholine receptor antagonists (LAMAs). Due to the distinct mechanisms of action of LAMAs and LABAs, the additive/synergistic effects of using these drug classes together has been extensively investigated. More recently, so-called "triple inhalers" containing fixed-dose combinations of both classes of bronchodilator (dual bronchodilation) and an inhaled corticosteroid in the same inhaler have been developed. Furthermore, a number of so-called "bifunctional drugs" having two different primary pharmacological actions in the same molecule are under development. This review discusses recent

\footnotetext{
ABBREVIATIONS: AC, adenylyl cyclase; ACh, acetylcholine; ACO, asthma-chronic obstructive pulmonary disease overlap; ASM, airway smooth muscle; $\beta_{2}$-AR, $\beta_{2}$-adrenoceptor; C26, 7-[(R)-2-((1R,2R)-2- benzyloxycyclopentylamino)-1-hydroxyethyl]-4-hydroxybenzothiazolone; $\left[\mathrm{Ca}^{2+}\right]_{\mathrm{i}}$, intracellular $\mathrm{Ca}^{2+}$ concentration; CaSR, calcium-sensing receptor; CAT, COPD assessment test; compound 5j, 8-hydroxy-5-(2-hydroxy-1-((4-hydroxyphenethyl)amino)ethyl)quinolin-2(1H)-one; COPD, chronic obstructive pulmonary disease; CPI-17, PKC-potentiated

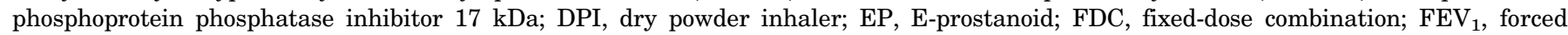
expiratory volume in 1 second; GINA, Global Initiative for Asthma; GOLD, Global Initiative for Chronic Obstructive Lung Disease; GPCR, G protein-coupled receptor; HRQL, health-related quality of life; ICL, intracellular loop; ICS, inhaled corticosteroid; IP 3 , inositol-1,4,5trisphosphate; $\mathrm{KCa}^{++}$, calcium-activated potassium; L-902688, (5-[(1E,3R)-4,4-difluoro-3-hydroxy-4-phenyl-1-buten-1-yl]-1-[6-(2H-tetrazol-5Ryl)hexyl]-2-pyrrolidinone); LABA, long-acting $\beta_{2}$-adrenoceptor agonist; LAMA, long-acting muscarinic acetylcholine receptor antagonist; LASSBio 596, (2-[4-(1,4-tiazinan-4-ylsulfonyl) phenylcarbamoyl] benzoic acid); MABA, muscarinic acetylcholine receptor antagonist- $\beta_{2}$ adrenoceptor agonist; mAChR, muscarinic acetylcholine receptor; MLC, myosin light chain; MLCP, myosin light chain phosphatase; NNT, number needed to treat; NO, nitric oxide; ONO-AE1-329, (2-[3-[(1R,2S,3R)-3-hydroxy-2-[(E,3S)-3-hydroxy-5-[2-(methoxymethyl)phenyl]pent-1enyl]-5-oxocyclopentyl]sulfanylpropylsulfanyl]acetic acid); PDE, phosphodiesterase; PKA, protein kinase A; PKC, protein kinase C; PLC, phospholipase C; PPAR $\gamma$, peroxisome proliferator-activated receptor- $\gamma$; ROCK, Rho-associated protein kinase; RXFP, relaxin family peptide receptor; SABA, short-acting $\beta_{2}$-adrenoceptor agonist; SAMA, short-acting muscarinic acetylcholine receptor antagonist; sGC, soluble guanylyl cyclase; SMART, single maintenance and reliever therapy; SNP, single nucleotide polymorphism; SPFF (trantinterol), 2-(4-amino-3-chloro-5trifluomethyl-phenyl)-2-tert-butylamino-ethanol hydrochloride; SR, sarcoplasmic reticulum; TAS2R, type 2 taste receptor; TD-4208 (revefenacin), biphenyl-2-ylcarbamic acid 1-(2-\{[4-(4-carbamoylpiperidin-1-ylmethyl)benzoyl]methylamino\}ethyl)piperidin-4-yl ester; TNFAIP3, tumor necrosis factor $\alpha$-induced protein 3; V0162, 10-[(3R)-1-azabicyclo[2.2.2]oct-3-ylmethyl]-10H-phenothiazine.
} 
advancements in knowledge on bronchodilators and bifunctional drugs for the treatment of asthma and COPD.

Significance Statement-Since our last review in 2012, there has been considerable research to identify novel classes of bronchodilator drugs, to further understand how to optimize the use of the existing classes of bronchodilator, and to better understand the role of bifunctional drugs in the treatment of asthma and chronic obstructive pulmonary disease.

\section{Introduction}

Inhaled bronchodilators are critical to the optimal management of patients with chronic obstructive pulmonary disease (COPD) at all phases of the disease (https:// www.goldcopd.org/) and are crucial in the management of patients with asthma (https://ginasthma.org).

In 2012 we published a comprehensive review on the pharmacology and therapeutics of bronchodilators (Cazzola et al., 2012b); since then, extensive research has been undertaken to identify novel classes of bronchodilator drugs (Cazzola and Matera, 2014) and to better understand how to optimize the use of the existing classes of bronchodilator. This review provides an update on the recent advances in this area of pharmacology since 2012 .

\section{Pharmacology of Bronchodilators}

\section{A. The Physiologic Rationale for Using Bronchodilators}

Physiologically, airway smooth muscle (ASM) tone is predominantly controlled by the parasympathetic nervous system via cholinergic and, to a lesser degree, noncholinergic innervation (Cazzola et al., 2012b). It is now well established that increased vagus nerve activity plays a key role in eliciting airway obstruction in patients with COPD or asthma and seems to be a major reversible component of airway obstruction. Acetylcholine $(\mathrm{ACh})$ is the neurotransmitter in the parasympathetic nervous system, both in the ganglia and at the neuroeffector junction. ACh activates muscarinic acetylcholine receptors (mAChRs) postsynaptically on ASM and mucous glands (reviewed by Cazzola et al., $2012 \mathrm{~b}$ ) to elicit bronchoconstriction and mucous secretion, respectively.

$\mathrm{G}_{\mathrm{i}}$-coupled $\mathrm{M}_{2}$ mAChRs are highly expressed on ASM and activation of this receptor type inhibits adenylyl cyclase (AC) to reduce the intracellular concentration of cAMP. ACh also activates $\mathrm{G}_{\mathrm{q}}$-coupled $\mathrm{M}_{3} \mathrm{mAChRs}$ on ASM to activate phospholipase C (PLC) and elevate intracellular $\mathrm{Ca}^{2+}$ concentration $\left(\left[\mathrm{Ca}^{2+}\right]_{\mathrm{i}}\right)$ through several pathways that involve $\mathrm{Ca}^{2+}$ influx and sarcoplasmic reticulum (SR) $\mathrm{Ca}^{2+}$ release. There is a nearly 4-fold higher expression of the $\mathrm{M}_{2}$ subtype in the large airways, although ASM contraction is mediated primarily through activation of $\mathrm{M}_{3}$ mAChRs (Cazzola et al., 2012b; Rydell-Törmänen et al., 2013).

The activation of $\mathrm{M}_{3} \mathrm{mAChRs}$ (reviewed by Meurs et al., 2013) by ACh and the subsequent activation of
PLC lead to the hydrolysis of phosphatidylinositol 4,5bisphosphate to generate inositol-1,4,5-trisphosphate $\left(\mathrm{IP}_{3}\right)$ and diacylglycerol in $\mathrm{ASM} . \mathrm{IP}_{3}$ causes the mobilization of $\mathrm{Ca}^{2+}$ from the SR, an effect that induces a fast and temporary increase in $\left[\mathrm{Ca}^{2+}\right]_{\mathrm{i}}$, which initiates contraction of ASM by activation of $\mathrm{Ca}^{2+}$-calmodulindependent myosin light chain (MLC) kinase that is followed by the phosphorylation of the $20-\mathrm{kDa}$ MLC. It is commonly believed that the tonic phase of contraction of ASM is the consequence of a continuing influx of $\mathrm{Ca}^{2+}$ through receptor-operated channels and store-operated channels, with the involvement of canonical transient receptor potential channels and Stim1/Orai1 proteins. Furthermore, $\mathrm{M}_{3} \mathrm{mAChRs}$ activate CD38, also known as cyclic ADP ribose hydrolase, which leads to an increase in the production of cyclic ADP ribose, resulting in the release of $\mathrm{Ca}^{2+}$ from the SR via ryanodine receptor channels. Diacylglycerol also activates protein kinase $\mathrm{C}$ (PKC), which may be involved in ASM contraction via $\mathrm{Ca}^{2+}$-dependent and $\mathrm{Ca}^{2+}$-independent mechanisms. PKC activation contributes to agonistinduced $\mathrm{Ca}^{2+}$ mobilization from the SR with the subsequent influx of extracellular $\mathrm{Ca}^{2+}$ and also causes the phosphorylation of PKC-potentiated phosphoprotein phosphatase inhibitor $17 \mathrm{kDa}$ (CPI-17), a phosphorylation-dependent inhibitory protein for myosin light chain phosphatase (MLCP) expressed in smooth muscle that, by inhibiting MLCP, induces $\mathrm{Ca}^{2+}$ sensitization. $\mathrm{Ca}^{2+}$ sensitization also regulates $M_{3}$ mAChR-mediated ASM contraction via activation of the RhoA/Rho kinase pathway that phosphorylates MLCP and CPI-17. Activation of $\mathrm{M}_{3} \mathrm{mAChRs}$ also influences $\beta_{2}$-adrenoceptor $\left(\beta_{2}\right.$-AR)-mediated relaxation of ASM by activating PKC, which successively phosphorylates $\beta_{2}$-AR and the $G_{\mathrm{s}}$ subunits leading to desensitization of these proteins (Calzetta et al., 2015).

The vagus nerve innervates larger airways and when stimulated releases ACh that activates $M_{3}$ mAChRs located on ASM cells. In the small airways, $\mathrm{M}_{3} \mathrm{mAChRs}$ are present on ASM but there is no vagal innervation, and it is thought that the so-called nonneurogenic ACh is released locally from epithelial cells lining the airways known to contain choline acetyltransferase activity (Matera and Cazzola, 2017).

Direct adrenergic innervation of ASM is sparse in humans, but $\beta_{2}$-ARs are densely expressed on this cell type. Activation of $\beta_{2}$-ARs on ASM generates intracellular cAMP by AC activation, which in turn involves the activation of its effector molecules, cAMP-dependent 
protein kinase A (PKA) and exchange protein activated directly by cAMP, which is a Rap1 guanine nucleotide exchange factor (reviewed by Billington et al., 2013; Cazzola et al., 2013b). PKA phosphorylates crucial regulatory proteins implicated in the control of ASM tone, whereas exchange protein activated directly by cAMP downregulates Rho and consequently induces ASM relaxation via a PKA-independent manner. The generation of intracellular cAMP results in sequestration of $\left[\mathrm{Ca}^{2+}\right]_{i}$ that results in the relaxation of ASM (Billington and Hall, 2012). However, increasing evidence is emerging that signaling through AC-coupled pathways is not as simple as previously thought (Billington and Hall, 2012). In fact, many studies have questioned whether cAMP formation indeed is the main mechanism whereby activation of $\beta_{2}$-ARs elicits ASM relaxation (Cazzola et al., 2013b). Thus, it has been demonstrated that calcium-activated potassium $\left(\mathrm{KCa}^{++}\right)$channel activation is important for $\beta_{2}-\mathrm{AR}-$ mediated ASM relaxation through either cAMP/PKAmediated signaling or non-cAMP pathways (Dale et al., 2014).

\section{B. The Pharmacological Optimization of Bronchodilation}

There is now considerable evidence suggesting that combining mAChR antagonists and $\beta_{2}$-AR agonists, with the possible addition of inhaled corticosteroids (ICSs), is a method to optimize bronchodilation, at least with the currently approved drugs. These combinations offer both short- and long-term benefit to subjects suffering from asthma or COPD, without the need to increase the dose of the monocomponents, which thus reduces the risk of adverse events (Fig. 1).

1. Combining $\beta_{2}$-Adrenoceptor Agonists and Muscarinic Acetylcholine Receptor Antagonists (Dual Bronchodilation). It is now well documented that combinations of low and isoeffective concentrations of long-acting $\beta_{2}$-adrenoceptor agonists (LABAs) and long-acting muscarinic acetylcholine receptor antagonists (LAMAs) induce a greater relaxation of ASM than using the monocomponents, likely due to significant synergistic interaction between the two distinct pharmacological approaches (Cazzola et al., 2014, 2016a). This synergistic interaction has been confirmed in small clinical trials in patients with COPD (Cazzola et al., 2015b,c).

Several mechanisms have been suggested to explain the synergy between LABAs and LAMAs at the ASM level and presynaptically in parasympathetic nerve fibers (Cazzola and Molimard, 2010; Calzetta et al., $2015,2018 b, d)$. At the presynaptic level, prejunctional $\beta_{2}$-ARs activated by LABAs in turn stimulate $\mathrm{KCa}^{++}$ channels and thus modulate the release of ACh into the synaptic space. It is likely that these channels reduce the concentration of $\left[\mathrm{Ca}^{2+}\right]_{\mathrm{i}}$ by hyperpolarizing the cell membrane and, consequently, inhibit the release of $\mathrm{ACh}$.
LAMAs can also inhibit ganglionic transmission because they antagonize $\mathrm{M}_{1} \mathrm{mAChRs}$, which are facilitatory to $\alpha 7$ nicotinic ACh receptors in the cell body of postganglionic parasympathetic neurons. LAMAs antagonize the activation of mAChRs by ACh on ASM to prevent contraction, whereas LABAs are agonists at $\beta_{2}$-ARs stimulating relaxation of ASM directly. $\beta_{2}$-AR activation of ASM induces intracellular signaling mechanisms described above that reduce $\mathrm{IP}_{3}$ production mediated by $\mathrm{M}_{3}$ mAChRs with the probable involvement of PKA. In contrast, $\mathrm{M}_{3} \mathrm{mAChR}$ antagonism can influence the relaxation of ASM induced by $\beta_{2}$-AR agonists, most likely because it blocks the activation of PKC and the consequent phosphorylation of $\beta_{2}$-AR and/or $\mathrm{G}_{\mathrm{s}}$ protein. Thus, the coadministration of a LAMA with a LABA increases the synthesis of cAMP to result in increased ASM relaxation. Protein tyrosine kinases and $\mathrm{KCa}^{++}$channels were also recently shown to be central to the synergistic interaction between LABAs and LAMAs. In small airways, the modulation of ASM tone is also under the control of non-neurogenic $\mathrm{ACh}$ that is synthetized in and released from the epithelium. LABAs and LAMAs also activate $\beta_{2}$-ARs and antagonize $\mathrm{M}_{3} \mathrm{mAChRs}$ expressed on the surface of bronchial epithelial cells, which leads to a reduction of the release of non-neurogenic ACh by modulating organic cationic transporter activity (Cazzola et al., 2016a).

A number of LABA/LAMA combinations in a single inhaler have now been approved for clinical use as treatments for patients with COPD (Table 1).

2. Combining $\beta_{2}$-Adrenoceptor Agonists and Inhaled Corticosteroids. Although it has been suggested that LABAs and ICSs each cause several independent, noninteracting responses that are associated in an additive way to induce clinical benefit (Newton and Giembycz, 2016), bidirectional molecular interactions between corticosteroids and $\beta_{2}$-agonists have also been suggested for the reciprocal potentiation of the pharmacological effects of ICS and LABAs (Pelaia et al., 2015). Such a cooperative cross-talk between these two drug classes is widely exploited in the treatment of patients with asthma and in some patients with COPD by providing complementary bronchodilator and antiinflammatory actions when these two drug classes are administered concomitantly (Cazzola and Matera, 2017). Furthermore, recent in vitro evidence indicates that LABA/ICS combinations can produce a synergistic bronchorelaxant effect in both small and medium-size human airways, with a greater synergistic effect in hyperresponsive airways than in nonsensitized tissues (Calzetta et al., 2018c).

The expression of tumor necrosis factor $\alpha$-induced protein 3 (TNFAIP3), a feedback regulator of nuclear factor $-\kappa \mathrm{B}$ that negatively influences the repression of nuclear factor- $\kappa \mathrm{B}$-dependent transcription and also the repression of TNF expression, is induced by 


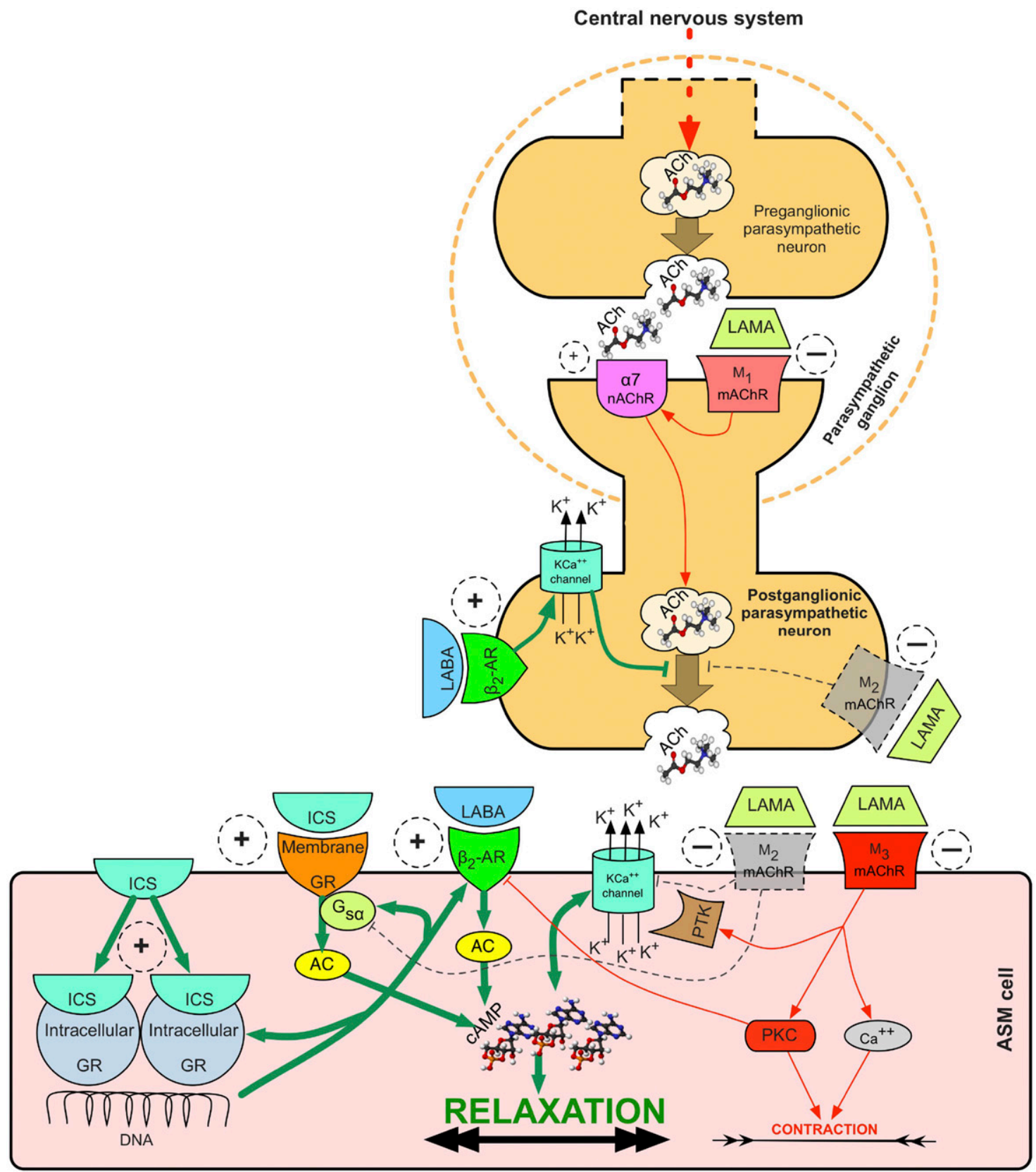

Fig. 1. The pharmacological optimization of bronchodilation. LABAs and LAMAs both modulate the bronchial tone via different pathways localized at the level of presynaptic parasympathetic fibers and ASM cells. The exact nature of the interactions between these pathways is not completely understood, but there is cross-talk at many levels in ASM cells that is also regulated by the activity of calcium-activated potassium channels and protein tyrosine kinases. ICSs freely diffuse from the circulation across cell membranes into cells, where they activate the GR. The activated ICS-GR also binds to the $\beta_{2}$-AR gene, leading to an increase in the number of $\beta_{2}$-ARs in the cell membrane. On the other side, LABA stimulates $\beta_{2}$-ARs, leading to the priming of the GR and increasing translocation of the receptor into the nucleus of the cell. GR, glucocorticoid receptor; PTK, protein tyrosine kinase.

a corticosteroid and is noticeably, although transiently, influenced by a LABA, which alone has only a minor effect on TNFAIP3 mRNA expression (Altonsy et al., 2017). Furthermore, treatment with an ICS plus a LABA enhances TNF-induced TNFAIP3 expression, a protein known to be reduced in patients with asthma (Rider et al., 2018).

Corticosteroids induce gene transcription via glucocorticoid receptor-mediated transactivation (Newton and Giembycz, 2016). LABAs can also increase the expression of some glucocorticoid-inducible genes (Rider et al., 2018), although the function of individual genes of relevance to treating asthma or COPD is not fully understood.

It is important to note that LABAs are not identical and the differences, which can also be significant, need to be taken into account when choosing a LABA/ICS combination (Cazzola et al., 2013c). In particular, formoterol has a very rapid onset of action compared with the slower-acting salmeterol and this important 
TABLE 1

Fixed-dose combination inhalers

\begin{tabular}{|c|c|c|c|}
\hline Drug Class & Generic Name & Form & Dose \\
\hline \multirow[t]{6}{*}{ LABA/LAMA } & Formoterol/aclidinium & $\begin{array}{l}\text { Inhalation } \\
\text { powder }\end{array}$ & $12 / 400 \mu \mathrm{g}$ twice a day \\
\hline & Indacaterol/glycopyrronium & $\begin{array}{l}\text { Inhalation } \\
\text { powder }\end{array}$ & 27.5/15.6 $\mu \mathrm{g}$ twice a day (United States) \\
\hline & Formoterol/glycopyrronium & $\begin{array}{l}\text { Inhalation } \\
\text { aerosol }\end{array}$ & $\begin{array}{l}\text { 9.6/18 } \mu \mathrm{g} \text { twice-a-day (United States); } 10 / 14.4 \mu \mathrm{g} \text { twice-a-day } \\
\text { (European Union) }\end{array}$ \\
\hline & Indacaterol/glycopyrronium & $\begin{array}{l}\text { Inhalation } \\
\text { powder }\end{array}$ & $85 / 43 \mu \mathrm{g}$ once-a-day \\
\hline & Olodaterol/tiotropium & Inhalation spray & $5 / 5 \mu \mathrm{g}$ once-a-day \\
\hline & Vilanterol/umeclidinium & $\begin{array}{l}\text { Inhalation } \\
\text { powder }\end{array}$ & $25 / 62.5 \mu \mathrm{g}$ once-a-day \\
\hline \multirow[t]{4}{*}{$\begin{array}{l}\text { LABA/LAMA/ } \\
\text { ICS }\end{array}$} & Formoterol/tiotropium/ciclesonide & $\begin{array}{l}\text { Inhalation } \\
\text { powder }\end{array}$ & $12 / 18 / 400 \mu \mathrm{g}$ once-a-day \\
\hline & $\begin{array}{l}\text { Formoterol/glycopyrronium/beclomethasone } \\
\text { dipropionate }\end{array}$ & Inhalation spray & $5 / 11 / 87 \mu \mathrm{g}$ twice-a-day \\
\hline & Vilanterol/umeclidinium/fluticasone furoate & $\begin{array}{l}\text { Inhalation } \\
\text { powder }\end{array}$ & $22 / 65 / 92 \mu \mathrm{g}$ once-a-day \\
\hline & Formoterol/glycopyrronium/budesonide & $\begin{array}{l}\text { Inhalation } \\
\text { aerosol }\end{array}$ & $9.6 / 14.4 / 320 \mu \mathrm{g}$ twice-a-day \\
\hline
\end{tabular}

difference is now being exploited in using formoterol with budesonide in so-called single maintenance and reliever therapy (SMART), whereby this combination can be used on demand and not just for maintenance treatment (Thomas and Pavord, 2012; Beasley et al., 2019). There is also evidence that corticosteroid insensitivity caused by oxidative stress is reversed by formoterol, but not salmeterol, and that formoterol is also able to inhibit phosphatidylinositol-3 kinase- $\delta$ signaling (Rossios et al., 2012). Moreover, it has been demonstrated that cytokines inhibit the tracheal relaxation and cAMP signaling induced by formoterol and salmeterol; however, budesonide is only able to prevent the inhibitory effects on the actions of formoterol (Adner et al., 2010). Formoterol has also been shown to increase corticosteroid sensitivity without receptor activation, but rather by activating the Ser/Thr protein phosphatase $2 \mathrm{~A}$, which results in the dephosphorylation of the glucocorticoid receptor at serine 226 (Kobayashi et al., 2012).

3. Combining Muscarinic Acetylcholine Receptor Antagonists and Inhaled Corticosteroids. There is increasing evidence that the LAMA, tiotropium bromide, at a low dose attenuates airway inflammation and remodeling in a guinea pig model of chronic asthma when chronically combined with the ICS ciclesonide. Such findings suggest that treatment with a LAMA and an ICS may also elicit anti-remodeling activity in addition to the well recognized bronchodilator and anti-inflammatory properties of these drugs, respectively (Kistemaker et al., 2016).

The pharmacological mechanisms of the interactions between mAChR antagonists and ICS are not yet clear. However, it has been shown that experimentally combining the mAChR antagonist, glycopyrronium, with the ICS, beclomethasone dipropionate, in isolated human ASM passively sensitized and precontracted with histamine is effective in relaxing both medium bronchi and bronchioles causing submaximal/maximal inhibition of the contractile tone, especially in small airways, where the combination is able to increase the relaxation of ASM by 2.5-fold compared with monocomponents (Cazzola et al., 2016b).

This synergist interaction between LAMAs with ICSs is detectable only in sensitized airways, likely because the challenge of airway tissue with high concentrations of IgE causes an increased release of endogenous ACh that activates $\mathrm{M}_{3} \mathrm{mAChRs}$ and LAMAs inhibit such activation (Cazzola et al., 2016b). It has also been hypothesized that in passively sensitized human ASM, airways can be protected against $\mathrm{G}_{\mathrm{S}}$ protein dysfunction by the low affinity of the LAMA for the $\mathrm{M}_{2} \mathrm{mAChR}$, whereas the response to $G_{\mathrm{s} \alpha}$ stimulation is increased by the short-term treatment with the ICS (Cazzola et al., 2016b). Indeed, there is evidence that when airways are passively sensitized with serum obtained from atopic donors, $\mathrm{M}_{2} \mathrm{mAChR} / \mathrm{G}_{\mathrm{i}}$-coupled expression increases, phosphorylation of $\mathrm{G}_{\mathrm{s}}$ protein and inhibition of $\mathrm{AC}$ and reduced cAMP accumulation occur, and, consequently, this has a negative effect on ASM relaxation (Hakonarson et al., 1995; Song et al., 2000).

4. Combining $\beta_{2}$-Adrenergic Receptor Agonists, Muscarinic Receptor Antagonists, and Inhaled Corticosteroids (Triple Inhalers). The concept of triple therapy with LABAs, LAMAs, and ICSs has recently attracted considerable attention as a potentially improved way of delivering an ICS with dual bronchodilator therapy in one inhaler device rather than having to take these drugs in separate inhalers. A number of these triple inhaler combinations have now been approved for clinical use for the treatment of patients with COPD (Table 1).

\section{Emerging Classes of Bronchodilator Drugs}

There remains an interest in identifying new targets for drugs to induce bronchodilation or to improve the 
effectiveness of existing drug classes. At least eight new classes of bronchodilator drugs are in development (Fig. 2), including bitter taste receptor agonists, E-prostanoid (EP) receptor 4 agonists, Rho kinase inhibitors, calcilytics, agonists of peroxisome proliferatoractivated receptor- $\gamma$ (PPAR $\gamma$ ), relaxin family peptide receptor 1 (RXFP1) receptor agonists, soluble guanylyl cyclase (sGC) activators, and pepducins (Table 2). Furthermore, there is a considerable amount of research being undertaken to improve the existing classes of bronchodilators with the development of novel selective phosphodiesterase (PDE) inhibitors, novel xanthines, novel $\beta_{2}$-AR agonists, and novel mAChR antagonists (Table 3). Research is also ongoing to develop new options for combination therapy such as bifunctional bronchodilator drugs and bifunctional bronchodilator/anti-inflammatory drugs (Table 4).

\section{Novel Classes of Bronchodilators.}

a. Bitter Taste Receptor Agonists. Stimulation of type 2 taste receptors (TAS2Rs), which are members of a family of about $25 \mathrm{G}$ protein-coupled receptors (GPCRs), expressed in respiratory epithelia and smooth muscle has been demonstrated to have effects on protective airway reflexes, to increase beat frequency of motile cilia of airway epithelial cells, and to induce bronchodilation (Deshpande et al., 2010). Three of the 25 TAS2Rs are highly expressed in human ASM, termed subtypes 10, 14, and 31 . When activated, these receptors elicit relaxation through a calcium-dependent, $\mathrm{G} \alpha_{\mathrm{i}}$-coupled mechanism (Kim et al., 2017) and subsequent activation of PLC. Activation of TAS2Rs increases SR $\mathrm{Ca}^{2+}$ release via $\mathrm{IP}_{3}$ receptor channels, leading to activation of largeconductance $\mathrm{KCa}^{++}$channels, membrane hyperpolarization, and bronchodilation (reviewed by Prakash, 2016).

Recent findings have also demonstrated that activation of TAS2Rs can counteract mAChR enhancement of $\mathrm{Ca}^{2+}$ influx via voltage-gated calcium channels, suggesting that TAS2Rs may modestly enhance $\left[\mathrm{Ca}^{2+}\right]_{i}$ without affecting the contraction under baseline conditions but they act to reduce $\left[\mathrm{Ca}^{2+}\right]_{\mathrm{i}}$ in the presence of an agent causing bronchoconstriction (reviewed by Prakash, 2016). Furthermore, TAS2Rs appear to have antimitogenic properties; as TAS2R stimulation activates intracellular signaling pathways that are distinct from those activated by $\beta_{2}$-ARs, TAS2R agonists appear to remain effective even when tachyphylaxis has been induced by prolonged $\beta_{2}$-AR activation (Devillier et al., 2015b).

However, there is currently very little clinical evidence supporting TAS2R agonists having significant bronchodilator activity, although several drugs currently marketed for a wide range of indications, including erythromycin, carisoprodol, flufenamic acid, dapsone, quinine, chloroquine, caffeine, azelastine, and colchicine, are known to activate TAS2Rs and improve lung function or decrease exercise- or histamine-induced

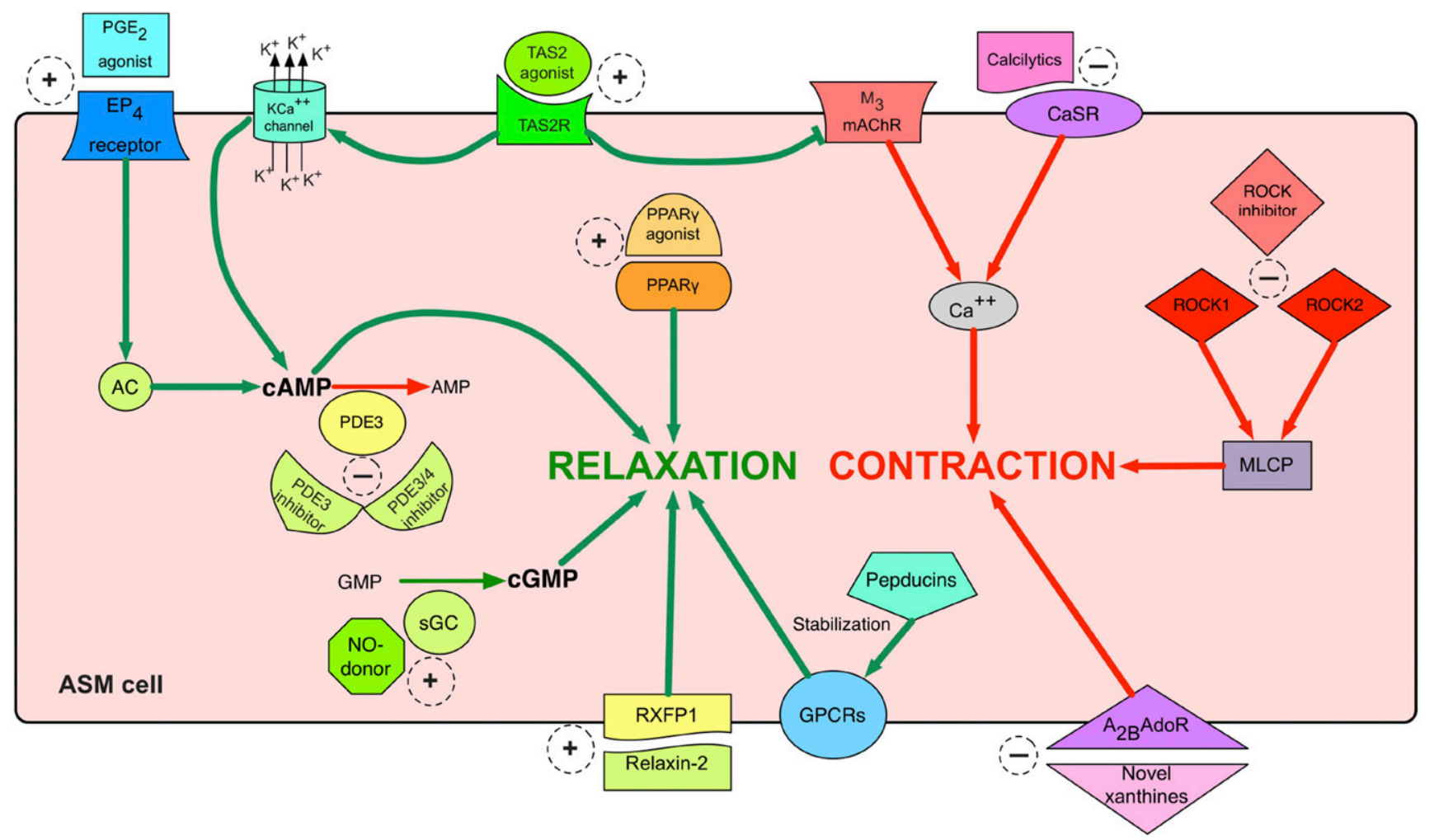

Fig. 2. Potential targets for new classes of bronchodilator. 
TABLE 2

Novel classes of bronchodilators

\begin{tabular}{|c|c|c|}
\hline Class & Molecule & Potential Therapeutic Effects \\
\hline TAS2R agonists & $\begin{array}{l}\text { Erythromycin } \\
\text { Arisoprodol } \\
\text { Flufenamic acid } \\
\text { Dapsone } \\
\text { Quinine } \\
\text { Chloroquine } \\
\text { Caffeine } \\
\text { Azelastine } \\
\text { Colchicine }\end{array}$ & $\begin{array}{l}\text { Bronchodilation, reduction in exercise- or histamine-induced bronchoconstriction in patients } \\
\text { with asthma }\end{array}$ \\
\hline $\begin{array}{l}\text { EP receptor } 4 \\
\text { agonists }\end{array}$ & $\begin{array}{l}\text { ONO-AE1-329 } \\
\text { L-902688 } \\
\text { TCS2510 } \\
\text { Rivenprost }\end{array}$ & $\begin{array}{l}\text { Relaxation of ASM, reversal of histamine-induced contraction of ASM, increase in } \\
\text { glucocorticoid response element-dependent transcription when combined with ICS }\end{array}$ \\
\hline $\begin{array}{l}\text { Rho kinase } \\
\text { inhibitors }\end{array}$ & $\begin{array}{l}\text { Fasudil } \\
\text { Ripasudil } \\
\text { Netarsudil } \\
\text { AMA0076/PHP-201 } \\
\text { Y-39983 }\end{array}$ & Relaxation of ASM, relaxation of methacholine-constricted human small airways \\
\hline Calcilytics & Calcityrol, B2.1-E1 & Bronchodilator and anti-inflammatory actions \\
\hline $\begin{array}{l}\text { Agonists of } \\
\text { PPAR } \gamma\end{array}$ & $\begin{array}{l}\text { Pioglitazone } \\
\text { Rosiglitazone } \\
\text { Troglitazone } \\
\text { Ciglitazone }\end{array}$ & $\begin{array}{l}\text { Relaxation of ASM, inhibition of the initiation and development of a maximal contraction } \\
\text { induced by methacholine, synergistic interaction with } \beta_{2} \text {-AR agonists on ASM cell } \\
\text { proliferation }\end{array}$ \\
\hline RXFP1 agonists & $\begin{array}{l}\text { Serelaxin } \\
\text { B-chain only agonists (B7-33) } \\
\text { Small molecule RXFP1 agonists } \\
\quad \text { (ML290) } \\
\text { Fatty acid conjugated relaxin-2 } \\
\quad \text { analogs (R9-13) }\end{array}$ & Relaxation of ASM, increase in airway dilator responsiveness to $\beta$-AR agonists \\
\hline sGC activators & $\begin{array}{l}\text { BAY } 41-2272 \\
\text { BAY } 60-2770 \\
\text { BAY } 58-2667\end{array}$ & Bronchodilation, reduction of airway hyperresponsiveness \\
\hline Pepducins & $\begin{array}{l}\text { Pepducin } \mathrm{ICL}_{3-9} \\
\text { AT1-2341 } \\
\text { P4pal-10 }\end{array}$ & Relaxation of ASM \\
\hline
\end{tabular}

bronchoconstriction in patients with asthma. In any case, most of these compounds have poor selectivity and weak potency for these receptors and many of them have pharmacological effects unrelated to the stimulation of TAS2Rs that cannot be ruled out as contributing to the beneficial effects seen on ASM (Grassin-Delyle et al., 2015). Furthermore, some TAS2Rs only respond to a limited number of bitter compounds, whereas other TAS2Rs can be activated by a broad range of agents; therefore, it is likely that drugs targeting TAS2Rs will have many off-target effects, and it is likely that these receptors play a role in the side effects of bitter-tasting drugs in clinical use (Lee et al., 2019). In addition, some TAS2Rs are highly polymorphic, which may affect the sensitivity of patients to bitter tastants (Lee et al., 2019).

b. E-Prostanoid Receptor 4 Agonists. The biologic actions of prostaglandin $\mathrm{E}_{2}\left(\mathrm{PGE}_{2}\right)$ are predominantly mediated by the activation of the four EP receptors, $\mathrm{EP}_{1}$ to $\mathrm{EP}_{4}$. The bronchodilator properties of $\mathrm{PGE}_{2}$ in human airways are well documented and are mediated via activation of $\mathrm{EP}_{4}$ receptors, whereas the undesirable triggering of airway sensory nerves, which causes airway irritation and cough, appears to be via activation of $\mathrm{EP}_{3}$ receptors (Buckley et al., 2011). Stimulation of the $\mathrm{EP}_{4}$ receptor with $\mathrm{PGE}_{2}$ induces a direct activation of $\mathrm{AC}$ via the $\mathrm{G} \alpha_{\mathrm{s}}$ subunit that converts adenosine triphosphate to cAMP. Therefore, it remains plausible that EP subtype-selective receptor agonists could have therapeutic potential as bronchodilators (Buckley et al., 2011).

This conclusion is reinforced by the observation that the selective $\mathrm{EP}_{4}$ receptor agonist ONO-AE1-329 (2-[3[(1R,2S,3R)-3-hydroxy-2-[(E,3S)-3-hydroxy-5-[2-(methoxymethyl)phenyl]pent-1-enyl]-5-oxocyclopentyl]sulfanylpropylsulfanyl]acetic acid) can relax human airways and the selective $\mathrm{EP}_{4}$ receptor antagonist ONO-AE3-208 (4Cyano-2-[[2-(4-fluoro-1-naphthalenyl)-1-oxopropyl] amino]benzenebutanoic acid) is able to reverse the bronchodilatation induced with $\mathrm{PGE}_{2}$ and ONO-AE1329 (Buckley et al., 2011). In addition, the selective $\mathrm{EP}_{4}$ agonists ONO-AE1-329 and L-902688 (5-[(1E,3R)4,4-difluoro-3-hydroxy-4-phenyl-1-buten-1-yl]-1-[6-(2Htetrazol-5R-yl)hexyl]-2-pyrrolidinone) have also been demonstrated to reverse histamine-induced contraction of ASM (Benyahia et al., 2012) and the specific $\mathrm{EP}_{4}$ antagonist GW62768X ((N-\{2-[4-(4,9-diethoxy-1-oxo-1,3dihydro-2H-benzo[f]isoindol-2-yl)phenyl]acetyl\} benzene 
TABLE 3

Novel molecules in the existing classes of bronchodilators

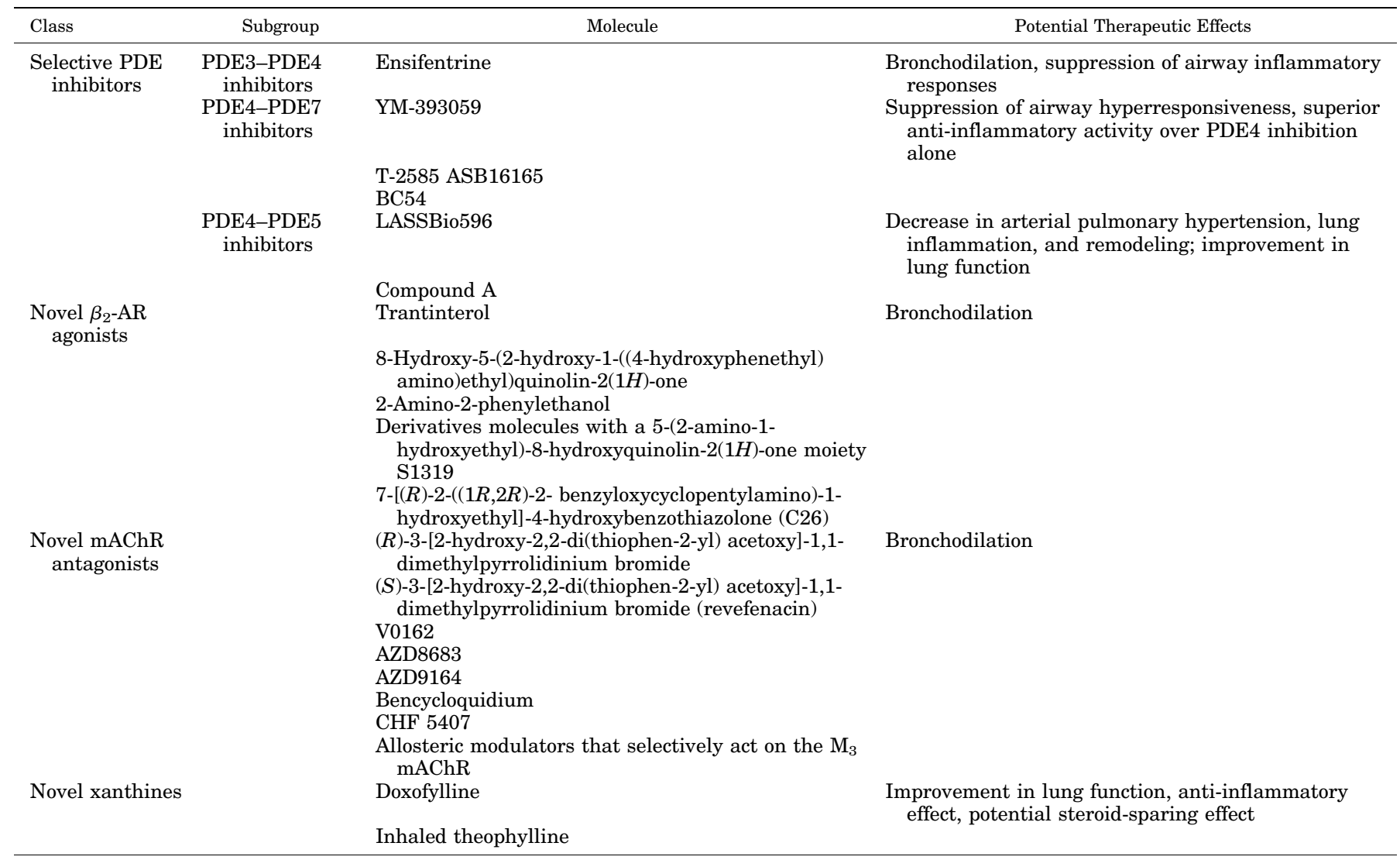

sulphonamide) was shown to prevent $\mathrm{PGE}_{2}$-induced relaxation of human bronchial tissue precontracted with histamine (Benyahia et al., 2012). There is also evidence that activation of the $\mathrm{EP}_{4}$ receptor in human airway epithelial cells augmented the glucocorticoids responsive element-dependent transcription in a manner that was qualitatively similar to that previously reported with a LABA (Yan et al., 2014). Thus, an ICS/EP 4 receptor

TABLE 4

Bifunctional bronchodilator drugs and bifunctional bronchodilator/antiinflammatory drugs

\begin{tabular}{|c|c|c|}
\hline Class & Subgroup & Molecules \\
\hline $\begin{array}{l}\text { Bifunctional } \\
\text { bronchodilator } \\
\text { drugs }\end{array}$ & MABAs & $\begin{array}{l}\text { Batefenterol, } \\
\text { AZD8871, } \\
\text { LAS190792, } \\
\text { CHF6366 }\end{array}$ \\
\hline \multirow{7}{*}{$\begin{array}{l}\text { Bifunctional } \\
\text { bronchodilator/ } \\
\text { anti-inflammatory } \\
\text { drugs }\end{array}$} & PDE3-PDE4 inhibitors & Ensifentrine \\
\hline & PDE4-PDE5 inhibitors & LASSBio596 \\
\hline & NO-ICS & TPI 1020 \\
\hline & $\mathrm{NO}-\beta_{2}$-AR agonist & NCX 950 \\
\hline & $\begin{array}{l}\mathrm{PDE} 4 \text { inhibitor }-\beta_{2}-\mathrm{AR} \\
\text { agonist }\end{array}$ & GS-5759 \\
\hline & $\begin{array}{l}\text { PDE4 inhibitor-mAChR } \\
\text { antagonist }\end{array}$ & UCB-101333-3 \\
\hline & $\begin{array}{l}\text { Vasoactive intestinal } \\
\text { peptide-pituitary AC- } \\
\text { activating polypeptide } \\
\text { type } 2 \text { receptor }\end{array}$ & RO 50-24118 \\
\hline
\end{tabular}

agonist combination may represent a novel approach to having a bronchodilator that can also suppress airway inflammation. However, none of the available $\mathrm{EP}_{4}$ receptor agonists, such as TCS2510 ((5R)-5-[(3S)-3-Hydroxy-4-phenyl-1-buten-1-yl]-1-[6-(2H-tetrazol-5-yl) hexyl]-2-pyrrolidinone), L-902688, rivenprost, and ONO-AE1-329, have been tested as bronchodilators in humans to date (Lebender et al., 2018).

c. Rho Kinase Inhibitors. Rho-associated protein kinases (ROCK1 and ROCK2) are serine/threonine kinases that can regulate the contraction of ASM and other smooth muscles. After being activated by the small GTPase RhoA, ROCKs phosphorylate and inactivate the constitutively active MLCP, an effect that maintains the contraction of human ASM by increasing and sustaining MLC phosphorylation (Chiba and Misawa, 2004; Chiba et al., 2010). Inhibition of RhoA has also been shown to induce relaxation of methacholine-constricted human small airways (Yoo et al., 2017). There are already two ROCK inhibitors approved for clinical use in Japan and China, but they are not approved for treating airway diseases. Fasudil was approved for the treatment of cerebral vasospasm and ripasudil for the treatment of glaucoma. There are also a number of novel ROCK inhibitors under development for the treatment of glaucoma, including netarsudil and AMA0076/PHP-201 (3-[2-(Aminomethyl)-5-[(pyridin-4-yl) 
carbamoyl]phenyl] benzoate), but to date there are no clinical data available using this class of drug for treating patients with asthma or COPD. Nonetheless, it has been suggested that ROCK inhibitors may act synergistically with other classes of bronchodilator and therefore provide additional benefit beyond existing classes of bronchodilator (Barnes, 2016).

However, a major concern with ROCK inhibitors is the potential for unwanted side effects, particularly in the cardiovascular system, given the ubiquitous expression of these enzymes across a range of tissues that may limit their use in patients with asthma or COPD. For this reason, a number of compounds have been described that intentionally include a metabolically labile aspect to their chemical structure, such that the drug undergoes rapid metabolism in plasma to produce nontoxic metabolites. Thus, development of such compounds by inhalation may be one approach to reduce unwanted systemic side effects with ROCK inhibitors (Defert and Boland, 2017).

d. Calcilytics. Calcilytics are small molecules that block the $\mathrm{G}$ protein (heterotrimeric guanine nucleotidebinding protein)-coupled calcium-sensing receptor (CaSR) that can exert beneficial effects in the context of airway diseases (Yarova et al., 2015). CaSR activation leads to $\left[\mathrm{Ca}^{2+}\right]_{\mathrm{i}}$ mobilization, cAMP breakdown, and p38 mitogenactivated protein kinase phosphorylation in ASM cells inducing airway hyperresponsiveness and airway remodeling (Penn, 2015). CaSRs are upregulated and constitutively activated in airways obtained from subjects with asthma (Yarova et al., 2015). Calcilytics (e.g., calcityrol) have been developed as drugs to affect calcium levels systemically and several have been evaluated for nonpulmonary indications clinically that have subsequently been stopped. However, calcilytics can also act as bronchodilators and anti-inflammatory agents and are therefore under development for local administration to the lung to reduce their effects on blood calcium concentrations because it has been documented in vivo using a mouse model of allergic asthma that inhaled calcilytics do not significantly modify plasma $\left[\mathrm{Ca}^{2+}\right]_{\mathrm{i}}$ levels up to 24 hours after inhalation, signifying that calcilytic delivered directly to the lung in humans should not negatively influence mineral ion homeostasis (Yarova et al., 2015).

e. Agonists of Peroxisome Proliferator-Activated Receptor- $\gamma$. PPAR $\gamma$ ligands are another class of drug developed for a different therapeutic use that have also been shown to relax ASM in vitro (Bourke et al., 2014), particularly under conditions of impaired or limited $\beta$-AR responsiveness (Donovan et al., 2015). Rosiglitazone, a PPAR $\gamma$ agonist, and chloroquine, a TAS2R agonist, but not $\beta$-AR agonists, were able to cause complete relaxation of mouse small airways, showing similar potency when maintained under conditions of homologous $\beta_{2}$-AR desensitization (Donovan et al., 2014). Although both rosiglitazone and chloroquine are able to counteract contraction due to calcium sensitivity alone, only rosiglitazone prevented the initiation and development of a maximal methacholineinduced contraction of ASM. Interestingly, it has been documented that PPAR $\gamma$ agonists and $\beta_{2}$-AR agonists interact in a synergistic manner on ASM cell proliferation (Fogli et al., 2013). These experimental observations have been extended to beneficial effects in steroid-naïve asthmatics where rosiglitazone has been demonstrated to improve both airway hyperresponsiveness and forced expiratory volume in 1 second $\left(\mathrm{FEV}_{1}\right)$ in a dose- and timedependent manner (Sandhu et al., 2010).

f. Relaxin Family Peptide Receptor 1 Receptor Agonists. Relaxin-2 is a member of the relaxin peptide family and is the major stored and circulating form of relaxin. Relaxin- 2 contains two chains (A and $\mathrm{B}$ ) that are linked by a disulfide bond (Lam et al., 2018). The B-chain has two arginine residues at positions 13 and 17 that allow the binding of relaxin to its cognate GPCR, RXFP1. Both relaxin and RXFP1 are detectable in epithelial cells as well as in fibroblasts and ASM, although in smaller quantities (Lam et al., 2016).

It has been shown that in methacholine-precontracted rat trachea, the recombinant human form of relaxin-2, serelaxin, elicited a partial relaxation relative to isoprenaline, although with a slower onset of action (Lam et al., 2016). This observation may suggest that this class of drug may not be appropriate to develop as a monotherapy, although the onset of relaxation of rat trachea induced by serelaxin was improved when combined with rosiglitazone compared with either treatment alone (Lam et al., 2016).

Serelaxin has been investigated in a large phase III clinical trial as a potential treatment of acute decompensated heart failure but with disappointing results, likely because of its short half-life (Teneggi et al., 2018). Nonetheless, serelaxin has been shown to increase $\beta$-AR agonist-induced ASM relaxation in multiple species (Bourke et al., 2018) using signaling pathways that seem to be independent of cAMP-dependent pathways downstream of $\beta_{2}$-AR signaling and due in part to the production of epithelial-derived relaxing factors (Lam et al., 2018).

Relaxin-2 analogs, single chain relaxin (B-chain), and small molecule RXFP1 agonists have been reported, but to date none of these drugs has been evaluated in the clinical setting apart from serelaxin. Recently, a series of potent fatty acid conjugated relaxin-2 analogs that have longer half-lives in vivo have been synthesized by means of a semisynthetic methodology and they are effective as bronchodilators (Muppidi et al., 2019).

g. Soluble Guanylyl Cyclase Activators. Nitric oxide (NO)-donor compounds are another class of drugs that have been shown to relax human airways in vitro, raising the probability that they may be useful as a novel class of bronchodilator (Cazzola et al., 2012b). NO binds to the heme moieties on the $\alpha / \beta$ heterodimer 
sGC, which catalyzes the conversion of guanosine triphosphate to cGMP that subsequently activates cGMPdependent protein kinases leading to ASM relaxation (Papapetropoulos et al., 2006). However, inflammation has been shown to desensitize sGC toward its natural activator NO (Gladwin, 2006), so it is of interest that recent evidence has shown that drugs targeting the NOsGC-cGMP pathway that bypass the need for NO, and instead activate sGC directly, cause bronchodilation (Ghosh et al., 2016). Thus, the sGC stimulator BAY 412272 ((3-(4-Amino-5-cyclopropylpyrimidin-2-yl)-1-(2fluorobenzyl)-1H-pyrazolo[3,4-b]pyridine) and activator BAY 60-2770 4-[((4-Carboxy-butyl)-\{2-[5-fluoro-2-(4'trifluoromethyl-biphenyl-4-ylmethoxy)-phenyl]-ethyl\}amino)-methyl]-benzoic acid, 4-[[(4-Carboxybutyl)[2[5-fluoro-2-[[4' -(trifluoromethyl)[1,1' -biphenyl]-4-yl] methoxy]phenyl]ethyl]amino]methyl]benzoic acid) reduced airway hyperresponsiveness in mice with allergic airway inflammation and were able to restore lung function (Ghosh et al., 2016). Furthermore, activating sGC induced significant bronchodilation in human lung slices similar to the bronchodilating effects observed with isoprenaline or formoterol (Stuehr et al., 2017).

h. Pepducins. Pepducins are cell-penetrating palmitoylated peptides corresponding to amino acid sequences found on the inside surface of certain GPCRs that can allosterically stabilize the active state to induce receptor-G protein signaling (Carr and Benovic, 2016).

$\beta$-arrestin-2-induced GPCR desensitization, an effect that manifests itself with the appearance of a steric modification that prevents the interaction between the receptor and $G$ protein and also causes receptor internalization and a decrease in the amount of cAMP generated by $\mathrm{G}$ protein signaling due to recruitment of PDEs, is induced when a GPCR kinase phosphorylates the GPCR and increases its affinity for $\beta$-arrestin-2 (Matera et al., 2013). Thus, it is plausible that tachyphylaxis may be reduced by using $\mathrm{G}$ protein-biased ligands that are able to avoid $\beta$-arrestin recruitment while inducing an effective relaxation of ASM (Matera et al., 2013). By accessing effectors from subcellular compartments, internalized receptors can form active ternary complexes that also contribute to cellular signaling. An incessant signaling from internalized compartments contributes to the overall extent of intracellular signaling as well as to the duration of cellular responses and can cause signal distortion by directing receptors toward alternative pathways/compartments or degradation (Rosethorne et al., 2016), socalled biased agonism.

It is now recognized that $\beta_{2}$-ARs can signal not only via activation of $\mathrm{G}$ proteins but also via $\beta$-arrestins. Therefore, binding of $\beta_{2}$-AR agonists to $\beta_{2}$-AR is pleiotropically coupled to many intracellular pathways, and a subset of different intracellular responses can be triggered depending on the state of the $\beta_{2}$-AR when activated (Matera et al., 2018a). Biased agonism essentially describes the capacity of ligands to stabilize different conformations of a GPCR linked to distinct intracellular signaling pathways that in turn cause specific functional outcomes in the cell. This concept has led to the search for pathway-specific drugs that may reduce the incidence of on-target side effects (Klein Herenbrink et al., 2016). For example, it has been suggested that differences between epinephrine and salmeterol in the hydrogen-bond network involving residues $\operatorname{Ser}^{204}$ and $\mathrm{Asn}^{293}$ are responsible for a dissimilar active-state conformation that causes the partial efficacy of $G$ protein activation and the limited $\beta$-arrestin recruitment observed with salmeterol, meaning that this drug is a partial agonist (Masureel et al., 2018).

Pepducins from the third intracellular loop (ICL3) of the $\beta_{2}$-AR mediate $\mathrm{G}_{\mathrm{s}}$-biased signaling (Carr et al., 2014), and those from ICL1 mediate arrestin-biased signaling (Carr et al., 2016). ICL3 pepducins can stabilize a conformation of the $\beta_{2}$-AR that interacts selectively with $G_{\mathrm{s}}$ or, alternatively, directly activate $G_{\mathrm{s}}$ (Panettieri et al., 2018). Because of the capacity of pepducins to bias $\mathrm{G}_{\mathrm{s}}$ signaling, there is strong interest in developing small compounds that would have a similar bias. Initial efforts have been focused on screening molecules using the $\beta_{2}$-AR as a target receptor population to find $\mathrm{G}_{\mathrm{s}}$-biased agonists, $\mathrm{G}_{\mathrm{s}}$-biased positive allosteric modulators, and arrestin-biased negative allosteric modulators (Panettieri et al., 2018).

\section{Improvements to Existing Classes of} Bronchodilators.

a. Selective Phosphodiesterase Inhibitors. PDE3 is the predominant PDE isoenzyme in ASM and its inhibition produces smooth muscle relaxation, whereas the PDE4 isoenzyme is predominant in inflammatory cells involved in the pathogenesis of asthma and COPD (Page and Cazzola, 2014, 2017). Furthermore, PDE3 inhibition leads to the enhancement of relaxation evoked by $\beta_{2}$-AR stimulation (Mokry and Mokra, 2013).

PDE3 inhibitors have also been demonstrated to inhibit allergen-induced early and late airway responses in patients with allergic asthma (Bardin et al., 1998). Moreover, PDE3 inhibitors have been shown to induce bronchodilation in patients with asthma (Matera et al., 2014a), although there is concern about the inhibition of PDE3 to treat pulmonary diseases because PDE3 also participates in the regulation of vascular smooth muscle and cardiac muscle function and PDE3 inhibition thus has the potential to elicit adverse events, particularly in the cardiovascular system. This concern has limited the amount of drug development in this field and to date no PDE3 inhibitor has been approved for the treatment of asthma or COPD, despite systemically active PDE3 inhibitors being approved for other clinical indications (Matera et al., 2014a,b). Nonetheless, studies initiated because of enoximone's known bronchodilatory activity 
(Leeman et al., 1987) have reported beneficial and lifesaving effects of this PDE3 inhibitor in patients with status asthmaticus (Beute, 2014).

Evidence from preclinical studies suggests that concomitant inhibition of PDE3 and PDE4 suppresses spasmogen-induced contraction of human and bovine ASM in a synergistic manner (reviewed by AbbottBanner and Page, 2014). This observation has been demonstrated by combining a PDE3 with a PDE4 inhibitor; more recently, these observations have been extended through experiments using a dual inhibitor of PDE3 and PDE4, ensifentrine (formerly called RPL 554 ), that is able to induce significant relaxation of human bronchi in vitro (see the section on bifunctional bronchodilator/anti-inflammatory drugs for further details) (Calzetta et al., 2013) and provides rapid and sustained bronchodilation in patients with asthma or COPD (Franciosi et al., 2013).

b. Novel $\beta_{2}$-Adrenoceptor Agonists. Despite the failure of some novel $\beta_{2}$ agonists such as carmoterol, milveterol, PF-610355 (N-[(4'-Hydroxy-3-biphenylyl) methyl]-2-[3-(2-\{[(2R)-2-hydroxy-2-\{4-hydroxy-3-[(methylsulfonyl)amino]phenyl\}ethyl]amino\}-2-methylpropyl) phenyl]acetamide), and AZD3199 (N-(2-(diethylamino) ethyl)-N-(2-((2-(4-hydroxy-2-oxo-2,3-dihydrobenzo[d] thiazol-7-yl)ethyl)amino)ethyl)-3-(2-(naphthalen-1-yl) ethoxy)propanamide), which suggests that challenges remain in identifying $\beta_{2}$-AR agonists having a better profile than those currently available, there is still interest in identifying novel $\beta_{2}$-AR agonists with a core structure different from the drugs in this class currently in clinical use. However, while it may be possible to find better $\beta_{2}$-AR agonists, the costs involved in their research and development may outweigh any incremental improvement such drugs might have (Van Ly and Oliver, 2015).

Nonetheless, trantinterol [SPFF; 2-(4-amino-3chloro-5-trifluomethyl-phenyl)-2-tert-butylamino-ethanol hydrochloride] bears a novel scaffold of 2-amino-2phenylethanol instead of the classic scaffold of 2-amino1-phenylethanol and is an example of a novel $\beta_{2}$-AR agonist under development (Gan et al., 2003). In guinea pigs, $(S)$-trantinterol was more effective than $(R)$ trantinterol at causing ASM relaxation, despite the observation that there was no significant difference observed for the receptor selectivity of $(S)$-trantinterol and $(R)$-trantinterol (Pan et al., 2014). This finding contrasts with the documentation that other $(S)$-enantiomers are effectively inert at the $\beta_{2}$-AR (Jacobson et al., 2018). However, it was found that the concentration of $(S)$-trantinterol was higher than that of $(R)$-trantinterol, implying the stereoselective disposition of trantinterol enantiomers in humans (Qin et al., 2015). This drug is currently being evaluated in phase III clinical trials in China for the treatment of patients with asthma.

A series of novel $\beta_{2}$-AR agonists based on the previously identified nonclassic 2 -amino-2-phenylethanol scaffold have been synthesized and evaluated in $\beta_{2^{-}}$ AR-expressing cells (Ge et al., 2018a). 8-Hydroxy-5(2-hydroxy-1-((4-hydroxyphenethyl)amino)ethyl)quinolin-2(1H)-one (compound 5j) demonstrated the best pharmacological profile among all of the evaluated compounds. Another series of 2-amino-2-phenylethanol derivatives have also been developed (Ge et al., 2018b), and these compounds are effective $\beta_{2}$-AR agonists with high selectivity and with the $(S)$-configuration again being more active. The binding of these compounds is reminiscent of $\beta_{2}$-AR agonists as predicted by molecular modeling (Ge et al., 2018b).

Furthermore, a series of novel $\beta_{2}$-AR agonists with a 5-(2-amino-1-hydroxyethyl)-8-hydroxyquinolin-2(1H)one moiety have been developed (Xing et al., 2019). Compounds $9 \mathrm{~g}$ and $(R)-18 \mathrm{c}$ produced potent relaxant effects on ASM with a rapid onset and sustained duration of action in guinea pig trachea in vitro. Furthermore, the disclosure of the marine natural product $\mathrm{S} 1319$ as a $\beta_{2^{-}}$ AR agonist with equivalent activity to formoterol, due to the presence of the 4-hydroxybenzothiazolone as a phenol-containing bicyclic catechol mimetic, has led to the exploration of a 4-hydroxybenzothiazolone series of $\beta_{2^{-}}$ AR agonists (Beattie et al., 2010). 7-[(R)-2- $((1 R, 2 R)-2-$ benzyloxycyclopentylamino)-1-hydroxyethyl]-4-hydroxybenzothiazolone (C26) was originally identified as a high-affinity $\beta_{2}$-AR agonist with a predicted long duration of action and this compound exhibited greater intrinsic activity than endogenous adrenaline in producing increases in cAMP and moreover it recruited $\beta$-arrestin- 2 , and internalized the $\beta_{2}$-AR slower than isoprenaline and adrenaline (Rosethorne et al., 2016). Compound C26 caused $\beta$-arrestin- 2 recruitment with levels that increased up to 4 hours, when the intrinsic activity was $126 \% \pm 3.52 \%$ of the maximal response to isoprenaline. The effect of isoprenaline and adrenaline on the levels of internalized $\beta_{2}$-ARs began to decline around 15 minutes after agonist washout and became increasingly less efficient until baseline levels were achieved within 2 hours after agonist washout. In contrast, the effects of compound C26 persisted over time; at 4 hours after agonist washout, C26 held approximately $80 \%$ of internalized $\beta_{2}$-ARs inside the cell, with a very slow rate of decline of internalized vesicles. Compound C26 also displayed very slow receptor kinetics, with a receptor residence half-life of 32.7 minutes at $37^{\circ} \mathrm{C}$, which is the slowest dissociation rate detected for any $\beta_{2}$-AR agonist examined to date. Because of these characteristics, it was proposed that compound C26 acts as a superagonist (Rosethorne et al., 2016). Superagonists at GPCRs may have relevance in therapy, specifically compensating for the reduction in the effectiveness of drugs as a result of desensitization that can sometimes occur after continuous therapy with some agonists (Schrage et al., 2016).

c. Novel Muscarinic Acetylcholine Receptor Antagonists. A series of chiral quaternary ammonium 
salts of pyrrolidinol esters designed by structural recombination of the privileged scaffolds of aclidinium bromide and glycopyrronium bromide have been developed as novel $\mathrm{M}_{3} \mathrm{mAChR}$ antagonists (Xiang et al., 2017). Among them, $(R)$-3-[2-hydroxy-2,2-di(thiophen2-yl)acetoxy]-1,1-dimethylpyrrolidinium bromide and (S)-3-[2-hydroxy-2,2-di(thiophen-2-yl)acetoxy]-1,1dimethylpyrrolidinium bromide appeared to be the most active $M_{3}$ mAChR antagonists. These novel $M_{3}$ $\mathrm{mAChR}$ antagonists also possessed longer stability in human plasma (half-life $=9.34,19.2$ minutes), particularly $(R)$-3-[2-hydroxy-2,2-di(thiophen-2-yl)acetoxy]1,1-dimethylpyrrolidinium bromide, which potentially could lead to more unwanted anticholinergic effects if the drugs entered the systemic circulation. In addition, structure-activity relationship studies showed that the target compounds with a $(3 R)$-pyrrolidine moiety were undoubtedly more effective than agents with the $(3 S)$-pyrrolidine moiety.

There is a considerable amount of ongoing research investigating the development of $\mathrm{mAChR}$ antagonists formulated differently from the currently available LAMAs. In particular, nebulizers are increasingly seen as the best delivery device for patients suffering from chronic airway diseases, particularly if the disease is severe or there are frequent exacerbations, in the presence of physical and/or cognitive limitations (Dhand et al., 2012) and when peak inspiratory flow rates are very compromised (Mahler et al., 2014).

One example is revefenacin (TD-4208; biphenyl-2-ylcarbamic acid 1-(2-\{[4-(4-carbamoylpiperidin-1-ylmethyl)benzoyl]methylamino\}ethyl)piperidin-4-yl ester), which is a LAMA under development as a nebulized inhalation solution that exhibits selective antagonism with high affinity at human recombinant $\mathrm{mAChRs}$ and kinetic functional selectivity for $\mathrm{M}_{3}$ over $\mathrm{M}_{2} \mathrm{mAChRs}$. Revefenacin is a potent, slowly reversible antagonist in rat, guinea pig, and human airway tissues expressing native mAChRs (Hegde et al., 2018). Single doses of revefenacin were more active than glycopyrronium, and repeat dosing regimens with this LAMA were superior to glycopyrronium and also tiotropium when the lung selectivity index (i.e., ratio of antisialagogue and bronchoprotective potency) was calculated (Pulido-Rios et al., 2013). In patients with COPD, revefenacin demonstrates a fast onset of action and a bronchodilator effect that lasts over 24 hours after once-a-day administration, with a pharmacokinetic profile that is commensurate with low systemic exposure (Quinn et al., 2018). In patients with COPD with a $\mathrm{FEV}_{1}$ of $<50 \%$ predicted and a suboptimal peak inspiratory flow rate of $<60 \mathrm{l} / \mathrm{min}$, nebulized revefenacin provided greater improvement in lung function compared with tiotropium bromide delivered by a dry powder inhaler (DPI) (Mahler et al., 2018), which may provide evidence of the type of patient who could benefit from nebulized therapy versus a DPI.
Many other new LAMAs are also under investigation with the hope that they are more effective than currently available $\mathrm{M}_{3} \mathrm{mAChR}$ antagonists, or at least equally effective but with a better safety profile (Mastrodicasa et al., 2017). For example, V0162 (10[(3R)-1-azabicyclo[2.2.2] oct-3-ylmethyl]-10H-phenothiazine) is the $R$-isomer of mequitazine, an existing oral racemic $\mathrm{H} 1$ receptor antagonist with one of the highest affinities for $\mathrm{mAChRs}$ being in the nanomolar range. V0162 exhibits both rapid and slow kinetic components with respect to the interaction with human $\mathrm{M}_{3}$ mAChRs; this drug exhibits considerable resistance to washout (Heusler et al., 2015). It has been suggested that V0162 has a "salmeterol-like" mechanism of action and a long period of receptor interaction may be relevant for its sustained activity. At least preclinically, this drug reversed bronchoconstriction induced either by ACh or histamine and also prevented ovalbumin-induced bronchoconstriction and lung inflammation (Devillier et al., 2015a).

Several other LAMAs (AZD8683 (R)-1-(2-oxo-2-(pyridin2-ylamino)ethyl)-3-((1-phenylcycloheptane-1-carbonyl) oxy)quinuclidin-1-ium bromide, AZD9164 (R)-1-(4-fluorophenethyl)-3-(((S)-2-phenyl-2-(piperidin-1-yl)propanoyl)oxy)quinuclidin-1-ium, bencycloquidium, CHF 5407 (3R)-3-[[[(3-fluorophenyl)[(3,4,5-trifluorophenyl) methyl]amino]carbonyl] oxy]-1-[2-oxo-2-(2-thienyl)ethyl]1-azoniabicyclo[2.2.2] octane bromide) have also been described, but to date there are no published results and no recent trials with these drugs are registered on ClinicalTrial.gov.

However, in recent years, as a consequence of substantial technological advances, there has been a renewed interest in broadening the knowledge on $\mathrm{M}_{3} \mathrm{mAChR}$ physiology and structure (Kruse et al., 2014). Starting from the well known $\mathrm{M}_{3} \mathrm{mAChR}$ structure, it is now possible to create drugs capable of modulating the $\mathrm{M}_{3}$ $\mathrm{mAChR}$ in an allosterically selective way, activating or blocking it. Such allosteric agents can influence the potency and efficacy of orthosteric ligands, may possess agonistic or inverse agonist activity in their own right, and reduce the risk of adverse events compared with orthosteric muscarinic ligands.

Beginning with the crystal structures of $\mathrm{M}_{2} \mathrm{mAChR}$ and $\mathrm{M}_{3} \mathrm{mAChR}$, a single amino acid difference in their orthosteric binding pockets using molecular docking and structure-based design has been exploited (Liu et al., 2018). The resulting $\mathrm{M}_{3} \mathrm{mAChR}$ antagonists had up to 100 -fold selectivity over $\mathrm{M}_{2} \mathrm{mAChR}$ in terms of affinity and over 1000-fold selectivity in vivo. The crystal structure of a $\mathrm{M}_{3} \mathrm{mAChR}$-selective antagonist in complex with $\mathrm{M}_{3} \mathrm{mAChRs}$ corresponded closely to the docking-predicted geometry, providing a template for further optimization of novel drugs in this class.

$d$. Novel Xanthines. Currently, the use of xanthines for the treatment of asthma or COPD is decreasing because xanthines can have numerous side effects or 
drug-drug interactions and often require the measurement of drug levels in plasma to prevent "toxicity," all of which serve to limit the use of this drug. Moreover, there is evidence generated by a meta-analysis of seven observational studies that theophylline slightly increases all-cause death in patients with COPD (Horita et al., 2016).

Nonetheless, although theophylline is a weak bronchodilator compared with other inhaled classes of bronchodilator, it can still be effective in the treatment of respiratory diseases, not only because it offers an advantageous oral bioavailability but also because it possesses anti-inflammatory effects of relevance to asthma and COPD (Barnes, 2013). For instance, theophylline reduces neutrophil-associated inflammation in the airways of patients with COPD (Kobayashi et al., 2004) and the numbers of eosinophils in the airways of patients with mild asthma (Sullivan et al., 1994; Lim et al., 2001). Interestingly, these anti-inflammatory effects occur at plasma concentrations much lower than those necessary for its bronchodilator action (Barnes, 2013). Furthermore, xanthines have been reported to affect diaphragm contractility, a pharmacological effect that may explain some of the clinical benefit of this class of drug in patients with COPD.

Therefore, other xanthines have been developed for treating these diseases (Basu et al., 2017). Doxofylline [7-(1,3-dioxolan-2-ylmethyl)-3,7-dihydro-1,3 dimethyl$\mathrm{l} H$-purine-2,6-dione] is a newer-generation xanthine with both bronchodilating and anti-inflammatory activities (Page, 2010). The presence of the dioxolane group at position 7 as well as a distinct pharmacological profile differentiate doxofylline from theophylline, and doxofylline thus should not be considered as just a modified theophylline (Matera et al., 2017a). In effect, doxofylline does not interact significantly with any type of adenosine receptor or any of the known PDE isoforms, except for PDE2A1, and its pharmacological action is not influenced by any of the known histone deacetylase enzymes (van Mastbergen et al., 2012). Doxofylline can also interact with $\beta_{2}$-ARs, eliciting relaxation of vascular smooth muscle and ASM (Zhang et al., 2016), inhibits lipopolysaccharide-induced inflammatory response in the lung, and regulates leukocyte migration in vivo and in vitro (Riffo-Vasquez et al., 2014). Furthermore, doxofylline elicits a substantial steroidsparing effect in both an allergic and a nonallergic model of lung inflammation (Riffo-Vasquez et al., 2018).

A fundamental pharmacokinetic difference between doxofylline and theophylline lies in the fact that doxofylline does not interfere with the cytochrome P450 enzymes CYP1A2, CYP2E1, and CYP3A4, which allows it to not interact with other drugs metabolized via these pathways in the liver (Lazzaroni et al., 1990).

In a recent network meta-analysis, doxofylline was shown to be more effective than aminophylline and theophylline in patients with COPD (Cazzola et al., 2018a). Doxofylline was not more efficacious than aminophylline or theophylline in improving basal $\mathrm{FEV}_{1}$, but it was more effective than theophylline in improving dyspnea and, above all, significantly safer than both aminophylline and theophylline. In patients with asthma, doxofylline was not significantly different from theophylline in increasing $\mathrm{FEV}_{1}$, in reducing the occurrence of asthma episodes, or in the use of salbutamol as a rescue medication to relieve acute asthma symptoms (Calzetta et al., 2018a). However, the safety profile of doxofylline was much better than that of theophylline. This would suggest that of the currently available xanthines, doxophylline has the best therapeutic window.

Recent studies have reported the development of inhaled formulations of theophylline for delivery by a propellant metered dose inhaler (Zhu et al., 2015a) and by DPI formulations containing $1.0 \%(\mathrm{w} / \mathrm{w})$ sodium stearate as a lipophilic adjunct (Zhu et al., 2015b) for possible administration to patients with COPD. It was suggested in these studies that methyl xanthines could potentially be repurposed successfully for delivery by inhalation if given by appropriate aerosol delivery systems (Zhu et al., 2015a,b) to try and improve the therapeutic window compared with administering xanthines systemically. Another approach is to combine theophylline with polyamines such as spermine to exploit the uptake system for polyamines from the systemic circulation into the lung (Benaouda et al., 2018).

e. Fixed-Dose Combination Therapies. The combination of two or more drugs with dissimilar but complementary mechanisms of action, of which at least one is a bronchodilator, has become standard in the treatment of asthma, COPD, and asthma-chronic obstructive pulmonary disease overlap (ACO) syndrome (Cazzola et al., 2012b). Thus, there is now accruing evidence that fixed-dose combination (FDC) therapies in a single inhaler (LABA/LAMA and LABA/ICS) seem to be more active in controlling symptoms than singleagent therapies (LAMA and LABA) (Oba et al., 2018).

Many LABA/LAMA, LABA/ICS, and LAMA/ICS FDCs as well as "triple inhaler" FDCs containing LABA/LAMA/ICS have been approved or are in clinical development as treatments for asthma and COPD. There are currently five LABA/LAMA FDCs licensed for maintenance treatment of COPD. Some are once-aday FDCs (110/50 $\mu \mathrm{g}$ indacaterol/glycopyrronium; 5/ $5 \mu \mathrm{g}$ olodaterol/tiotropium; $25 / 62.5 \mu \mathrm{g}$ vilanterol/umeclidinium), whereas others are twice-a-day FDCs (12/ $400 \mu \mathrm{g}$ formoterol/aclidinium; 27.5/15.6 $\mu \mathrm{g}$ indacaterol/ glycopyrronium approved in the United States; 9.6/ $18 \mu \mathrm{g}$ formoterol/glycopyrronium in the United States and $10 / 14.4 \mu \mathrm{g}$ in the European Union) (Table 3). With the use of appropriate doses, 12- to 24-hour bronchodilation can be achieved with these FDCs.

There are also several LABA/ICS FDCs (salmeterol/ fluticasone propionate, formoterol/budesonide, formoterol/beclomethasone, formoterol/fluticasone propionate, 
formoterol/mometasone, vilanterol/fluticasone furoate, indacaterol/mometasone, formoterol/ciclesonide) that are already available or will be marketed within the next few years for the treatment of asthma and/or COPD. No LAMA/ICS FDC has yet been approved, but umeclidinium/fluticasone furoate is under development. The first triple combination to enter the market in India was $12 / 18 / 400 \mu \mathrm{g}$ formoterol/tiotropium/ciclesonide and there are now three other LABA/LAMA/ICS FDCs (formoterol/ glycopyrronium/beclomethasone dipropionate, vilanterol/ umeclidinium/fluticasone furoate, and formoterol/glycopyrronium/budesonide) available, with others still under development.

i. Bifunctional Bronchodilator Drugs. The use of combinations containing drugs with complementary pharmacological actions in the treatment of patients with asthma or COPD suggested the need to develop single molecules able to elicit two different primary pharmacological actions. These molecules have been called "bifunctional drugs" (Page and Cazzola, 2014, 2017). A number of new drugs that have both $\mathrm{mAChR}$ antagonism and $\beta_{2}$-AR agonist activity in the same molecule and are referred to as MABAs have now reached clinical development or are at a preclinical stage.

In a phase IIb trial, the MABA, batefenterol (GSK961081), was numerically better than salmeterol in improving trough $\mathrm{FEV}_{1}$, the primary endpoint, after 4-week treatment in patients with moderate to severe COPD (Wielders et al., 2013). Another MABA, AZD8871 (LAS191351; 2-Thiopheneacetic acid, alpha-hydroxyalpha-2-thienyl-, trans-4-((3-(5-((((2R)-2-(1,2-dihydro-8hydroxy-2-oxo-5-quinolinyl)-2-hydroxyethyl)amino) methyl)-1H-benzotriazol-1-yl)propyl)methylamino) cyclohexyl ester), has been shown to be safe, well tolerated, and able to elicit sustained bronchodilation at doses of 200-2100 $\mu \mathrm{g}$ in patients with mild asthma (Jimenez et al., 2017); at a 400 or $1800 \mu \mathrm{g}$ dose, this drug delivered significant and sustained bronchodilation, superior to placebo, and at the highest dose was superior to $150 \mu \mathrm{g}$ indacaterol or $18 \mu \mathrm{g}$ tiotropium, with no obvious safety concerns (Singh et al., 2017). LAS190792 (((trans)-4-((2-)((2-chloro-4- $(((\mathrm{R})-2-$ hydroxy2-(8-hydroxy-2-oxo-1,2-dihydroquinolin-5-yl)ethyl) amino)methyl)-5-methoxyphenyl)carbamoyl)oxy)ethyl)(methyl)amino)cyclohexyl 2-hydroxy-2,2-di(thiophen-2-yl)acetate), another MABA, is able to induce relaxation of electrically stimulated airway tissue with a similar efficacy to batefenterol, with muscarinic receptor antagonism in the presence of propranolol being slightly higher than batefenterol, and with a longer duration of action (Aparici et al., 2017). In dogs, CHF6366 ((S)-3,5-dichloro-4-(2-(3-(cyclopropylmethoxy)-4-(difluoromethoxy)phenyl)-2-(3-(cyclopropylmethoxy)-4-(methylsulfonamido)benzoyloxy) ethyl)pyridine 1-oxide), but not batefenterol or formoterol, provided full, 24-hour bronchoprotection without systemic side effects (Carnini et al., 2017).
MABAs have some advantages compared with combination therapy, mainly the possibility of delivering a fixed ratio of $\mathrm{mAChR}$ antagonism and $\beta_{2}$-AR agonist activity at the cellular level. However, the development of MABAs is also associated with some major challenges in optimizing the LABA and LAMA activities in the molecule because there are often different pharmacodynamic half-lives for the mAChR antagonism and $\beta_{2}$-AR agonist activity in these drugs, with most MABAs having a predominance of either LAMA or LABA activity and the ratio of the two different pharmacological activities cannot be adjusted as needed, which obviously limits dosing flexibility (Cazzola et al., 2013a).

Nonetheless, MABA compounds are believed to be a better opportunity than LABA/LAMA combinations to be coformulated in "triple therapy" combinations that could elicit three complementary therapeutic actions in patients with asthma or COPD (Page and Cazzola, 2014, 2017). In fact, MABAs combined with an ICS are already in development and administration of a single high dose of batefenterol/fluticasone furoate resulted in a reduction of the fluticasone furoate exposure compared with administering fluticasone furoate alone (Ambery et al., 2019).

ii. Bifunctional Bronchodilator/Anti-Inflammatory Drugs. Since PDE4 inhibitors are mainly antiinflammatory agents and PDE3 inhibitors are bronchodilators, molecules able to induce dual inhibitory activity for both PDE3 and PDE4 enzymes have been developed to obtain simultaneously both bronchodilator and antiinflammatory activity (Page and Cazzola, 2014, 2017). Ensifentrine, previously known as RPL554, is an inhaled PDE3/4 inhibitor that has been shown to induce bronchodilation with peak bronchodilator effect in patients with asthma or COPD comparable to that seen after administration of an inhaled $\beta_{2}$-AR agonist, and also bronchoprotective and anti-inflammatory activities at the same dose, with negligible adverse events (Franciosi et al., 2013). Ensifentrine combined with standard bronchodilators (salbutamol, ipratropium, or tiotropium) was recently shown to cause additional bronchodilation and, importantly, a significant reduction of hyperinflation in patients with stable moderate-to-severe COPD (Singh et al., 2018). Unfortunately, studies demonstrating an anti-inflammatory effect in patients with COPD are still lacking (Cazzola and Page, 2018; Cazzola et al., 2018c), although this drug has been demonstrated to reduce lipopolysaccharide-induced neutrophilia in the airways of healthy subjects (Franciosi et al., 2013) at doses that induce bronchodilation.

LASSBio596 (2-[4-(1,4-tiazinan-4-ylsulfonyl) phenylcarbamoyl] benzoic acid), which originates from thalidomide and an aryl sulphonamide, is a molecule that powerfully blocks both PDE4 and PDE5 (Rocco et al., 2003). In preclinical studies that used a murine model of elastase-induced emphysema, this drug decreased lung inflammation and remodeling with consequent 
improvement of lung mechanics (Guimaraes et al., 2014).

The combination of the bronchodilator effects of NO with the anti-inflammatory actions of an ICS is another approach to induce anti-inflammatory and bronchodilator actions with a single molecule. NObudesonide (TPI 1020) was the first agent with these characteristics. In guinea pigs, it potentiated the bronchoprotection induced by formoterol or tiotropium (Turner et al., 2012), but the development of this drug has been discontinued because of limited clinical efficacy. Furthermore, NO was combined with salbutamol into a single molecule (NCX 950, $\left(\alpha^{\prime}-[[(1,1-\right.$ dimethylethy)amino]methyl]-4-hydroxy-1,3-benzenedimethanol nitrate) to simultaneously induce bronchodilation and anti-inflammatory activity (Lagente et al., 2004), but again this drug showed limited efficacy in comparison with salbutamol alone.

Another approach has covalently linked a PDE4 inhibitor to a LABA in an attempt to develop a drug with both anti-inflammatory and bronchodilator activity in a single molecule. Since both PDE4 inhibitors and LABAs increase intracellular levels of cAMP in ASM, such an approach is attractive because it is anticipated that this type of drug could induce additive or synergistic bronchodilator and anti-inflammatory activity in the lung (Matera et al., 2014b), especially in target tissues in which $\beta_{2}$-AR numbers are a limiting factor (Giembycz and Newton, 2015). An example of this approach is GS5759 ((R)-6-[(3-\{[4-(5-\{[2-hydroxy-2-(8-hydroxy-2-oxo1,2-dihydroquinolin-5-yl)ethyl]amino\}pent-1-yn-1-yl) phenyl] carbamoyl\}phenyl)sulphonyl]-4-[(3-methoxyphenyl)amino]-8-methylquinoline-3-carboxamide trifluoroacetic acid), a novel, bifunctional ligand, in which the quinolinone-containing pharmacophore that causes $\beta_{2}$-AR agonism in several LABAs has been conjugated to a PDE4 inhibitor (Joshi et al., 2017). These two ligands can interact on target tissues in a synergistic manner (Joshi et al., 2017) and the inhibition of PDE4 with this drug was shown to be similar to that induced by roflumilast, although the $\beta_{2^{-}}$ AR agonism is not substantially different from that elicited by indacaterol (Tannheimer et al., 2014).

The possibility of combining PDE4 inhibition with mAChR antagonism in a single molecule has also been investigated. UCB-101333-3 (6-(azepan-1-yl)- $N$,2-dicyclopropyl-5-methylpyrimidin-4-amine) was the first such compound described (Provins et al., 2007). However, other compounds that use a pyrazolopyridine pharmacophore as the PDE4 inhibitor and a biarylcontaining pharmacore to achieve $\mathrm{mAChR}$ antagonism have also been described (Phillips and Salmon, 2012).

RO 50-24118 is a stable synthetic peptide analog of vasoactive intestinal peptide that is highly selective for the vasoactive intestinal peptide/pituitary AC-activating polypeptide type 2 receptor and is able to elicit both bronchodilation and anti-inflammatory activity. Thus,
RO 50-24118 relaxes ASM cells, prevents bronchoconstriction, and reduces the influx of neutrophils and CD8 ${ }^{+}$ $\mathrm{T}$ cells, at least in a preclinical model of inflammatory lung disease (Tannu et al., 2010).

\section{What Is the Optimal Use of Bronchodilators?}

Bronchodilators are fundamental in the management of patients with airway obstruction, but there are still questions about their optimal use that need to be clarified.

\section{A. Is It Appropriate to Treat All Patients Suffering from Airway Obstruction with Long- Acting Bronchodilators?}

There is still no convergence of opinion on the use of long-acting bronchodilators in all patients with airway obstruction. This is a critical issue because many patients suffering from airway obstruction do not complain about the classic disturbing symptoms such as cough, sputum, wheezing, and dyspnea. Although the use of bronchodilators is considered a key element in the treatment of COPD, scientific support for their use in asymptomatic patients with COPD is still very poor (Qaseem et al., 2011). However, in patients who remain asymptomatic in early-stage COPD, there is often a rapid decline in lung function with a clear association between $\mathrm{FEV}_{1}$ decline and the appearance of functional small airway disease, even before the development of spirometrically detected airflow obstruction (Bhatt et al., 2016). There is documentation that a treatment with long-acting bronchodilators in early-stage disease could slow the disease progression by influencing both the decline in lung function and health status (Welte et al., 2015). Unquestionably, as far as possible, patients should not be allowed to become symptomatic, because once symptomatic, they have a faster decline in lung function and a lower health-related quality of life (HRQL) with increased health utilization compared with asymptomatic individuals (Decramer et al., 2008).

However, this opinion contrasts with the U.S. Preventive Services Task Force recommendation against screening for COPD in asymptomatic adults because there is a lack of evidence showing the benefit of early detection and treatment (Siu et al., 2016). Nevertheless, in a large cohort of patients who had Global Initiative for Chronic Obstructive Lung Disease (GOLD) strategy stage 1 or stage 2 COPD, tiotropium bromide resulted in a higher $\mathrm{FEV}_{1}$ than placebo at 24 months and decelerated the annual decline in the postbronchodilator $\mathrm{FEV}_{1}$ in patients with a COPD assessment test (CAT) score of $<10$ (milder disease), but not in those with a CAT score of $\geq 10$ (more severe disease) (Zhou et al., 2017). Furthermore, tiotropium bromide was more effective than placebo in improving other parameters of lung function and quality of life and reducing the rate of acute COPD exacerbations. 
These findings suggest that, due to the current inability to identify patients who are fast decliners, it would seem appropriate to treat all patients with COPD with long-acting bronchodilators, including those at the early stages of the disease (Cazzola and Page, 2014). However, it has not yet been determined whether early intervention with a long-acting bronchodilator modifies the long-term course of COPD. Therefore, much larger and longer studies are needed to address this challenge (Cazzola and Rogliani, 2018).

In contrast, it is not appropriate to treat all asthmatic patients with long-acting bronchodilators. In patients with asthma, ICSs are central to fully control symptoms for many patients, but LABAs should be considered as an add-on long-term controller medication when this pharmacological approach does not control asthma when administered at a medium dose (Ducharme et al., 2010). However, LABAs must not be used as monotherapy because patients are at risk of exacerbating (Cazzola and Matera, 2007), although combination inhalers containing a LABA/ICS have been shown to be superior to ICS alone, with no such safety concerns (Bateman et al., 2014). Given that fast-acting inhaled $\beta_{2}$-AR agonists are the most active bronchodilators for rapid relief of asthma symptoms and therefore form a central component of asthma management, a SMART strategy that contains formoterol, which produces a very fast onset of action that is similar to that of short-acting $\beta_{2}$-adrenoceptor agonists (SABAs) and also induces the long-acting bronchodilator benefits of LABAs, combined with ICSs in a single inhaler is fundamental because it can control symptoms during acute exacerbations of asthma and prevent further exacerbations (Sobieraj et al., 2018b). In addition, there is also evidence that LAMAs added to ICSs lower the risk of asthma exacerbations compared with placebo (Cazzola et al., 2017d).

\section{B. Is It Better to Start with a $\beta_{2}$-Adrenergic Receptor Agonist or with a Muscarinic Acetylcholine \\ Receptor Antagonist?}

There is currently not much evidence that can help us differentiate the effectiveness of LABAs from that of LAMAs, or that of different agents within each class of long-acting bronchodilator used as maintenance therapy in patients suffering from COPD.

The choice of bronchodilator in a patient with COPD depends mainly on the outcome of interest (Cazzola and Page, 2014). A recent meta-analysis showed that patients treated with a LAMA were at a lower risk of suffering from acute exacerbations and reporting adverse events than those treated with a LABA. However, in terms of lung function (trough $\mathrm{FEV}_{1}$ ), symptom score (transition dyspnea index), and health status (Saint George's Respiratory Questionnaire score), there were no significant differences between treatment with a LAMA or a LABA (Chen et al., 2017).
Conversely, LAMAs seem more effective than LABAs in the treatment of exacerbations, and this is regardless of whether LABAs are dosed once- or twice-a-day. LAMAs are able to significantly reduce the number of hospitalizations due to COPD exacerbations, and they also decrease the risk of severe adverse effects, but do not alter mortality (Maia et al., 2017). Therefore, if a single bronchodilator must be chosen for treating a patient with COPD, a LAMA seems to be a better option than a LABA, mainly for patients who are frequent exacerbators.

In patients with asthma, there is a weak signal in favor of LAMAs compared with LABAa as add-on therapy when measures of lung function are the goal of treatment, whereas LABAs are significantly better if quality of life is the goal, but the differences are all small (Kew et al., 2015). Given the much larger evidence base for LABAs versus placebo for people whose asthma is not well controlled on ICSs, the current evidence is not strong enough to say that a LAMA can be substituted for a LABA as add-on therapy. However, the choice of LAMAs makes most sense when asthma has a psychogenic origin or is characterized by chronic bronchial obstruction, when patients suffer from bronchospasm triggered by $\beta$-AR blockers, or in the presence of arginine/glycine variation in codon 16 of the $A D R B 2$ gene, which predisposes to a reduced response to $\beta$-AR agonists (Cazzola et al., 2017d).

\section{Is It Useful to Use a Bronchodilator with a Rapid Onset of Action?}

Generally, a rapid bronchodilation is accompanied by an almost immediate relief of dyspnea; in fact, salbutamol is used as a rescue medication in this setting (Cazzola et al., 2015a). There is evidence showing that fast-acting LABAs and LAMAs may also have an additional role in the control of symptoms that many patients experience during the morning and/or nighttime and that impact daily activities and HRQL, thus improving HRQL (Lopez-Campos et al., 2013). Such observations suggest that in the symptomatic patient, formoterol, indacaterol, and olodaterol are preferred over salmeterol and vilanterol, and glycopyrronium or aclidinium to tiotropium or umeclidinium.

As discussed above, acute bronchodilation correlates significantly with symptom improvement in patients with COPD, a correlation that is strongest in patients with baseline hyperinflation (Di Marco et al., 2006), although some evidence suggests that the ability to reduce dyspnea at rest may be better associated with reduction in airway resistance rather than lung deflation (Santus et al., 2014). However, fast onset does not seem to be particularly useful in patients with relatively stable symptoms who receive regular treatment with bronchodilators (Cazzola et al., 2015a). Conversely, fast onset of bronchodilation seems to be helpful when adherence to treatment is suboptimal, 
since compliance increases when the patient perceives rapid improvement of symptoms. Fast onset could also be convenient in patients with a large variability of symptoms.

Two recent studies have explored the advantage of the fast onset of action of the LABA formoterol combined with the ICS budesonide in patients with mild asthma (Bateman et al., 2018; O’Byrne et al., 2018). Both studies showed that formoterol/budesonide used as needed was not inferior to using budesonide alone in reducing exacerbations, while allowing the metered daily dose of ICS to be reduced. Furthermore, formoterol/budesonide was better than terbutaline, a SABA, used on demand to both control asthma symptoms and decrease the risk of asthma exacerbations (O'Byrne et al., 2018); maintenance therapy with budesonide plus as-needed SABA was marginally better for symptom control, with differences in lung function and patient-reported outcomes such as Asthma Control Questionnaire-5 score well below the clinically relevant and minimal clinically important differences (Bateman et al., 2018).

\section{Is Once-a-Day or Twice-a-Day Dosing Preferable?}

When once-a-day LAMAs or LABAs have been compared with twice-a-day agents (LABAs) in clinical studies, it was observed that the former induced better results in terms of standard clinical results (lung function, symptoms, and state of health) (Cazzola et al., 2015a). Once-a-day dosing is relatively simple and convenient compared with multiple daily dosing and, consequently, may increase patient adherence when such drugs are required chronically (Bjerg et al., 2012). Thus, it has been demonstrated that persistence of using inhaled medications in patients with COPD is directly associated with the daily frequency of administration (Cramer et al., 2007). However, it has also been suggested that because of the diurnal nature of lung function, night-time symptoms might be better controlled with twice-a-day dosing ensuring bronchodilation through the night (Celli, 2018).

In patients with COPD, a high self-perceived need for controller medication is associated with once-a-day preference (Price et al., 2013). In patients with asthma, good control and low self-perceived controller medication need were also associated with once-a-day preference. However, in patients with asthma, the observed bronchodilator efficacy over 24 hours was similar when using $5 \mu \mathrm{g}$ tiotropium once-a-day or $2.5 \mu \mathrm{g}$ twice-a-day as an add-on to ICS therapy (Beeh et al., 2016).

\section{E. When Should a Second Bronchodilator with a Different Mechanism of Action Be Added?}

Meta-analyses of LABA/LAMA FDC studies in patients with COPD have documented that LABA/ LAMA FDC therapy gave superior improvements overall in lung function (trough $\mathrm{FEV}_{1}$ ), symptoms (transition dyspnea index score), and quality of life (Saint George's Respiratory Questionnaire score) compared with the constituent monocomponents (Calzetta et al., 2016). This evident superiority of LABA/LAMA FDCs appeared in the first 3 months of treatment and then decreased, although modestly, after 6 and 12 months of treatment (Calzetta et al., 2017c). These studies suggest that improvements in $\mathrm{FEV}_{1}$ induced by LABA/LAMA FDCs emerge in the first 3 months of treatment and then remain stable. Furthermore, LABA/LAMA combinations constantly meet the assumed clinically important differences for both endurance time and inspiratory capacity and, in this respect, are superior to their monocomponents (Calzetta et al., 2017b). Notably, the evaluation of the safety profile of different LABA/LAMA FDCs in the pivotal studies involving patients with COPD showed that dual bronchodilation is a safe therapeutic approach and, above all, it does not increase the risk of the adverse events that characterize LAMAs and LABAs when used as monotherapy (Matera et al., 2016).

It has been suggested that it is sensible to start treatment of patients with COPD with dual bronchodilation soon after a diagnosis of COPD is made to optimize bronchodilation by using the maximal doses currently approved (Cazzola and Matera, 2018a). However, given the well described pharmacological synergistic interaction between LAMAs and LABAs, at least in modulating bronchial tone and improving lung function (Cazzola et al., 2014, 2015b,c, 2016a), the possibility that lowering the doses of the single drugs in any inhaled LABA/LAMA FDC should reduce the risk of unwanted systemic exposure and consequently decrease the risk of cardiovascular adverse events while preserving an adequate level of clinical effectiveness should be explored. It was recently shown that $27.55 / 15.6 \mu \mathrm{g}$ indacaterol/glycopyrronium twicea-day was better than 110/50 $\mu$ g indacaterol/glycopyrronium once-a-day when efficacy and safety profiles were combined using the improved bidimensional surface under the cumulative ranking curve score (Rogliani et al., 2019).

Although the clinical benefits of LABA/LAMA FDCs are now extensively established, very few head-to-head studies between all of the available LABA/LAMA FDCs have been carried out, making choosing the most appropriate FDC difficult (Rogliani et al., 2018a). There is therefore a need for such evidence to clarify which FDC is best from both an efficacy and safety standpoint (Rogliani et al., 2018b).

In asthma, a second bronchodilator with a different mechanism of action, usually a LAMA, is added for patients with poorly controlled disease despite receiving gold standard regular treatment with a LABA/ICS combination (Kerstjens et al., 2012) and regardless of age, sex, cigarette use, ACO, initial $\mathrm{FEV}_{1}$, serum eosinophil count, and body mass index (Kerstjens et al., 2016). However, adding a LAMA must not be 
considered the first choice in symptomatic asthmatics with serum total IgE levels $>430 \mu \mathrm{g} / \mathrm{l}$ (Cheng et al., 2018).

\section{F. When Must an Inhaled Corticosteroid Be Added?}

1. Combination Therapy of $\beta_{2}$-Adrenergic Receptor Agonists and Inhaled Corticosteroids. Most LABAs used in clinical practice are now dispensed as an FDC with an ICS (LABA/ICS), including those prescribed as initial treatment, because there is compelling evidence that LABA/ICS combinations are superior compared with ICSs and LABAs administered as monotherapy or versus placebo in reducing the risk of exacerbations in patients with stable moderate-to-very severe COPD (Criner et al., 2015). However, in an observational study conducted in routine daily practice, starting to treat COPD with LABA/ICS inhalers appeared more effective than LAMAs only in patients who had high concentrations $(>4 \%)$ or counts $(>300$ cells $/ \mu$ l) of eosinophils in the blood and possibly in frequent exacerbators (Suissa et al., 2018).

However, LABA/ICS combinations can increase the risk of pneumonia in patients with COPD compared with LABA/LAMA combinations or LAMA and LABA monotherapies (Oba et al., 2018). Salmeterol/fluticasone propionate use tends to show a higher risk of pneumonia than does use of formoterol/budesonide (Janson et al., 2013). It has been suggested that when an ICS has a longer retention in the airways/lung because of its very low water solubility and relative lipophilicity, there is the risk of a greater local immunosuppression that may explain the intraclass difference in risk of pneumonia. In fact, the immunosuppressive effect can make patients more susceptible to respiratory infectious risk and potentially increases the risk of pneumonia mainly in the presence of impaired mucociliary clearance and altered lung microbiome, which are common in COPD (Janson et al., 2017). However, no difference in COPD-related exacerbations or pneumonia events was observed in real-world practice between salmeterol/fluticasone propionate and formoterol/budesonide when patients were new to LABA/ICS treatment (Kern et al., 2015).

Nevertheless, patients with COPD with elevated circulating eosinophils have more exacerbations and ICSs are beneficial for decreasing the occurrence of exacerbations in patients with high eosinophil counts; in addition, the clinical response to ICSs is enhanced with increasing eosinophil counts (Bafadhel et al., 2017). Therefore, it has been suggested that adding an ICS to a LABA should be considered only in patients with a history of asthma when blood eosinophil counts are $<100$ eosinophils/ $\mu$ l, and always in patients who still experience exacerbations of COPD despite appropriate bronchodilator treatment when blood eosinophil counts are $>300$ eosinophils/ $\mu$ l (Agusti et al., 2018). In patients with 100-300 eosinophils/ $\mu$ l, the choice of adding an ICS is individual for each patient, considering the potential benefits and risks of this approach.

In patients with asthma, adding a LABA must be always considered when asthma is not adequately controlled with a low-to-moderate dose of ICS alone (https://ginasthma.org). However, by using a quasicohort design, a recent study concluded that subjects with asthma were also at greater risk for pneumonia if they used ICS therapy (Qian et al., 2017). The relative risk was dose related, and the risk was higher for budesonide and fluticasone compared with other agents. For this reason, in mild asthma, patientadjusted symptom-driven treatment with low-dose ICS/fast-acting LABA on an intermittent or regular basis should be considered (Cho and Oh, 2019).

2. Combining Muscarinic Acetylcholine Receptor Antagonists and Inhaled Corticosteroids. There are only a few studies specifically designed to evaluate the effect of LAMA/ICS combinations in patients with COPD or asthma, and this is an area that deserves further investigation (Matera and Cazzola, 2017). There are some data that suggest there is no advantage in combining a LAMA with an ICS in patients with COPD (Cazzola et al., 2016b). Furthermore, a small clinical study has shown that adding ciclesonide to regular glycopyrronium does not influence lung volumes or exercise tolerance in patients with severe COPD (Rogliani et al., 2018c).

Nevertheless, in patients with COPD, the combination of a LAMA with an ICS elicits better spirometric responses than those induced by a LABA/ICS combination and, moreover, it is also better than LABA/ICS in affecting clinically important endpoints such as dyspnea, health status, and frequency of exacerbations (Hodder et al., 2007). Furthermore, there is documentation that among patients who in real life take only long-acting bronchodilators, alone or in combination, LAMA/ICS, but not LABA/ICS, is able to reduce allcause mortality (Manoharan et al., 2014). These findings, and also the indirect evidence that adding an ICS to tiotropium can reduce the risk of COPD exacerbations (Calverley et al., 2018), suggest that a LAMA/ICS combination is an effective therapeutic option for patients with COPD and a history of exacerbations (Rogliani et al., 2018d).

In asthma, adding tiotropium to background treatment with an ICS induces advantageous effects that are not substantially different from those obtained with adding a LABA in terms of lung function measurements, exacerbations, asthma control, and other clinically relevant endpoints (Buhl et al., 2018). These benefits can be seen not only in patients with severe asthma, but also in patients with less severe disease and in those who experience adverse events from LABA treatment or in those where LABAs are ineffective. However, evidence that LAMAs are more effective than LABAs on trough $\mathrm{FEV}_{1}$ in adults whose asthma is not 
well controlled on ICS alone is of moderate quality, whereas there is some high-quality evidence suggesting that LABAs are a little better at improving quality of life, although the differences in the Asthma Quality of Life Questionnaire are small (Kew et al., 2015).

Certainly, the possibility of adding a LAMA instead of the classic controllers to low or moderate doses of ICSs in patients with moderate symptomatic asthma is supported by increasing evidence (Chung, 2015), mainly in patients suffering from fixed airflow obstruction (Lee et al., 2015). Tiotropium bromide as a once-aday add-on to a low- to medium-dose ICS may also be efficacious and well tolerated in adults with moderate uncontrolled asthma (Wang et al., 2019). However, the results of a recent systematic review and meta-analysis confirmed the usefulness of combining a LAMA with an ICS as maintenance therapy in patients aged $\geq 12$ years with persistent uncontrolled asthma (Sobieraj et al., 2018a). In these patients, LAMA/ICS combination reduced exacerbation risk and improved spirometric values compared with patients treated with ICS alone. However, there is no evidence that adding a LAMA to an ICS in this population is clinically preferable to adding a LABA.

3. Combining Dual Bronchodilation and Inhaled Corticosteroids. The key question when treating a patient with COPD is no longer whether and/or when it is appropriate to switch the patient from a LABA/ICS regimen to a LABA/LAMA one, but rather what is the type of patient for which we can add an ICS to dual bronchodilation and, above all, when (Cazzola et al., 2018e)?

In general, adding an ICS to a LABA/LAMA combination provides some clinical advantage in patients with COPD, but the presence of a high blood eosinophil count greatly affects the clinical response (Cazzola et al., 2018d). The protective effect of triple therapy compared with dual bronchodilation, relative to the risk of moderate or severe acute exacerbation of COPD, seems to be superior in patients with higher blood eosinophil counts. When blood eosinophil counts are $\geq 300$ cells $/ \mu$ l, the number needed to treat (NNT) for LABA/LAMA/ICS therapy versus LABA/LAMA therapy, to prevent one exacerbation of COPD in 1 year, is approximately nine patients, whereas when blood eosinophil counts are $<300$ cells/ $\mu$ l, the NNT is approximately 46 (Cazzola et al., 2018d).

However, although dual bronchodilation therapy with a LABA plus a LAMA is the basis of the therapy of stable COPD (https://goldcopd.org), a LABA/ICS FDC is still among the most prescribed treatments for patients with COPD. This suggests that triple therapy is usually approached by adding a LAMA to the LABA/ ICS FDC, which is of interest because there is some evidence that adding a LAMA to a LABA/ICS combination elicited relevant clinical benefit in patients with COPD regardless of the blood eosinophil count (Calzetta et al., 2019), with a NNT of approximately four patients treated to have a patient with $\mathrm{a} \geq 100$-ml increase from baseline in trough $\mathrm{FEV}_{1}$, and of approximately 23 patients to be treated for 1 year to prevent one moderate or severe exacerbation of COPD when triple therapy was compared with the LABA/ICS combination.

In patients with asthma, there is high-quality evidence demonstrating a benefit to lung function with the addition of tiotropium bromide (vs. placebo) to LABA/ ICS (Kew and Dahri, 2016). However, the studies reporting scores from the Asthma Quality of Life Questionnaire did not show any significant and clinically relevant benefit of tiotropium bromide over LABA/ ICS alone, but the effect estimate favored adding tiotropium bromide and, furthermore, the addition of tiotropium bromide (studied over 48-52 weeks) led to fewer exacerbations. Nevertheless, it was impossible to rule out a lack of difference (Kew and Dahri, 2016).

\section{Therapeutics of Using Bronchodilators}

\section{A. The Role of Bronchodilators in the Management of Asthma}

The current view is to never begin asthma treatment using a bronchodilator in the absence of an ICS. Patients should not be given a SABA alone, except for the treatment of infrequent short-lived wheeze (White et al., 2018). According to the Global Initiative for Asthma (GINA) recommendations published in 2019 (https://ginasthma.org), SABA-only treatment should be reserved for patients with "occasional daytime symptoms (e.g., less than twice-a-month) of short duration (a few hours), with no night waking and normal lung function," as asthma death can occur in patients who are treated only with a SABA (Selroos, 2008). The use of more than three SABA inhalers a year seems to be associated with the risk of hospital admission (Hull et al., 2016), and morbidity and mortality increase progressively with the increased use of SABAs administered per year (Suissa et al., 1994). An alternative strategy for these patients would be the use of an inhaled combination of a SABA plus an ICS or a LABA plus an ICS to be taken when symptoms are present, used as a reliever rather than for regular maintenance use (Beasley et al., 2014). However, this strategy only works if the $\beta_{2}$-AR agonist component has a fast onset of action for symptom relief (Papi et al., 2007) and some evidence suggests that this approach seems to have advantages over regular ICS therapy (Beasley et al., 2014).

As discussed above, a LABA should always be combined with an ICS, either separately or in an FDC, and is considered first-line maintenance treatment of patients whose symptoms are poorly controlled despite a low-to-moderate dose of ICS alone (https:// ginasthma.org). In addition, the already-mentioned option of prescribing a formoterol/ICS FDC for both maintenance and reliever therapy, rather than using 
a fast-acting $\beta_{2}$-AR agonist as monotherapy for rapid symptom relief(rescue use), so-called SMART therapy, is recommended in the GINA strategy (https://ginasthma. org) as per the license for this product. However, few physicians currently use this approved strategy, instead prescribing additional SABAs or other bronchodilators on top of maintenance doses of ICS (Chapman et al., 2017).

There have been ongoing safety concerns with medicines containing LABAs, causing the U.S. Food and Drug Administration to call for large postmarketing surveillance studies with these medicines and to introduce black box warnings for these drugs (Chowdhury and Dal Pan, 2010). However, in December 2017, the U.S. Food and Drug Administration eliminated the black box warning on LABA/ICS combinations because of the results of recently completed large safety trials that manufacturers have conducted at the request of the agency (Seymour et al., 2018). In fact, the combined analysis of four large, harmonized, postmarketing safety trials did not find a greater risk of the most severe asthma-related outcomes (endotracheal intubation or death) among patients who received LABA/ICS combination therapy than among those receiving an ICS alone (Busse et al., 2018).

Short-acting muscarinic acetylcholine receptor antagonists (SAMAs) do not seem to be very efficient in controlling asthma, although there is consistent evidence from clinical trials that combinations of inhaled therapy with SAMAs and SABAs could play a role in asthmatic patients who develop fixed airway obstruction despite receiving regular treatment and also in the presence of severe asthma exacerbations, because these bronchodilators when combined have the potential to lead to greater and more rapid improvement in lung function and can reduce the need for prolonged emergency room treatments and hospitalization (Cazzola et al., 2017d). This clinical evidence has been incorporated into many clinical guidelines for asthma management (https://www.sign.ac.uk/assets/sign158.pdf; https://ginasthma.org). However, a population-based nested case-control study documented that the use of ipratropium bromide was associated with an increased risk of arrhythmias in asthmatic patients aged 12-24 years (Adimadhyam et al., 2014).

According to the GINA recommendations, tiotropium bromide should be added at steps 4 and 5 in patients aged $\geq 12$ years who still exacerbate despite treatment with ICS and LABAs, before stepping up to biologics (https://ginasthma.org)). Similarly, German (Buhl et al., 2017), Spanish (Plaza Moral et al., 2016), and British asthma guidelines (https://www.sign.ac. uk/assets/sign158.pdf) recommend using tiotropium bromide as add-on therapy in patients with severe asthma when high-dose LABA/ICS therapies are unable to control asthma. However, this recommendation is for adults only. The use of tiotropium bromide in place of a LABA as an addition to an ICS should be considered in patients at GINA step 4 who are susceptible to the adverse effects of LABAs (e.g., palpitations, tremor) (https://ginasthma.org; Oppenheimer and Borish, 2018). Furthermore, it seems correct to treat with triple therapy asthmatic patients who have smoked and remain symptomatic or suffer from frequent exacerbations despite initial inhaler therapy with an ICS/LABA (Cazzola et al., 2019).

Other LAMAs may also be advantageous in the treatment of patients with severe asthma, but robust proof is still lacking (Cazzola et al., 2017d).

For patients who are well controlled on triple therapy, the step-down strategy should begin with discontinuation of the LAMA and maintenance of the LABA/ICS therapy (Chipps et al., 2019). For patients well controlled on LAMA/ICS therapy, the recommended first step is to discontinue the LAMA. However, as there is still limited availability of data, it may also be necessary to reduce the dose of ICS before discontinuing tiotropium bromide, particularly if the patient is sensitive to the adverse effects of ICS.

Current international guidelines do not recommend the use of theophylline in the treatment of asthma because an ICS is much more effective when combined with a LABA than with sustained-release theophylline (Adachi et al., 2008). Nevertheless, theophylline can induce additional bronchodilation even when maximally effective doses of a $\beta_{2}$-AR agonist have been administered (Bonini and Usmani, 2016). Thus, the two can be usefully combined in specific circumstances. Furthermore, theophylline can help in the treatment of nocturnal asthma because slow-release preparations ensure the maintenance of therapeutic concentrations throughout the night, although they are less effective than a LABA. A number of studies have demonstrated that theophylline elicits corticosteroid-sparing effects (Markham and Faulds, 1998; Spina and Page, 2017).

\section{$B$. The Role of Bronchodilators in the Management of Chronic Obstructive Pulmonary Disease}

According to the GOLD 2020 strategy document (https://goldcopd.org), a trial of short-acting bronchodilator treatment of intermittent symptoms and a long-acting bronchodilator for low-grade persistent symptoms is recommended, with provision for stopping or switching medications on the basis of response in patients with lower symptom burden who are not frequent exacerbators. For patients with a high symptom burden but not frequent or severe exacerbations, long-acting bronchodilator monotherapy is recommended with escalation to dual bronchodilator therapy for persistent symptoms. However, for patients with severe dyspnea, initial therapy with two bronchodilators is also a possibility to be considered. Treatment can be stepped down to a single bronchodilator if the addition of a second bronchodilator does not improve symptoms. 
The choice of LABA/LAMA should be individualized for each patient's preferences and degree of disease burden, as there are currently no recommendations that prioritize any specific LABA/LAMA therapy over another and no LABA/LAMA therapy is approved for specific subgroups of patients with COPD (Anzueto and Miravitlles, 2018). According to the 2017 Spanish COPD guidelines (Miravitlles et al., 2017), in patients with a low risk, those with mild or moderate airflow obstruction and low-grade dyspnea in the absence of therapy, and patients who are of the nonexacerbator phenotype, a LAMA should be the initial treatment choice. In symptomatic patients or in patients with any limitation to perform exercise despite LAMA monotherapy, therapy with LABA/LAMA should be tried because it offers a further functional advantage compared with the LAMA, reducing the need for rescue medications and improving symptoms and quality of life.

For frequent exacerbators with lower symptom burden, recommendations are for use of a LAMA as preferred monotherapy (https://goldcopd.org). For escalation of treatment, the use of two bronchodilators is recommended for those patients with persistent dyspnea or exercise limitation on LAMA monotherapy. LABA/LAMA or LABA/ICS are recommended for those patients with recurrent exacerbations on LAMA monotherapy. LABA/ICS may be preferred for patients with a history or findings suggestive of asthma. For patients with persistent dyspnea or exercise limitation on LABA/ ICS treatment, it is advisable to switch to triple therapy by adding a LAMA. However, if maximization of therapy with the addition of an ICS in patients with a degree of clinical instability is useful to control the disease, then such an approach may not be necessary during periods of clinical stability (Cazzola et al., 2015d). Generally, if the patient is strongly symptomatic and is at high risk of exacerbation, therapy can be started with a LAMA that affects both dyspnea and exacerbations (https://goldcopd.org). For patients with more severe symptoms, mainly dyspnea and/or exercise limitation, LABA/LAMA may be considered as the preferable initial therapy. In some patients, LABA/ ICS may be the first choice because it is the treatment that is the most effective in reducing exacerbations in patients with blood eosinophil counts $\geq 300$ cells $/ \mu$ l.

If LABA/ICS therapy does not reduce the risk of exacerbation, the use of triple therapy by adding a LAMA is recommended. Triple therapy can further improve outcomes in patients with COPD on LABA/ICS combination without increasing the risk of severe cardiovascular adverse events (Calzetta et al., 2019).

In the event that treatment with an ICS is ineffective or causes too many side effects, it is possible to switch the therapy to LABA/LAMA, discontinuing the ICS. In patients with persistent exacerbations despite triple therapy, ICS may be discontinued, although it has been demonstrated that ICS withdrawal can significantly increase the risk of severe exacerbations and also impairs both lung function and quality of life, but in a nonclinically important manner (Calzetta et al., 2017a).

The 2017 Spanish COPD guidelines recommend that dual bronchodilation should be tried in symptomatic patients or those with clear exercise limitation despite bronchodilator monotherapy, and in any case it is the initial choice in patients with severe or very severe spirometric impairment (Miravitlles et al., 2017). Furthermore, it is preferred over treatment with LABA/ICS in patients who are symptomatic despite a long-acting bronchodilator, especially if they present exacerbations. Only patients with ACO should be initially treated with a LABA/ICS combination. If there is not a good control of exacerbations with two drugs, triple therapy with LABA/LAMA/ICS should be considered.

The use of xanthines for treating patients with COPD remains controversial. According to the 2017 Spanish COPD guidelines (Miravitlles et al., 2017), xanthines are a third-line treatment because of the limited clinical efficacy and narrow therapeutic window. Xanthines should be used mainly in high-risk patients who continue to be dyspneic while receiving regular dual bronchodilator therapy. Furthermore, adding theophylline to an ICS and a LABA might be associated with an increased risk for overall exacerbation (Wilairat et al., 2019). A large study in patients with COPD treated with ICSs because they were considered at high risk of exacerbation demonstrated that adding low-dose theophylline did not decrease the episodes of COPD exacerbations over a 1-year period compared with placebo (Devereux et al., 2018). In its last report, GOLD strategy does not recommend the use of theophylline because its small therapeutic index and most of benefits occurs only when near-toxic doses are given an also because there are more efficient medications (https://goldcopd.org).

Bronchodilators are also critical in the treatment of acute exacerbations of COPD, together with systemic corticosteroids and appropriate antibiotics. The GOLD 2020 strategy document (https://goldcopd.org) suggests using a SABA alone at high dose or combined with a SAMA, while starting treatment with a long-acting bronchodilator as soon as possible before hospital discharge if the patient was hospitalized, and avoiding the use of xanthines. Some small studies suggest the possibility of using formoterol (Cazzola et al., 2003) instead of salbutamol (Cazzola et al., 2002) to overcome the short pharmacodynamic half-life of this SABA and thus reduce the need for rescue medication. Interestingly, there is a signal in favor of the use of the formoterol/tiotropium combination in patients with mild-to-moderate acute exacerbations of COPD (Di Marco et al., 2006). In particular, it has been reported that hospital stays were shorter when tiotropium 
bromide was added to the respiratory care protocol including formoterol (Drescher et al., 2008).

In addition, indacaterol, a once-a-day (ultra)-LABA, was found to be effective in improving lung function during an acute exacerbation of COPD at the dose of $300 \mu \mathrm{g}$, with an effect that was similar to that obtained with high doses of nebulized salbutamol (1250 $\mu \mathrm{g}$ three times a day) (Segreti et al., 2013), although this caused transient episodes of oxygen desaturation (Rogliani et al., 2014b).

Systemic corticosteroids play a key role in treating severe exacerbations of COPD, but their use is limited to a few days of treatment because of unwanted side effects. It is of interest therefore that adding budesonide influenced the fast onset of action of formoterol (Cazzola et al., 2004) and reduced the potential for acute effects of formoterol on arterial blood gases (Cazzola et al., 2006).

It is anticipated that bifunctional drugs such as ensifentrine or GS-5759 could also be useful in the treatment of acute exacerbations of COPD, but to date there is no evidence supporting this approach.

\section{Use of Bronchodilators for Treatable Traits in Airway Diseases}

Overlapping characteristics of asthma and COPD, such as airway inflammation, atopy, hyperresponsiveness, and a smoking history, can coexist in some patients (Rogliani et al., 2016). ACO has been defined as a presence of fixed airflow obstruction and bronchodilator reversibility and/or bronchial hyperresponsiveness, in addition to eosinophilic inflammation, a history of allergic disease, and cigarette smoke exposure. However, ACO is not a disease entity (Cazzola and Rogliani, 2016), just as asthma and COPD are not, all being defined merely by a set of symptoms or changes in lung function (Fingleton et al., 2018).

However, it has recently been proposed that patients with airway diseases should be treated based on treatable traits such as airflow obstruction, exacerbations, and eosinophilic inflammation that may be differently present in each patient (both asthma and COPD together with ACO share these treatable traits) (Agusti et al., 2016). This would involve the abandonment of the traditional diagnostic labels, but thus far this approach has not been recommended in any guidelines.

Traditionally, airflow limitation is subclassified as variable or fixed, with the former often assumed to be due to airway hyperresponsiveness. However, there could be other potentially treatable factors contributing to variable airflow limitation, including but not limited to sensitization of airway nerves and release of airway inflammatory mediators that affect ASM contractility, intrinsic abnormality of ASM, and structural changes to the airway architecture (Shrimanker et al., 2017).

Bronchial hyperresponsiveness can be targeted symptomatically by treatment including inhaled $\beta_{2}$-AR agonists. mAChR antagonists are potentially less able to prevent bronchoconstriction mediated by inflammatory mechanisms such as mast cell mediator release, although in practice seem to be as effective as $\beta_{2}$-AR agonists in most patients with established airflow limitation. In this population, the combination of LABAs and LAMAs produced additive benefits and this is increasingly regarded as the optimum treatment (Shrimanker et al., 2017).

A small study recently suggested that traits associated with the treatment response to LABAs in patients with stable COPD are postbronchodilator $\mathrm{FEV}_{1}$, bronchodilator reversibility to salbutamol, expression of three genes (CLN8, PCSK5, and SKP2), and damagedgene scores of four genes (EPG5, FNBP4, SCN10A, and SPTBN5) (Kang et al., 2017). Traits associated with the treatment response to a LAMA were CAT score, bronchodilator reversibility to salbutamol, expression of four genes (C1orf115, KIAA1618, PRKX, and RHOQ), and damaged-gene scores of three genes (FBN3, FDFT1, and $Z B E D 6$ ). However, this approach is very complicated and is not suitable for most levels of care.

A simpler approach that could be adapted to different levels of care has been proposed (Shrimanker et al., 2017), which focuses on just two of the major treatable traits in patients with airway disease, eosinophilic inflammation and airflow limitation, with the risk of exacerbations as a result of eosinophilic inflammation and symptoms due to airflow limitation. When symptoms predominate and inflammation is absent or modest, bronchodilators (LABA and LAMA alone or in combination) are the cornerstone of treatment. When both symptoms and inflammation are predominant, triple therapy (LABA/LAMA/high-dose ICS) is needed.

Obviously, this is an oversimplification that does not take into account, for example, that it is necessary to establish at the beginning of the therapy which of the three main phenotypes of ACO-eosinophilic COPD (high T 2 inflammation), neutrophilic asthma (low T 2 inflammation), and also paucigranulocytic ACO-is the one that must be treated (Barnes, 2015). For those patients with ACO without a distinct cellular inflammatory response, bronchodilators are the cornerstone of treatment (Leung and Sin, 2017). In paucigranulocytic ACO, inflammatory cell counts do not increase. Therefore, this phenotype can be treated advantageously with long-acting bronchodilators, including LABAs, LAMAs, or their combination, which are important because they reduce hyperinflation, or triple combination with an ICS (Cazzola et al., 2017b).

\section{Challenges with the Use of Bronchodilators}

\section{A. Bronchodilators in Children and Elderly Patients}

1. In Children. In the acute care setting, SABAs are the most effective bronchodilators, with a significant bronchodilator effect documented in children aged 
$\geq 1$ year (Grigg and Ducharme, 2019). No specific SABA is favored in terms of efficacy or safety. The addition of ipratropium bromide to $\beta_{2}$-AR agonists has been shown to be superior to $\beta_{2}$-AR agonists alone (Griffiths and Ducharme, 2013).

Currently, there are very limited data on the pharmacokinetic behavior of LABAs in the pediatric population and, consequently, pediatric LABA use is based primarily on data from adults, despite children not being small adults, and the magnitude of changes in dose exposure and/or exposure response may not be solely reflected by differences in body weight (Matera et al., 2017b). This is an explanation for why the use of LABAs is unlicensed in children aged $<4$ years for salmeterol and 6 years for formoterol.

In effect, the systemic exposure to formoterol for children versus adults is almost doubled and that for adolescents is about $30 \%$ higher compared with adults; both correlate inversely with age and body size (Chawes et al., 2014). Nevertheless, the lack of relationship between once-a-day vilanterol exposure and age or sex in pediatric asthma subjects aged 5-11 years inadequately controlled on an ICS has been documented, suggesting that a single dose may be suitable for this population; however, the study did not show any significant increase in trough $\mathrm{FEV}_{1}$ from baseline with any of the vilanterol doses examined (Oliver et al., 2014) and there are very few studies investigating the use of vilanterol in pediatric patients (Dwan et al., 2016).

Interestingly, an increased responsiveness to $\beta_{2}$-AR stimulation in children compared with adults has been documented (Bisgaard and Szefler, 2006), which may be the reason why children who receive a LABA present a higher rate of serious adverse effects compared with adults (Rodrigo et al., 2009). Nevertheless, the risk of a serious asthma-related event induced by salmeterol/ fluticasone FDC in children aged between 4 and 11 years who needed daily asthma treatment and had a history of asthma exacerbations in the previous year was similar to that caused by fluticasone alone (Stempel et al., 2016). Although it was not a primary safety endpoint, staying on an FDC containing an ICS reduced the risk of having a severe exacerbation of asthma by $25 \%$ compared with switching to ICS monotherapy. In addition, an FDC of formoterol/budesonide was effective in children, being able to induce larger lung function improvements than budesonide alone with no remarkable safety differences between treatments (Pearlman et al., 2017). These findings show that it is an appropriate therapeutic option for asthmatic children aged 6-11 years who remain symptomatic on ICS alone.

In children and adolescents taking ICSs, LAMAs are capable of inducing a further benefit compared with placebo but have a minimal effect on exacerbation rate and asthma worsening in children who are responsive to bronchodilators (Blake and Raissy, 2018). It has been shown that tiotropium bromide delivered via the
Respimat inhaler was well tolerated as an add-on controller option to ICSs regardless of the presence of additional maintenance therapy in children aged 1-5 years with persistent asthmatic symptoms, with a safety and tolerability profile similar to that of placebo (Vrijlandt et al., 2018). However, several questions remain unanswered, including evidence on the longterm safety, the efficacy of tiotropium bromide compared with LABAs and leukotriene receptor antagonists individually as add-on therapy, and biomarkers to predict treatment response (Anderson et al., 2017).

Almost all children achieve a serum concentration of $5-15 \mathrm{mg} / \mathrm{l}$ and $70 \%$ achieve levels $<10 \mathrm{mg} / \mathrm{l}$ using the current aminophylline intravenous loading dosage recommendation $(5 \mathrm{mg} / \mathrm{kg}$ infused over $20-30$ minutes; Morris et al., 2015; Cooney et al., 2017). Obviously, serum concentrations must be maintained in the therapeutic range using an aminophylline infusion and the British National Formulary for Children recommends choosing the dose of intravenous aminophylline infusion taking into account the patient's age (Paediatric Formulary Committee, 2016). Children aged $<11$ years must receive $1 \mathrm{mg} / \mathrm{kg}$ per hour and adolescents aged $12-18$ years must receive $0.5-0.7 \mathrm{mg} / \mathrm{kg}$ per hour, to achieve the therapeutic range (10-20 mg/l). However, the therapeutic range is often not reached or can be exceeded due to high interindividual variation that is seen with this approach and so many children will be over- or underdosed (Saint et al., 2018).

A recent review of population pharmacokinetic analyses concluded that body weight and age (postconceptional age and postnatal age) were the most important factors associated with the clearance of theophylline in pediatric patients ( $\mathrm{Ma}$ et al., 2016). In these patients, the volume of distribution was influenced only by body weight. The median values of volume of distribution in pediatric patients $(0.897 \mathrm{l} / \mathrm{kg})$ were larger than those in children $(0.57 \mathrm{l} / \mathrm{kg})$ and in adults $(0.485 \mathrm{l} / \mathrm{kg})$. This difference may be due to the larger volume of extracellular fluids in newborns and the increased total body water in neonates.

2. In Elderly Patients. Aging disturbs the absorption of several drugs (including inhaled ones), which may influence their action and safety profile (Matera et al., 2018b). It can affect the pharmacokinetics of a drug because of factors such as renal and hepatic impairment, weight reduction, body fat increase, and a decrease in body water that can characterize elderly patients. In particular, the pharmacokinetics of inhaled drugs is influenced by aging also because of the progressive reduction in respiratory function (Wallin et al., 2018).

However, solid information on the role that age can play on responses induced by inhaled bronchodilators is still lacking. Subgroup analysis of the TORCH study has shown that increased age is a risk factor for future exacerbations (Jenkins et al., 2012). However, in a pooled analysis of 11 studies that included 8445 
patients with moderate to severe COPD, indacaterol once-a-day was equally effective in improving lung function, dyspnea, and HRQL and in reducing the use of rescue medication in patients aged $\geq 65$ years and in those aged $<65$ years. Although older patients frequently suffer from comorbidities, indacaterol was also well tolerated in subjects aged $\geq 75$ years (Girodet et al., 2017).

Nevertheless, the cardiovascular safety of LABAs, LAMAs, and their combination, particularly in elderly individuals, is still debated. A large observational population-based study focused on patients with a mean age of $79.0 \pm 7.1$ years documented that both LABAs and LAMAs equally increase the cardiovascular-related hospitalization rate (Gershon et al., 2013). However, in a group of patients aged $\geq 80$ years with COPD with several comorbidities, a single dose of indacaterol/ glycopyrronium (110/50 $\mu \mathrm{g})$ FDC did not increase shortterm proarrhythmic risk and was associated with a good cardiac safety profile (Spannella et al., 2018).

In a COPD population-based study in which patients were older than 65 years, starting a treatment with a LABA/ICS combination induced a modest but significant reduction in deaths and hospitalizations for COPD compared with starting therapy with LABA alone, an effect that was even more significant in those who suffered from asthma or did not take LAMAs (Gershon et al., 2014).

In a nested case-control study, use of mAChR antagonists by older adults was significantly associated with a greater risk of developing community-acquired pneumonia compared with no use (Chatterjee et al., 2016). The mechanisms that explain the onset of communityacquired pneumonia are still unclear. It is possible that blockage of peripheral mAChRs causing dry mouth compromises the transport of the oropharyngeal bolus, and eventually induces aspiration. However, it cannot be excluded that the scarce dense secretions that follow the use of mAChR antagonists act as pabulum increasing the risk of bacterial growth and depress the mucociliary transport, which facilitates bacterial residence in the lungs and can eventually cause respiration infection. Furthermore, it also cannot be excluded that these pharmacological agents can cause acid reflux and subsequent aspiration by relaxing lower esophageal sphincter muscles(Chatterjee et al., 2016).

Older men, but not women, with COPD initiated on LAMAs are at increased risk of urinary tract infection (Gershon et al., 2017) because LAMAs can inhibit contraction of the detrusor muscle, which causes partial urinary obstruction and urinary stasis predisposing to urinary tract infection. Although this complication is more likely with oral $\mathrm{mAChR}$ antagonists, it can occur even with inhaled preparations; therefore, there is a need for careful monitoring of older patients prescribed inhaled LAMAs because these drugs can also cause cognitive impairment, falls, and closed angle glaucoma (Dunn et al., 2018).
At least as far as we can understand from studies with vilanterol/umeclidinium, the LABA/LAMA combinations are effective in elderly patients, improving lung function in a clinically important manner regardless of age (Ray et al., 2018). Furthermore, age does not influence the safety profile of vilanterol/umeclidinium.

\section{B. Bronchodilators and Comorbidities}

Bronchodilators can impact comorbidities of asthma and COPD, sometimes favorably and sometimes negatively.

1. Cardiovascular Diseases. Patients with COPD or asthma often also suffer from cardiovascular diseases (Cazzola et al., 2012a). This is an important issue when using bronchodilators because both LABAs and LAMAs can potentially affect cardiac function (Matera et al., 2016). In patients with COPD who start to use LABAs or LAMAs, there is a 1.5-fold increased cardiovascular risk within 30 days of therapy initiation (Wang et al., 2018).

Nevertheless, both salbutamol and indacaterol have been demonstrated to induce a rapid reduction in B-type natriuretic peptide levels in patients with an acute exacerbation of COPD (Segreti et al., 2013). A plausible explanation of this effect is that the capacity of $\beta_{2}$-AR agonists in reducing air trapping causes a reduction in intrathoracic pressure, including pressure on the whole heart and, consequently, right-ventricular overload and left-ventricular diastolic dysfunction improve. LABA/LAMA combinations can also reduce lung hyperinflation in a significant manner, and this improvement in lung-function parameters translates into an approximately $10 \%$ increase in left-ventricular enddiastolic volume, with an improved cardiac index mediated by increased stroke volume (Hohlfeld et al., 2018).

Besides, a large trial that enrolled $>16,000$ patients showed that treatment of patients with moderate COPD with the inhaled ultra-LABA, vilanterol, alone or combined with an ICS, appeared to be safe for patients with heightened cardiovascular risk (Brook et al., 2017).

Often, bronchoconstriction is present in patients with heart failure. Fortunately, it can be treated with inhaled $\beta_{2}$-AR agonists, which then decrease the work of breathing that otherwise could possibly further decrease cardiac workload (Minasian et al., 2013). This means that inhaled bronchodilators are useful in the management of these patients if they suffer from airway obstruction.

Furthermore, when a patient suffers from COPD and also from chronic heart failure at the same time, concurrent administration of a LABA and a $\beta$-AR blocker is an option that must always be taken into consideration (Cazzola et al., 2017a; Cazzola and Matera, 2018b) because there is experimental evidence that the coadministration of a $\beta_{2}$-AR agonist and a $\beta_{1^{-}}$ AR blocker can influence cardiac remodeling (Rinaldi et al., 2015). In this study in rats with heart failure, both 
indacaterol and metoprolol alone significantly diminished the infarct size compared with the untreated group. However, when the two drugs were combined, the infarct size was further reduced, both blood pressure and heart rate decreased, and the ejection fraction and left-ventricular systolic and diastolic internal diameters were normalized. Furthermore, the decreased $\beta_{1}$-AR mRNA and cardiac GPCR kinase 2 expression returned to normal, and cAMP levels and catecholamine, atrial natriuretic peptide, B-type natriuretic peptide, and collagen 1 mRNA levels were also normalized. Interestingly, a post hoc analysis of two large clinical trials that investigated the efficacy and safety of olodaterol/tiotropium FDC documented that the addition of a $\beta$-AR blocker for treating a concomitant cardiovascular disease in patients with COPD was safe (Maltais et al., 2018).

SAMAs may slightly increase the risk of heart failure, whereas there seems to be no additional risk of incident heart failure due to LAMAs or with a LABA/LAMA combination (Roversi et al., 2016).

Cardiac arrhythmias are common in patients with COPD or asthma (Cazzola et al., 2012a). Although bronchodilators are potentially arrhythmogenic agents (Cazzola et al., 2012b), available evidence suggests an overall satisfactory safety profile when using a LABA, LAMA, or dual bronchodilation (Matera et al., 2016; Rogliani et al., 2018b). Thus, the overall risk of cardiac arrhythmias does not increase with tiotropium bromide (Cazzola et al., 2017c), whereas glycopyrronium bromide causes a slightly higher incidence of atrial fibrillation compared with placebo, despite an overall good safety profile (D'Urzo et al., 2015). In contrast, SABAs and theophylline may precipitate atrial fibrillation and worsen ventricular rate control and caution is thus needed when using them (Roversi et al., 2016).

2. Diabetes Mellitus. Insulin and glucagon secretion, hepatic glucose production, and uptake of glucose into skeletal muscle can be modulated by $\beta$-agonists that can in turn influence glucose homeostasis and increase blood sugar levels, although this effect seems to be important only when patients are near glucose intolerance (Philipson, 2002).

Conversely, $\beta_{2}$-agonists can protect against the vascular complications of diabetes (Galvan and Danesh, 2017), an effect that is probably related to the $\beta$-arrestin2/inhibitor of $\kappa \mathrm{B} /$ nuclear factor $-\kappa \mathrm{B}$ signaling pathway. When activated, $\beta_{2}$-ARs increase the levels of $\beta$-arrestin 2 and its interaction with inhibitor of $\kappa \mathrm{B}$, causing a reduction in the effects of inflammatory stimuli and allowing tissue protection. There is also experimental evidence that $\beta_{2}$-AR agonists increase the survival of pericytes, which are central to preserving the quiescence of endothelial cells and the integrity of their tight junctions, thereby preventing diabetes-induced pericyte loss in the retina (Yun et al., 2018). Furthermore, it has been suggested that chronic administration of salbutamol could ameliorate nerve dysfunction, as well as exert an antinociceptive effect in diabetic peripheral neuropathy, an effect that is most likely mediated by $\beta_{2}$-ARs (Baraka et al., 2015).

At least in patients with COPD, the combination of an ICS with a $\beta_{2}$-AR agonist apparently reduces, and that with a mAChR antagonist increases, the association between COPD and diabetes (Rogliani et al., 2014a). However, there is no evidence to date that this happens in patients with asthma, but hyperinsulinemia associated with obesity increases vagally induced bronchoconstriction as this inhibits neuronal $\mathrm{M}_{2} \mathrm{mAChRs}$ and facilitates ACh release from airway parasympathetic nerves (Nie et al., 2014).

3. Anxiety/Depression. Anxiety and depression are associated with $\beta$-adrenergic and cholinergic initiated signaling (Drevets et al., 2013; Naka et al., 2013). An experimental study in rats documented that $\beta$-AR agonists, by activating $\beta$-ARs in the bed nucleus of the stria terminalis, elicited an anxiety-like behavior in a dosedependent manner (Naka et al., 2013). It has also been suggested that depression and related structural and functional changes in certain brain areas are associated with cholinergic dysfunction (Drevets et al., 2013).

In some adult asthmatics, there is an association between major depression and a reduced bronchodilator response that is independent of anxiety symptoms (Han et al., 2016). In patients with COPD, SABAs are associated with a considerably increased risk of onset of bipolar disorder, a risk that is absent with LABAs, SAMAs, and LAMA (Su et al., 2017). There is experimental and clinical evidence that peripheral inflammation is associated with the upregulation of inflammation in the central nervous system and SABAs, when used regularly, increase airway inflammation and bronchial hyperresponsiveness and reduce lung function, whereas LABAs, SAMAs, and LAMAs are capable of exerting a clinically relevant anti-inflammatory activity $\mathrm{Su}$ et al., 2017). Nevertheless, it has also been documented that bronchodilator therapy for COPD has no significant direct effects on depression or anxiety (Hyun et al., 2016), although others have suggested that the valuable effects on dyspnea are likely to relieve associated emotional and mood symptoms (Yohannes et al., 2018).

Intriguingly, in some adult asthmatics, theophylline, but not LABAs, can induce an increased risk of suicidal ideation (Favreau et al., 2012). This effect might be caused by a theophylline-induced increase in cerebral blood resistance, with decreased cerebral blood flow and cerebral oxygen, or by increased blood levels of catecholamines in a pathophysiological manner similar to that observed in patients with panic disorder (Favreau et al., 2012). It would seem sensible therefore to exert caution when prescribing theophylline or similar agents to asthmatics at risk of suicide and ensure adequate follow-up.

4. Gastroesophageal Reflux Disease. $\beta$-AR agonists decrease the tone of the lower esophageal sphincter in 
patients with COPD or asthma, reducing the function of the antireflux barrier, whereas theophylline increases reflux, although the exact mechanisms that cause these effects are still unknown (Shimizu et al., 2012; Del Grande et al., 2016). There is evidence suggesting that $\beta_{2}$-AR agonists, mainly nebulized salbutamol, can worsen reflux in some patients (Babu and Morjaria, 2018). However, the use of salbutamol is less problematic than theophylline in this context (Mungan and Pınarbaşı Şimşek, 2017).

Inhaled mAChR antagonists may decrease or, at least, not increase the risk of gastroesophageal reflux disease (Kim et al., 2013). However, the reduction of the lower esophageal sphincter pressure induced by central and peripherally acting $\mathrm{mAChR}$ antagonists is balanced by their antitussive effect that can suppress cough and thereby minimize the occurrence of changes in intraabdominal pressure, which may facilitate the onset of gastroesophageal reflux disease (Kim et al., 2013).

5. Cough. Since it is often difficult to differentiate chronic cough derived from asthma from that accompanying rhinosinusitis or gastroesophageal reflux disease, it has been proposed to consider chronic cough as a single independent disease entity referred to as "hypersensitivity of the cough reflex" (Morice et al., 2011).

Experimental studies suggest that modifications in airway caliber increase the sensitivity of the afferents involved in the cough reflex, although there are difficulties in proving this effect in the clinical setting. This finding suggests that bronchodilators might have a rather minor role in the treatment of cough (Matera et al., 2017d). However, the mechanism(s) by which these agents alleviate cough still need to be clarified (Dicpinigaitis et al., 2014).

There is evidence that $\mathrm{mAChR}$ antagonists reduce experimental cough (Dicpinigaitis et al., 2014). In naive guinea pigs, tiotropium bromide and ipratropium bromide improved cough reflex sensitivity by modulating transient receptor potential cation channel subfamily $\mathrm{V}$ member 1 (Birrell et al., 2014). A study in rabbits showed that acid-sensing ion channels and mechanoreceptors might mediate LAMA-induced downregulation of cough (Mutolo et al., 2016). Furthermore, modulation of cough reflex sensitivity, but not bronchodilation, is the mechanism by which tiotropium bromide may alleviate asthmatic cough refractory to LABA/ICS (Fukumitsu et al., 2018), although mAChR antagonists do not inhibit ozone-induced hypertussive responses at doses that are bronchodilatory (Clay et al., 2016). Results from phase III studies suggest that aclidinium bromide $(400 \mu \mathrm{g})$ taken twice-a-day may improve cough by reducing, in particular, night-time cough frequency and severity (McGarvey et al., 2016). LAMAs are also used in tertiary care to dampen down laryngeal nerve irritability as well as treat (dry) airway secretions that may be aggravating the cough reflex pathways (Wang et al., 2017).
The antitussive properties of $\beta_{2}$-AR agonists, if any, are mediated by acting directly on $\beta_{2}$-ARs on sensory nerve endings in the lung (Maher et al., 2011). However, the use of $\beta_{2}$-AR agonists in children with acute cough, but without bronchoconstriction, is not supported by any evidence and the evidence supporting the routine use of $\beta_{2}$-AR agonists in adults with acute cough is also very modest (Becker et al., 2015).

Nonetheless, postviral cough is effectively improved by a combination of inhaled ipratropium bromide and salbutamol (Zanasi et al., 2014). There is also documentation that the combination of aclidinium/formoterol significantly improves night-time and early-morning cough severity in patients with moderate to severe COPD (Bateman et al., 2015).

Interestingly, in guinea pig models of allergic inflammation, budesonide and salmeterol combined at half-dose show comparable antitussive, bronchodilatory, and anti-inflammatory effects to a full-dose therapy with budesonide alone but are more effective in stimulating the ciliary beat frequency (Pappová et al., 2016). Indeed, cough symptoms in patients with cough-variant asthma improve significantly when treated with a combination of a $\beta_{2}$-AR agonist plus an ICS (Bao et al., 2013).

\section{Use of Bronchodilators in Pregnancy}

Within the LABA class, formoterol and salmeterol seem to be associated with similar prevalences of low birth weight, preterm birth, and neonates being small for gestational age (Cossette et al., 2014). Importantly, however, there is no evidence of a higher risk of major congenital malformations among asthmatic pregnant women treated with a LABA plus ICS combination than that seen in women receiving ICS monotherapy at a higher dose during the first trimester (Eltonsy et al., 2015).

Nevertheless, data from a database of congenital anomaly registries documented the risk of cleft palate and gastroschisis when pregnant women are exposed to inhaled $\beta_{2}$-AR agonists in the first trimester (Garne et al., 2015). Additionally, a meta-analysis of aggregated data from three cohort studies performed in Norway, Wales, and Denmark found associations between the use of SABAs in the first trimester of pregnancy and onset of renal dysplasia (Garne et al., 2016). However, because these outcomes are uncommon and the relative risks are very low, they represent an absolute risk that is truly minimal (Namazy and Schatz, 2017). In addition, these increased relative risks may be the result of asthma exacerbations that could be associated with a risk of congenital malformations, and SABAs are only a confounding factor in that they are used for the treatment of asthma exacerbations (Namazy and Schatz, 2017). However, in a Swedish study, the risk of cleft palate was lower for SABAs than for ICSs and other bronchodilators and 
no increased risk of gastroschisis linked to the use of SABAs was reported (Källén, 2014).

It has been suggested that exposure to $\beta_{2}$-AR agonists during the prenatal period is associated with an increased risk for autism spectrum disorders (Gidaya et al., 2016). Furthermore, there is an increased risk of cerebral palsy associated with maternal use of $\beta_{2}$-AR agonists during pregnancy in female offspring born at term ( $\mathrm{Li}$ et al., 2018). Nonetheless, no association between tocolytic exposure and subsequent development of autistic disorders or behavioral or developmental disabilities among term and preterm born infants has been found (Altay et al., 2017). Neither the time of treatment initiation nor the duration and dosage of $\beta$-AR agonist exposure is correlated with an increased risk of autism spectrum disorders.

There have been no adequate well-controlled clinical studies of tiotropium bromide or other LAMAs specifically performed in pregnant women. Therefore, LAMAs should be used with caution in this population (Kerstjens and O’Byrne, 2016).

\section{Pharmacogenetics of Airway Obstruction and Bronchodilators}

Genetic polymorphisms can modify responses to inhaled bronchodilators (Kersten and Koppelman, 2017); therefore, the discovery, or confirmation, of a genetic marker that could accurately predict responses to LABA and/or LAMA treatment would have high clinical value.

Pharmacogenetic studies of $\beta_{2}$-AR agonists have mainly focused on the gene encoding the $\beta_{2}-\mathrm{AR}(A D R B 2)$. There is evidence for functional relevance of Gly ${ }^{16} \mathrm{Arg}$ (rs1042713), Gln ${ }^{27} \mathrm{Glu}$ (rs1042714), and $\mathrm{Thr}^{164} \mathrm{Ile}$ (rs1800888). These three single nucleotide polymorphisms (SNPs) lessen the level of agonist-promoted downregulation of $\beta_{2}$-AR expression and stimulate AC activity (Slob et al., 2018). Variants that alter ADRB2 function could increase disease risk or reduce the response to endogenous and inhaled $\beta_{2}$-AR agonists in asthma (Zuurhout et al., 2013) and COPD (Nielsen et al., 2017), but there are contradictory reports as to whether functional genetic variants in $A D R B 2$ are associated with response to bronchodilator treatment. ADRB2 $\mathrm{Gly}^{16} \mathrm{Arg}$ variant is consistently associated with response to LABA; however, it increases the risk of exacerbation only in children, but not adults (Slob et al., 2018). Rare variants can also influence responses to SABAs (Drake et al., 2014) or LABAs (Ortega et al., 2014), with a large effect size.

A systematic review and meta-analysis found neither a significant association between $\mathrm{Gly}^{16} \mathrm{Arg}, \mathrm{Gln}{ }^{27} \mathrm{Glu}$, and $\mathrm{Thr}^{164}$ Ile genotypes and the risk of COPD nor consistent differences in treatment response to $\beta_{2}$-AR agonists in patients with COPD as a function of $A D R B 2$ (Nielsen et al., 2017). However, a large pharmacogenetics genome-wide association study of patients with
COPD showed that responses to inhaled SABAs are associated with variants upstream from the gene KCNJ2 (Hardin et al., 2016). Furthermore, it has been documented that patients with COPD with the Arg ${ }^{16}$ Arg genotype had better exacerbation outcomes in response to salmeterol than those with Gly ${ }^{16} \mathrm{Gly}$ and Arg ${ }^{16}$ Gly genotypes (Rabe et al., 2014). In addition, there is a significant association between bronchodilator responsiveness and several SNPs in the genes CDH13 and SGCD in African Americans (Hardin et al., 2016).

There are significant variations between ethnic groups in genetics of ADRB2(Cazzola et al., 2018b). Several uncommon variants with a frequency of $<5 \%$, most of which were unique to a particular ethnic group, have been identified by resequencing $A D R B 2$ in multiethnic groups of asthmatics (Ortega et al., 2015). Thus, the infrequent coding variant $\mathrm{Thr}^{164}$ Ile was identified mainly in non-Hispanic whites, whereas it was possible to detect a 24-basepair promoter insertion variant at nucleotide position -376 relative to the start codon (i.e., - 376 In-Del) only in African Americans and Puerto Ricans (Ortega et al., 2015).

A meta-analysis that investigated the link between childhood asthma exacerbations and the $\mathrm{Arg}^{16}$ polymorphism using data from five White Northern European and Hispanic/Latin pediatric populations recruited in five cross-sectional studies documented the association between the variant rs1042713 and an increased risk of asthma exacerbation in children treated with ICS/ LABAs (Turner et al., 2016). However, a large pharmacogenetic study, in which the entire genome of 1441 asthmatic children belonging to different racial and ethnic groups (Puerto Ricans, Mexicans, and African Americans) with extreme responses to salbutamol was sequenced, failed to identify any association between the response of bronchodilator and specific variants from $\beta_{2^{-}}$ AR signaling pathways (Mak et al., 2018).

Several polymorphisms in the $\mathrm{M}_{2} \mathrm{mAChR}$ and also, although less frequently, in the $\mathrm{M}_{3} \mathrm{mAChR}$ subtype genes have been described (Matera et al., 2017c). The possible existence of an increased risk to develop a more severe disease in patients with COPD carrying the SNP of the $\mathrm{M}_{2} \mathrm{mAChR}$ (rs1824024) has been suggested (Cherubini et al., 2016). This risk is linked to lower lung function parameters and symptoms and increased susceptibility to exacerbations in these individuals than in patients not having this SNP. Despite the key function of CHRM3, which codes for the $\mathrm{M}_{3} \mathrm{mAChR}$ and consequently is important in the physiology of human airways, and the number of its polymorphisms, there is not solid documentation that these variations have pharmacological relevance (Matera et al., 2017c).

Theophylline mainly undergoes 8-hydroxylation to 1,3dimethyl uric acid by CYP1A2, a subtype of cytochrome P450, and also $N$-demethylation to 1-methylxanthine or to 3-methylxanthine by CYP2E1 and CYP1A2. It has been 
documented that increased theophylline clearance was significantly related to the $-3860 \mathrm{G}>\mathrm{A}$ polymorphism in the CYP1A2 gene, and this polymorphism could influence the enzyme inducibility of CYP1A2, at least in Korean nonsmoking asthmatics (Yim et al., 2013). In a Chinese population, the rate of theophylline clearance was not related to the genotypes of the CYP1A2 gene, G-3860A; in contrast, that of the two groups of CYP1A2 G-3113A gene loci A allele carriers (AA + GA genotype) appeared to be significantly lower than that of the $\mathrm{G}$ allele carriers (GG genotype) (Xiong and $\mathrm{Li}, 2018$ ). The frequency of G-3113A mutation was much higher in Chinese and ethnic minority groups (approximately $10 \%$ and $11 \%$, respectively) than in a Korean population $(2.7 \%)$ and a Swedish population (2.3\%) (Hatta et al., 2015). CYP1A2 enzyme activity is intensified by polymorphism of $C Y P 1 A 2 * 1 F$ allele $(C Y P 1 A 2 * 1 F(-163 \mathrm{C}>\mathrm{A})$ allele) and conversely, is decreased by five SNPs of CYP2E1 $(-1055 \mathrm{C}>\mathrm{T}$, $-1027 \mathrm{~T}>\mathrm{C},-807 \mathrm{~T}>\mathrm{C},-1566 \mathrm{~T}>\mathrm{A}$, and $-1295 \mathrm{G}>\mathrm{C}$ ) that also reduce 1,3- dimethyl uric acid/theophylline ratio (Sutrisna, 2016).

\section{Authorship Contributions}

Wrote or contributed to the writing of the manuscript: Matera, Page, Calzetta, Rogliani, Cazzola.

\section{References}

Abbott-Banner KH and Page CP (2014) Dual PDE3/4 and PDE4 inhibitors: novel treatments for COPD and other inflammatory airway diseases. Basic Clin Pharmacol Toxicol 114:365-376.

Adachi M, Aizawa H, Ishihara K, Ohta K, Sano Y, Taniguchi H, and Nakashima M (2008) Comparison of salmeterol/fluticasone propionate (FP) combination with $\mathrm{FP}+$ sustained release theophylline in moderate asthma patients. Respir Med 102 : $1055-1064$

Adimadhyam S, Schumock GT, Walton S, Joo M, McKell J, and Lee TA (2014) Risk of arrhythmias associated with ipratropium bromide in children, adolescents, and young adults with asthma: a nested case-control study. Pharmacotherapy 34: $315-323$.

Adner M, Larsson B, Säfholm J, Naya I, and Miller-Larsson A (2010) Budesonide prevents cytokine-induced decrease of the relaxant responses to formoterol and terbutaline, but not to salmeterol, in mouse trachea. J Pharmacol Exp Ther 333: 273-280.

Agusti A, Bel E, Thomas M, Vogelmeier C, Brusselle G, Holgate S, Humbert M, Jones P, Gibson PG, Vestbo J, et al. (2016) Treatable traits: toward precision medicine of chronic airway diseases. Eur Respir J 47:410-419.

Agusti A, Fabbri LM, Singh D, Vestbo J, Celli B, Franssen FME, Rabe KF, and Papi A (2018) Inhaled corticosteroids in COPD: friend or foe? Eur Respir $J$ 52:1801219.

Altay MA, Görker I, Aslanova R, Bozatl L, Turan N, and Kaplan PB (2017) Association between beta-sympathomimetic tocolysis and risk of autistic spectrum disorders, behavioural and developmental outcome in toddlers. Open Access Maced $J$ Med Sci 5:730-735.

Altonsy MO, Mostafa MM, Gerber AN, and Newton R (2017) Long-acting $\beta_{2}$-agonists promote glucocorticoid-mediated repression of NF-kB by enhancing expression of the feedback regulator TNFAIP3. Am J Physiol Lung Cell Mol Physiol 312: L358-L370.

Ambery C, Young G, Fuller T, Georgiou A, Ramsay D, Puri A, and Daley-Yates P (2019) Open-label, crossover study to determine the pharmacokinetics of fluticasone furoate and batefenterol when administered alone, in combination, or concurrently. Clin Pharmacol Drug Dev 8:188-197.

Anderson WC 3rd, Gleason MC, Miyazawa N, and Szefler SJ (2017) Approaching current and new drug therapies for pediatric asthma. Pediatr Clin North Am 64: 1197-1207.

Anzueto A and Miravitlles M (2018) Considerations for the correct diagnosis of COPD and its management with bronchodilators. Chest 154:242-248.

Aparici M, Carcasona C, Ramos I, Montero JL, Ortiz JL, Cortijo J, Puig C, Vilella D, Doe C, Gavaldà A, et al. (2017) Pharmacological preclinical characterization of LAS190792, a novel inhaled bifunctional muscarinic receptor antagonist $/ \beta_{2}$ adrenoceptor agonist (MABA) molecule. Pulm Pharmacol Ther 46:1-10.

Babu KS and Morjaria JB (2018) Inhaled, nebulised and oral bronchodilators in reflux disease, in Reflux Aspiration and Lung Disease (Morice AH and Dettmar PW eds) pp 333-341, Springer International Publishing AG, Cham, Switzerland.

Bafadhel M, Pavord ID, and Russell REK (2017) Eosinophils in COPD: just another biomarker? Lancet Respir Med 5:747-759.

Bao W, Chen Q, Lin Y, Liu H, Zhao G, Chen Z, and Zhou X (2013) Efficacy of procaterol combined with inhaled budesonide for treatment of cough-variant asthma. Respirology 18 (Suppl 3):53-61.
Baraka AM, Darwish IE, Ghoneim MT, and Korayem HK (2015) $\beta_{2}$-Adrenoceptor agonists as potential therapeutic drugs in diabetic peripheral neuropathy. Eur $J$ Pharmacol 746:89-95.

Bardin PG, Dorward MA, Lampe FC, Franke B, and Holgate ST (1998) Effect of selective phosphodiesterase 3 inhibition on the early and late asthmatic responses to inhaled allergen. Br J Clin Pharmacol 45:387-391.

Barnes PJ (2013) Theophylline. Am J Respir Crit Care Med 188:901-906.

Barnes PJ (2015) Therapeutic approaches to asthma-chronic obstructive pulmonary disease overlap syndromes. J Allergy Clin Immunol 136:531-545.

Barnes PJ (2016) Kinases as novel therapeutic targets in asthma and chronic obstructive pulmonary disease. Pharmacol Rev 68:788-815.

Basu S, Barawkar DA, Ramdas V, Patel M, Waman Y, Panmand A, Kumar S, Thorat S, Naykodi M, Goswami A, et al. (2017) Design and synthesis of novel xanthine derivatives as potent and selective $\mathrm{A}_{2 \mathrm{~B}}$ adenosine receptor antagonists for the treatment of chronic inflammatory airway diseases. Eur J Med Chem 134:218-229

Bateman ED, Chapman KR, Singh D, D'Urzo AD, Molins E, Leselbaum A, and Gil EG (2015) Aclidinium bromide and formoterol fumarate as a fixed-dose combination in COPD: pooled analysis of symptoms and exacerbations from two six-month, multicentre, randomised studies (ACLIFORM and AUGMENT). Respir Res 16:92.

Bateman ED, O’Byrne PM, Busse WW, Lötvall J, Bleecker ER, Andersen L, Jacques L, Frith L, Lim J, and Woodcock A (2014) Once-daily fluticasone furoate (FF)/ vilanterol reduces risk of severe exacerbations in asthma versus $\mathrm{FF}$ alone. Thorax 69:312-319.

Bateman ED, Reddel HK, O’Byrne PM, Barnes PJ, Zhong N, Keen C, Jorup C, Lamarca R, Siwek-Posluszna A, and FitzGerald JM (2018) As-needed budesonideformoterol versus maintenance budesonide in mild asthma. $N$ Engl J Med 378: 1877-1887.

Beasley R, Holliday M, Reddel HK, Braithwaite I, Ebmeier S, Hancox RJ, Harrison T, Houghton C, Oldfield K, Papi A, et al.; Novel START Study Team (2019) Controlled trial of budesonide-formoterol as needed for mild asthma. $N$ Engl J Med 380: 2020-2030

Beasley R, Weatherall M, Shirtcliffe P, Hancox R, and Reddel HK (2014) Combination corticosteroid $/ \beta$-agonist inhaler as reliever therapy: a solution for intermittent and mild asthma? J Allergy Clin Immunol 133:39-41.

Beattie D, Bradley M, Brearley A, Charlton SJ, Cuenoud BM, Fairhurst RA Gedeck P, Gosling M, Janus D, Jones D, et al. (2010) A physical properties based approach for the exploration of a 4-hydroxybenzothiazolone series of $\beta_{2}$ adrenoceptor agonists as inhaled long-acting bronchodilators. Bioorg Med Chem Lett 20:5302-5307.

Becker LA, Hom J, Villasis-Keever M, and van der Wouden JC (2015) Beta -agonists $^{-}$ for acute cough or a clinical diagnosis of acute bronchitis. Cochrane Database Syst $\operatorname{Rev}(9): \mathrm{CD} 001726$.

Beeh KM, Kirsten AM, Dusser D, Sharma A, Cornelissen P, Sigmund R, MoroniZentgraf P, and Dahl R (2016) Pharmacodynamics and pharmacokinetics following once-daily and twice-daily dosing of tiotropium Respimat ${ }^{\circledR}$ in asthma using standardized sample-contamination avoidance. J Aerosol Med Pulm Drug Deliv 29 $406-415$

Benaouda F, Jones SA, Chana J, Dal Corno BM, Barlow DJ, Hider RC, Page CP, and Forbes B (2018) Ion-pairing with spermine targets theophylline to the lungs via the polyamine transport system. Mol Pharm 15:861-870.

Benyahia C, Gomez I, Kanyinda L, Boukais K, Danel C, Leséche G, Longrois D, and Norel X (2012) PGE( $\left.{ }_{2}\right)$ receptor $\left(\mathrm{EP}_{4}\right)$ ) agonists: potent dilators of human bronchi and future asthma therapy? Pulm Pharmacol Ther 25:115-118.

Beute J (2014) Emergency treatment of status asthmaticus with enoximone. $\mathrm{Br}$ $J$ Anaesth 112:1105-1108.

Bhatt SP, Soler X, Wang X, Murray S, Anzueto AR, Beaty TH, Boriek AM, Casaburi R, Criner GJ, Diaz AA et al · COPDGene Investigators (2016) Association between functional small airway disease and $\mathrm{FEV}_{1}$ decline in chronic obstructive pulmonary disease. Am J Respir Crit Care Med 194:178-184.

Billington CK and Hall IP (2012) Novel cAMP signalling paradigms: therapeutic implications for airway disease. $\mathrm{Br} J$ Pharmacol 166:401-410.

Billington CK, Ojo OO, Penn RB, and Ito S (2013) cAMP regulation of airway smooth muscle function. Pulm Pharmacol Ther 26:112-120.

Birrell MA, Bonvini SJ, Dubuis E, Maher SA, Wortley MA, Grace MS, Raemdonck K, Adcock JJ, and Belvisi MG (2014) Tiotropium modulates transient receptor potential V1 (TRPV1) in airway sensory nerves: a beneficial off-target effect? $J \mathrm{Al}$ lergy Clin Immunol 133:679-687.e9.

Bisgaard H and Szefler S (2006) Long-acting beta2 agonists and paediatric asthma. Lancet 367:286-288.

Bjerg A, Lundbäck B, and Lötvall J (2012) The future of combining inhaled drugs for COPD. Curr Opin Pharmacol 12:252-255.

Blake KV and Raissy HH (2018) Asthma guidelines priority topic: long-acting antimuscarinic agents in asthma management as add-on to inhaled corticosteroids. Pediatr Allergy Immunol Pulmonol 31:199-293.

Bonini M and Usmani OS (2016) Drugs for airway disease. Medicine (Baltimore) 44 $271-280$

Bourke JE, Bai Y, Donovan C, Esposito JG, Tan X, and Sanderson MJ (2014) Novel small airway bronchodilator responses to rosiglitazone in mouse lung slices. Am J Respir Cell Mol Biol 50:748-756.

Bourke JE, Royce S, Samuel C, and Lam M (2018) Serelaxin is a novel bronchodilator which enhances $\beta$-adrenoceptor-mediated airway relaxation in multiple species. Am J Respir Crit Care Med 197:1232.

Brook RD, Anderson JA, Calverley PM, Celli BR, Crim C, Denvir MA, Magder S, Martinez FJ, Rajagopalan S, Vestbo J, et al.; SUMMIT Investigators (2017) Cardiovascular outcomes with an inhaled beta2-agonist/corticosteroid in patients with COPD at high cardiovascular risk. Heart 103:1536-1542.

Buckley J, Birrell MA, Maher SA, Nials AT, Clarke DL, and Belvisi MG (2011) EP4 receptor as a new target for bronchodilator therapy. Thorax 66:1029-1035.

Buhl R, Bals R, Baur X, Berdel D, Criée CP, Gappa M, Gillissen A, Greulich T, Haid P, Hamelmann E, et al.; Deutsche Gesellschaft für Arbeitsmedizin und Umweltmedizin e.V.; Deutsche Gesellschaft für Rehabilitationswissenschaften e.V.; und 
Deutsche Gesellschaft für Gynäkologie und Geburtshilfe e.V. (2017) [Guideline for the diagnosis and treatment of asthma - guideline of the German Respiratory Society and the German Atemwegsliga in Cooperation with the Paediatric Respiratory Society and the Austrian Society of Pneumology] [published correction appears in Pneumologie (2017) 71:e2; published correction appears in Pneumologie (2017) 71:e3]. Pneumologie 71:849-919.

Buhl R, FitzGerald JM, and Busse WW (2018) Tiotropium add-on to inhaled corticosteroids versus addition of long-acting $\beta_{2}$-agonists for adults with asthma. Respir Med 143:82-90.

Busse WW, Bateman ED, Caplan AL, Kelly HW, O'Byrne PM, Rabe KF, and Chinchilli VM (2018) Combined analysis of asthma safety trials of long-acting $\beta_{2}$-agonists. N Engl J Med 378:2497-2505.

Calverley PMA, Anzueto AR, Carter K, Grönke L, Hallmann C, Jenkins C, Wedzicha J, and Rabe KF (2018) Tiotropium and olodaterol in the prevention of chronic obstructive pulmonary disease exacerbations (DYNAGITO): a doubleblind, randomised, parallel-group, active-controlled trial. Lancet Respir Med 6: 337-344.

Calzetta L, Cazzola M, Matera MG, and Rogliani P (2019) Adding a LAMA to ICS/ LABA therapy: a meta-analysis of triple combination therapy in COPD. Chest $\mathbf{1 5 5}$ : $758-770$

Calzetta L, Hanania NA, Dini FL, Goldstein MF, Fairweather WR, Howard WW, and Cazzola M (2018a) Impact of doxofylline compared to theophylline in asthma: a pooled analysis of functional and clinical outcomes from two multicentre, doubleblind, randomized studies (DOROTHEO 1 and DOROTHEO 2). Pulm Pharmacol Ther 53:20-26.

Calzetta L, Matera MG, Braido F, Contoli M, Corsico A, Di Marco F, Santus P, Scichilone N, Cazzola M, and Rogliani P (2017a) Withdrawal of inhaled corticosteroids in COPD: a meta-analysis. Pulm Pharmacol Ther 45:148-158.

Calzetta L, Matera MG, and Cazzola M (2015) Pharmacological interaction between LABAs and LAMAs in the airways: optimizing synergy. Eur $J$ Pharmacol $\mathbf{7 6 1}$ $168-173$.

Calzetta L, Matera MG, and Cazzola M (2018b) Pharmacological mechanisms leading to synergy in fixed-dose dual bronchodilator therapy. Curr Opin Pharmacol 40: 95-103.

Calzetta L, Matera MG, Facciolo F, Cazzola M, and Rogliani P (2018c) Beclomethasone dipropionate and formoterol fumarate synergistically interact in hyperresponsive medium bronchi and small airways. Respir Res 19:65.

Calzetta L, Matera MG, Rogliani P, and Cazzola M (2018d) Dual LABA/LAMA bronchodilators in chronic obstructive pulmonary disease: why, when, and how. Expert Rev Respir Med 12:261-264.

Calzetta L, Ora J, Cavalli F, Rogliani P, O’Donnell DE, and Cazzola M (2017b) Impact of LABA/LAMA combination on exercise endurance and lung hyperinflation in COPD: a pair-wise and network meta-analysis. Respir Med 129. 189-198.

Calzetta L, Page CP, Spina D, Cazzola M, Rogliani P, Facciolo F, and Matera MG (2013) Effect of the mixed phosphodiesterase 3/4 inhibitor RPL554 on human isolated bronchial smooth muscle tone. J Pharmacol Exp Ther 346:414-423.

Calzetta L, Rogliani P, Matera MG, and Cazzola M (2016) A systematic review with meta-analysis of dual bronchodilation with LAMA/LABA for the treatment of stable COPD. Chest 149:1181-1196.

Calzetta L, Rogliani P, Ora J, Puxeddu E, Cazzola M, and Matera MG (2017c) LABA LAMA combination in COPD: a meta-analysis on the duration of treatment. Eur Respir Rev 26:160043.

Carnini C, Cesari N, Rudolph K, Barrett E, Patacchini R, Civelli M, Villetti G, and Chand R (2017) Bronchoprotective activity and safety evaluation of the nove antimuscarinic/ $\beta_{2}$ agonist (MABA) CHF6366 in dogs. Eur Respir J 50 (Suppl 61): PA1804

Carr R 3rd and Benovic JL (2016) From biased signalling to polypharmacology: unlocking unique intracellular signalling using pepducins. Biochem Soc Trans 44 $555-561$.

Carr R 3rd, Du Y, Quoyer J, Panettieri RA Jr, Janz JM, Bouvier M, Kobilka BK, and Benovic JL (2014) Development and characterization of pepducins as Gsbiased allosteric agonists. J Biol Chem 289:35668-35684.

Carr R 3rd, Schilling J, Song J, Carter RL, Du Y, Yoo SM, Traynham CJ, Koch WJ, Cheung JY, Tilley DG, et al. (2016) $\beta$-arrestin-biased signaling through the $\beta_{2}$ adrenergic receptor promotes cardiomyocyte contraction. Proc Natl Acad Sci USA 113:E4107-E4116.

Cazzola M, Beeh KM, Price D, and Roche N (2015a) Assessing the clinical value of fast onset and sustained duration of action of long-acting bronchodilators for COPD. Pulm Pharmacol Ther 31:68-78.

Cazzola M, Calzetta L, Barnes PJ, Criner GJ, Martinez FJ, Papi A, and Gabriella Matera M (2018a) Efficacy and safety profile of xanthines in COPD: a network meta-analysis. Eur Respir Rev 27:180010.

Cazzola M, Calzetta L, Bettoncelli G, Cricelli C, Romeo F, Matera MG, and Roglian $\mathrm{P}$ (2012a) Cardiovascular disease in asthma and COPD: a population-based retrospective cross-sectional study. Respir Med 106:249-256.

Cazzola M, Calzetta L, Matera MG, Hanania NA, and Rogliani P (2018b) How does race/ethnicity influence pharmacological response to asthma therapies? Expert Opin Drug Metab Toxicol 14:435-446.

Cazzola M, Calzetta L, Ora J, Puxeddu E, Rogliani P, and Matera MG (2015b) Searching for the synergistic effect between aclidinium and formoterol: from bench to bedside. Respir Med 109:1305-1311.

Cazzola M, Calzetta L, Page CP, Rogliani P, Facciolo F, Gavaldà A, and Matera MG (2014) Pharmacological characterization of the interaction between aclidinium bromide and formoterol fumarate on human isolated bronchi. Eur J Pharmacol 745:135-143.

Cazzola M, Calzetta L, Puxeddu E, Ora J, Facciolo F, Rogliani P, and Matera MG (2016a) Pharmacological characterisation of the interaction between glycopyrronium bromide and indacaterol fumarate in human isolated bronchi, small airways and bronchial epithelial cells. Respir Res 17:70.
Cazzola M, Calzetta L, Rinaldi B, Page C, Rosano G, Rogliani P, and Matera MG (2017a) Management of chronic obstructive pulmonary disease in patients with cardiovascular diseases. Drugs 77:721-732.

Cazzola M, Calzetta L, Rogliani P, and Matera MG (2017b) The challenges of precision medicine in COPD. Mol Diagn Ther 21:345-355.

Cazzola M, Calzetta L, Rogliani P, and Matera MG (2017c) Tiotropium formulations and safety: a network meta-analysis. Ther Adv Drug Saf 8:17-30.

Cazzola M, Calzetta L, Rogliani P, Puxeddu E, Facciolo F, and Matera MG (2016b) Interaction between corticosteroids and muscarinic antagonists in human airways. Pulm Pharmacol Ther 36:1-9.

Cazzola M, Calzetta L, Segreti A, Facciolo F, Rogliani P, and Matera MG (2015c) Translational study searching for synergy between glycopyrronium and indacaterol. COPD 12:175-181.

Cazzola M, D'Amato M, Califano C, Di Perna F, Calderaro E, Matera MG, and D'Amato G (2002) Formoterol as dry powder oral inhalation compared with salbutamol metered-dose inhaler in acute exacerbations of chronic obstructive pulmonary disease. Clin Ther 24:595-604.

Cazzola M, Lopez-Campos JL, and Puente-Maestu L (2013a) The MABA approach: a new option to improve bronchodilator therapy. Eur Respir J 42:885-887.

Cazzola M and Matera MG (2007) Safety of long-acting $\beta_{2}$-agonists in the treatment of asthma. Ther Adv Respir Dis 1:35-46.

Cazzola M and Matera MG (2014) Bronchodilators: current and future. Clin Chest Med 35:191-201.

Cazzola M and Matera MG (2017) Fixed-dose combination inhalers. Handb Exp Pharmacol 237:117-129.

Cazzola M and Matera MG (2018a) POINT: should LAMA/LABA combination therapy be used as initial maintenance treatment for COPD? Yes. Chest 154:746-748 Cazzola M and Matera MG (2018b) Combining dual bronchodilation and $\beta$-blockade in patients with an overlap between COPD and cardiovascular diseases. Chest 153: $1289-1291$

Cazzola M and Molimard M (2010) The scientific rationale for combining long-acting beta2-agonists and muscarinic antagonists in COPD. Pulm Pharmacol Ther 23 257-267.

Cazzola M, Noschese P, De Michele F, D'Amato G, and Matera MG (2006) Effect of formoterol/budesonide combination on arterial blood gases in patients with acute exacerbation of COPD. Respir Med 100:212-217.

Cazzola M, Ora J, Rogliani P, and Matera MG (2017d) Role of muscarinic antagonists in asthma therapy. Expert Rev Respir Med 11:239-253.

Cazzola M and Page C (2014) Long-acting bronchodilators in COPD: where are we now and where are we going? Breathe 10:110-120.

Cazzola M and Page C (2018) An inhaled "bifunctional" dual PDE3/4 inhibitor provides additional short-term improvements in lung function compared to existing classes of bronchodilator: implications for future treatment of COPD. Eur Respir $J$ 52:1801675.

Cazzola M, Page CP, Calzetta L, and Matera MG (2012b) Pharmacology and therapeutics of bronchodilators. Pharmacol Rev 64:450-504.

Cazzola M, Page C, Calzetta L, and Matera MG (2018c) Ensifentrine (RPL554): an inhaled 'bifunctional' dual PDE3/4 inhibitor for the treatment of asthma and chronic obstructive pulmonary disease. Pharm Pat Anal 7:249-257.

Cazzola M, Page CP, Rogliani P, and Matera MG (2013b) $\beta_{2}$-agonist therapy in lung disease. Am J Respir Crit Care Med 187:690-696.

Cazzola M, Puxeddu E, Matera MG, and Rogliani P (2019) A potential role of triple therapy for asthma patients. Expert Rev Respir Med 13:1079-1085.

Cazzola M and Rogliani P (2016) Do we really need asthma-chronic obstructive pulmonary disease overlap syndrome? J Allergy Clin Immunol 138:977-983.

Cazzola M and Rogliani P (2018) Tiotropium could provide benefits in the early stage of COPD, but further studies are needed. BMJ Evid Based Med 23:183-184.

Cazzola M, Rogliani P, Calzetta L, and Matera MG (2018d) Triple therapy versus single and dual long-acting bronchodilator therapy in COPD: a systematic review and meta-analysis. Eur Respir J 52:1801586.

Cazzola M, Rogliani P, and Matera MG (2015d) Escalation and de-escalation of therapy in COPD: myths, realities and perspectives. Drugs 75:1575-1585.

Cazzola M, Rogliani P, and Matera MG (2018e) Double or triple therapy in chronic obstructive pulmonary disease. BRN Rev 4:287-303.

Cazzola M, Rogliani P, Novelli L, and Matera MG (2013c) Inhaled corticosteroids for chronic obstructive pulmonary disease. Expert Opin Pharmacother 14:2489-2499.

Cazzola M, Santus P, Di Marco F, Carlucci P, Mondoni M, Matera MG, and Centanni $\mathrm{S}$ (2004) Onset of action of formoterol/budesonide in single inhaler vs. formoterol in patients with COPD. Pulm Pharmacol Ther 17:121-125.

Cazzola M, Santus P, Matera MG, Carlucci P, Belloli E, Di Marco F, and Centanni S (2003) A single high dose of formoterol is as effective as the same dose administered in a cumulative manner in patients with acute exacerbation of COPD. Respir Med 97:458-462.

Celli BR (2018) Pharmacological therapy of COPD: reasons for optimism. Chest $\mathbf{1 5 4}$ $1404-1415$

Chapman KR, Hinds D, Piazza P, Raherison C, Gibbs M, Greulich T, Gaalswyk K, Lin J, Adachi M, and Davis KJ (2017) Physician perspectives on the burden and management of asthma in six countries: the Global Asthma Physician Survey (GAPS). BMC Pulm Med 17:153.

Chatterjee S, Carnahan RM, Chen H, Holmes HM, Johnson ML, and Aparasu RR (2016) Anticholinergic medication use and risk of pneumonia in elderly adults: a nested case-control study. J Am Geriatr Soc 64:394-400.

Chawes BL, Govoni M, Kreiner-Møller E, Vissing NH, Poorisrisak P, Mortensen L, Nilsson E, Bisgaard A, Dossing A, Deleuran M, et al. (2014) Systemic exposure to inhaled beclometasone/formoterol DPI is age and body size dependent. Respir Med 108:1108-1116.

Chen WC, Huang CH, Sheu CC, Chong IW, Chu KA, Chen YC, Tsai JR, Lee CH, and Wei YF (2017) Long-acting beta2-agonists versus long-acting muscarinic antagonists in patients with stable COPD: a systematic review and meta-analysis of randomized controlled trials. Respirology 22:1313-1319. 
Cheng WC, Wu BR, Liao WC, Chen CY, Chen WC, Hsia TC, Tu CY, Chen CHAND, and Hsu WH (2018) Clinical predictors of the effectiveness of tiotropium in adults with symptomatic asthma: a real-life study. J Thorac Dis 10: 3661-3669.

Cherubini E, Esposito MC, Scozzi D, Terzo F, Osman GA, Mariotta S, Mancini R, Bruno P, and Ricci A (2016) Genetic polymorphism of CHRM2 in COPD: clinical significance and therapeutic implications. J Cell Physiol 231:1745-1751.

Chiba Y, Matsusue K, and Misawa M (2010) RhoA, a possible target for treatment of airway hyperresponsiveness in bronchial asthma. J Pharmacol Sci 114:239-247.

Chiba Y and Misawa M (2004) The role of RhoA-mediated $\mathrm{Ca}^{2+}$ sensitization of bronchial smooth muscle contraction in airway hyperresponsiveness. J Smooth Muscle Res 40:155-167.

Chipps BE, Bacharier LB, Murphy KR, Lang D, Farrar JR, Rank M, Oppenheimer J, and Zeiger RS (2019) The asthma controller step-down yardstick. Ann Allergy Asthma Immunol 122:241-262.e4.

Cho YS and Oh YM (2019) Dilemma of asthma treatment in mild patients. Tuberc Respir Dis (Seoul) 82:190-193.

Chowdhury BA and Dal Pan G (2010) The FDA and safe use of long-acting betaagonists in the treatment of asthma. N Engl J Med 362:1169-1171.

Chung KF (2015) Tiotropium as an add-on therapy in patients with symptomatic asthma. Lancet Respir Med 3:331-333.

Clay E, Patacchini R, Trevisani M, Preti D, Branà MP, Spina D, and Page C (2016) Ozone-induced hypertussive responses in rabbits and guinea pigs. J Pharmacol Exp Ther 357:73-83.

Cooney L, McBride A, Lilley A, Sinha I, Johnson TN, and Hawcutt DB (2017) Using pharmacokinetic modelling to improve prescribing practices of intravenous aminophylline in childhood asthma exacerbations. Pulm Pharmacol Ther 43:6-11.

Cossette B, Beauchesne MF, Forget A, Lemière C, Larivée P, Rey E, and Blais L (2014) Relative perinatal safety of salmeterol vs formoterol and fluticasone vs budesonide use during pregnancy. Ann Allergy Asthma Immunol 112:459-464.

Cramer JA, Bradley-Kennedy C, and Scalera A (2007) Treatment persistence and compliance with medications for chronic obstructive pulmonary disease. Can Respir $J$ 14:25-29.

Criner GJ, Bourbeau J, Diekemper RL, Ouellette DR, Goodridge D, Hernandez P, Curren K, Balter MS, Bhutani M, Camp PG, et al. (2015) Prevention of acute exacerbations of COPD: American College of Chest Physicians and Canadian Thoracic Society guideline. Chest 147:894-942.

Dale PR, Cernecka H, Schmidt M, Dowling MR, Charlton SJ, Pieper MP, and Michel MC (2014) The pharmacological rationale for combining muscarinic receptor antagonists and $\beta$-adrenoceptor agonists in the treatment of airway and bladder disease. Curr Opin Pharmacol 16:31-42.

Decramer M, Rennard S, Troosters T, Mapel DW, Giardino N, Mannino D, Wouters E, Sethi S, and Cooper CB (2008) COPD as a lung disease with systemic consequences--clinical impact, mechanisms, and potential for early intervention. COPD 5:235-256.

Defert O and Boland S (2017) Rho kinase inhibitors: a patent review (2014-2016). Expert Opin Ther Pat 27:507-515.

Del Grande LM, Herbella FA, Bigatao AM, Jardim JR, and Patti MG (2016) Inhaled beta agonist bronchodilator does not affect trans-diaphragmatic pressure gradient but decreases lower esophageal sphincter retention pressure in patients with chronic obstructive pulmonary disease (COPD) and gastroesophageal reflux disease (GERD). J Gastrointest Surg 20:1679-1682.

Deshpande DA, Wang WC, McIlmoyle EL, Robinett KS, Schillinger RM, An SS, Sham JS, and Liggett SB (2010) Bitter taste receptors on airway smooth muscle bronchodilate by localized calcium signaling and reverse obstruction. Nat Med 16 1299-1304.

Devereux G, Cotton S, Fielding S, McMeekin N, Barnes PJ, Briggs A, Burns G, Chaudhuri R, Chrystyn H, Davies L, et al. (2018) Effect of theophylline as adjunct to inhaled corticosteroids on exacerbations in patients with COPD: a randomized clinical trial. JAMA 320:1548-1559.

Devillier P, Garrigue E, D’Auzers G, Monjotin N, Similowski T, and Clerc T (2015a) V0162 a new long-acting bronchodilator for treatment of chronic obstructive lung diseases: preclinical and clinical results. Respir Res 16:68.

Devillier P, Naline E, and Grassin-Delyle S $(2015 \mathrm{~b})$ The pharmacology of bitter taste receptors and their role in human airways. Pharmacol Ther 155:11-21.

Dhand R, Dolovich M, Chipps B, Myers TR, Restrepo R, and Farrar JR (2012) The role of nebulized therapy in the management of COPD: evidence and recommendations. COPD 9:58-72.

Dicpinigaitis PV, Morice AH, Birring SS, McGarvey L, Smith JA, Canning BJ, and Page CP (2014) Antitussive drugs--past, present, and future. Pharmacol Rev 66:468-512.

Di Marco F, Verga M, Santus P, Morelli N, Cazzola M, and Centanni S (2006) Effect of formoterol, tiotropium, and their combination in patients with acute exacerbation of chronic obstructive pulmonary disease: a pilot study. Respir Med 100 $1925-1932$.

Donovan C, Bailey SR, Tran J, Haitsma G, Ibrahim ZA, Foster SR, Tang ML, Royce SG, and Bourke JE (2015) Rosiglitazone elicits in vitro relaxation in airways and precision cut lung slices from a mouse model of chronic allergic airways disease. Am J Physiol Lung Cell Mol Physiol 309:L1219-L1228.

Donovan C, Simoons M, Esposito J, Ni Cheong J, Fitzpatrick M, and Bourke JE (2014) Rosiglitazone is a superior bronchodilator compared to chloroquine and $\beta$-adrenoceptor agonists in mouse lung slices. Respir Res 15:29.

Drake KA, Torgerson DG, Gignoux CR, Galanter JM, Roth LA, Huntsman S, Eng C, Oh SS, Yee SW, Lin L, et al. (2014) A genome-wide association study of bronchodilator response in Latinos implicates rare variants. J Allergy Clin Immunol 133: 370-378.

Drescher GS, Carnathan BJ, Imus S, and Colice GL (2008) Incorporating tiotropium into a respiratory therapist-directed bronchodilator protocol for managing in patients with COPD exacerbations decreases bronchodilator costs. Respir Care 53: 1678-1684
Drevets WC, Zarate CA Jr, and Furey ML (2013) Antidepressant effects of the muscarinic cholinergic receptor antagonist scopolamine: a review. Biol Psychiatry 73:1156-1163.

Ducharme FM, Ni Chroinin M, Greenstone I, and Lasserson TJ (2010) Addition of long-acting beta2-agonists to inhaled corticosteroids versus same dose inhaled corticosteroids for chronic asthma in adults and children. Cochrane Database Syst $\operatorname{Rev}(5)$ :CD005535.

Dunn RM, Busse PJ, and Wechsler ME (2018) Asthma in the elderly and late-onset adult asthma. Allergy 73:284-294.

D'Urzo AD, Kerwin EM, Chapman KR, Decramer M, DiGiovanni R, D'Andrea P, Hu H, Goyal P, and Altman P (2015) Safety of inhaled glycopyrronium in patients with COPD: a comprehensive analysis of clinical studies and post-marketing data. Int J Chron Obstruct Pulmon Dis 10:1599-1612.

Dwan K, Milan SJ, Bax L, Walters N, and Powell C (2016) Vilanterol and fluticasone furoate for asthma. Cochrane Database Syst Rev 9:CD010758.

Eltonsy S, Forget A, Beauchesne MF, and Blais L (2015) Risk of congenital malformations for asthmatic pregnant women using a long-acting $\beta_{2}$-agonist and inhaled corticosteroid combination versus higher-dose inhaled corticosteroid monotherapy. J Allergy Clin Immunol 135:123-130.

Favreau H, Bacon SL, Joseph M, Labrecque M, and Lavoie KL (2012) Association between asthma medications and suicidal ideation in adult asthmatics. Respir Med 106:933-941.

Fingleton J, Hardy J, and Beasley R (2018) Treatable traits of chronic airways disease. Curr Opin Pulm Med 24:24-31.

Fogli S, Stefanelli F, Picchianti L, Del Re M, Mey V, Bardelli C, Danesi R, and Breschi MC (2013) Synergistic interaction between PPAR ligands and salbutamol on human bronchial smooth muscle cell proliferation. Br J Pharmacol 168: 266-275.

Franciosi LG, Diamant Z, Banner KH, Zuiker R, Morelli N, Kamerling IM, de Kam ML, Burggraaf J, Cohen AF, Cazzola M, et al. (2013) Efficacy and safety of RPL554 a dual PDE3 and PDE4 inhibitor, in healthy volunteers and in patients with asthma or chronic obstructive pulmonary disease: findings from four clinical trials. Lancet Respir Med 1:714-727.

Fukumitsu K, Kanemitsu Y, Asano T, Takeda N, Ichikawa H, Yap JMG, Fukuda S, Uemura T, Takakuwa O, Ohkubo H, et al. (2018) Tiotropium attenuates refractory cough and capsaicin cough reflex sensitivity in patients with asthma. J Allergy Clin Immunol Pract 6:1613-1620.e2.

Galvan DL and Danesh FR (2017) $\beta_{2}$-adrenergic receptors in inflammation and vascular complications of diabetes. Kidney Int 92:14-16.

Gan LL, Wang MW, Cheng MS, and Pan L (2003) Trachea relaxing effects and beta2selectivity of SPFF, a newly developed bronchodilating agent, in guinea pigs and rabbits. Biol Pharm Bull 26:323-328.

Garne E, Hansen AV, Morris J, Zaupper L, Addor MC, Barisic I, Gatt M, Lelong N, Klungsøyr K, O'Mahony M, et al. (2015) Use of asthma medication during pregnancy and risk of specific congenital anomalies: a European case-malformed control study. J Allergy Clin Immunol 136:1496-1502.e7.

Garne E, Vinkel Hansen A, Morris J, Jordan S, Klungsøyr K, Engeland A, Tucker D, Thayer DS, Davies GI, Nybo Andersen AM, et al. (2016) Risk of congenital anomalies after exposure to asthma medication in the first trimester of pregnancy a cohort linkage study. BJOG 123:1609-1618

Ge X, Mo Y, Xing G, Ji L, Zhao H, Chen J, He B, Chen X, Xing R, Li X, et al. (2018b) Synthesis, biological evaluation and molecular modeling of 2-amino-2phenylethanol derivatives as novel $\beta_{2}$-adrenoceptor agonists. Bioorg Chem $\mathbf{7 9}$ 155-162.

Ge X, Woo AY, Xing G, Lu Y, Mo Y, Zhao Y, Lan Y, Li J, Yan H, Pan L, et al. (2018a) Synthesis and biological evaluation of $\beta_{2}$-adrenoceptor agonists bearing the 2amino-2-phenylethanol scaffold. Eur $J$ Med Chem 152:424-435.

Gershon AS, Campitelli MA, Croxford R, Stanbrook MB, To T, Upshur R, Stephenson $\mathrm{AL}$, and Stukel TA (2014) Combination long-acting $\beta$-agonists and inhaled corticosteroids compared with long-acting $\beta$-agonists alone in older adults with chronic obstructive pulmonary disease. JAMA 312:1114-1121.

Gershon A, Croxford R, Calzavara A, To T, Stanbrook MB, Upshur R, and Stukel TA (2013) Cardiovascular safety of inhaled long-acting bronchodilators in individuals with chronic obstructive pulmonary disease. JAMA Intern Med 173:1175-1185.

Gershon AS, Newman AM, Fischer HD, Austin PC, Daneman N, Bell CM, Stephenson AL, Gill SS, Vozoris NT, and Rochon PA (2017) Inhaled long-acting anticholinergics and urinary tract infection in individuals with COPD. COPD 14: 105-112.

Ghosh A, Koziol-White CJ, Asosingh K, Cheng G, Ruple L, Groneberg D, Friebe A, Comhair SA, Stasch JP, Panettieri RA Jr et al (2016) Soluble guanylate cyclase as an alternative target for bronchodilator therapy in asthma. Proc Natl Acad Sci USA 113:E2355-E2362.

Gidaya NB, Lee BK, Burstyn I, Michael Y, Newschaffer CJ, and Mortensen EL (2016 In utero exposure to $\beta$-2-adrenergic receptor agonist drugs and risk for autism spectrum disorders. Pediatrics 137:e20151316.

Giembycz MA and Newton R (2015) Potential mechanisms to explain how LABAs and PDE4 inhibitors enhance the clinical efficacy of glucocorticoids in inflammatory lung diseases. F1000Prime Rep 7:16.

Girodet PO, Jasnot JY, Le Gros V, Decuypère L, Cao W, and Devouassoux G (2017) Efficacy and safety of indacaterol in patients with chronic obstructive pulmonary disease aged over 65 years: a pooled analysis. Respir Med 128:92-101.

Gladwin MT (2006) Deconstructing endothelial dysfunction: soluble guanylyl cyclase oxidation and the NO resistance syndrome. J Clin Invest 116:2330-2332.

Grassin-Delyle S, Naline E, and Devillier P (2015) Taste receptors in asthma. Curr Opin Allergy Clin Immunol 15:63-69.

Griffiths B and Ducharme FM (2013) Combined inhaled anticholinergics and shortacting beta2-agonists for initial treatment of acute asthma in children. Paediatr Respir Rev 14:234-235.

Grigg J and Ducharme FM (2019) Asthma in the preschool age child, in Kendig's Disorders of the Respiratory Tract in Children, 9th ed (Wilmott RW, Deterding R, 
Li A, Ratjen F, Sly P, Zar HJ, and Bush A eds) p 677-685.e2, Elsevier, Philadelphia.

Guimaraes IH, Padilha GDA, Lopes-Pacheco M, Crossetti J, Lima L, Barreiro E, Xisto GD, and Rocco PRM (2014) Therapy with a new phosphodiesterase 4 and 5 inhibitor in experimental elastase-induced emphysema (Abstract). Am J Respir Crit Care Med 189:A6557.

Hakonarson H, Herrick DJ, and Grunstein MM (1995) Mechanism of impaired betaadrenoceptor responsiveness in atopic sensitized airway smooth muscle. Am J Physiol 269:L645-L652.

Han YY, Forno E, Marsland AL, Miller GE, and Celedón JC (2016) Depression, asthma, and bronchodilator response in a nationwide study of US adults. J Allergy Clin Immunol Pract 4:68-73.

Hardin M, Cho MH, McDonald ML, Wan E, Lomas DA, Coxson HO, MacNee W, Vestbo J, Yates JC, Agusti A, et al.; ECLIPSE and COPDGene Investigators; COPDGene Investigators-clinical centers (2016) A genome-wide analysis of the response to inhaled $\beta_{2}$-agonists in chronic obstructive pulmonary disease. Pharmacogenomics $J$ 16:326-335.

Hatta FH, Lundblad M, Ramsjo M, Kang JH, Roh HK, Bertilsson L, Eliasson E, and Aklillu E (2015) Differences in CYP2C9 genotype and enzyme activity between Swedes and Koreans of relevance for personalized medicine: role of ethnicity, genotype, smoking, age, and sex. OMICS 19:346-353.

Hegde SS, Pulido-Rios MT, Luttmann MA, Foley JJ, Hunsberger GE, Steinfeld T, Lee T, Ji Y, Mammen MM, and Jasper JR (2018) Pharmacological properties of revefenacin (TD-4208), a novel, nebulized long-acting, and lung selective muscarinic antagonist, at human recombinant muscarinic receptors and in rat, guinea pig, and human isolated airway tissues. Pharmacol Res Perspect 6:e0400.

Heusler P, Cussac D, Naline E, Tardif S, Clerc T, and Devillier P (2015) Characterization of $\mathrm{V} 0162$, a new long-acting antagonist at human $\mathrm{M}_{3}$ muscarinic acetylcholine receptors. Pharmacol Res 100:117-126.

Hodder R, Kesten S, Menjoge S, and Viel K (2007) Outcomes in COPD patients receiving tiotropium or salmeterol plus treatment with inhaled corticosteroids. Int $J$ Chron Obstruct Pulmon Dis 2:157-167.

Hohlfeld JM, Vogel-Claussen J, Biller H, Berliner D, Berschneider K, Tillmann HC, Hiltl S, Bauersachs J, and Welte T (2018) Effect of lung deflation with indacaterol plus glycopyrronium on ventricular filling in patients with hyperinflation and COPD (CLAIM): a double-blind, randomised, crossover, placebo-controlled, singlecentre trial. Lancet Respir Med 6:368-378.

Horita N, Miyazawa N, Kojima R, Inoue M, Ishigatsubo Y, and Kaneko T (2016) Chronic use of theophylline and mortality in chronic obstructive pulmonary disease: a meta-analysis. Arch Bronconeumol 52:233-238.

Hull SA, McKibben S, Homer K, Taylor SJ, Pike K, and Griffiths C (2016) Asthma prescribing, ethnicity and risk of hospital admission: an analysis of 35,864 linked primary and secondary care records in East London. NPJ Prim Care Respir Med 26:16049.

Hyun MK, Lee NR, Jang EJ, Yim JJ, and Lee CH (2016) Effect of inhaled drugs on anxiety and depression in patients with chronic obstructive pulmonary disease: a prospective observational study. Int J Chron Obstruct Pulmon Dis 11:747-754.

Jacobson GA, Raidal S, Hostrup M, Calzetta L, Wood-Baker R, Farber MO, Page CP and Walters EH (2018) Long-acting $\beta 2$-agonists in asthma: enantioselective safety studies are needed. Drug Saf 41:441-449.

Janson C, Larsson K, Lisspers KH, Ställberg B, Stratelis G, Goike H, Jörgensen L, and Johansson G (2013) Pneumonia and pneumonia related mortality in patients with COPD treated with fixed combinations of inhaled corticosteroid and long acting $\beta 2$ agonist: observational matched cohort study (PATHOS). BMJ 346:f3306.

Janson C, Stratelis G, Miller-Larsson A, Harrison TW, and Larsson K (2017) Scientific rationale for the possible inhaled corticosteroid intraclass difference in the risk of pneumonia in COPD. Int J Chron Obstruct Pulmon Dis 12:3055-3064.

Jenkins CR, Celli B, Anderson JA, Ferguson GT, Jones PW, Vestbo J, Yates JC, and Calverley PM (2012) Seasonality and determinants of moderate and severe COPD exacerbations in the TORCH study. Eur Respir $J$ 39:38-45.

Jimenez L, Astbury C, Seoane B, Villarroel C, Pujol H, Bermejo M-J, Aggarwal A, and Albayaty M (2017) A randomized placebo controlled trial of AZD8871 a novel dual acting bronchodilator in asthmatics. Eur Respir J 50 (Suppl 61):PA1811.

Joshi T, Yan D, Hamed O, Tannheimer SL, Phillips GB, Wright CD, Kim M, Salmon M, Newton R, and Giembycz MA (2017) GS-5759, a bifunctional $\beta_{2}$-adrenoceptor agonist and phosphodiesterase 4 inhibitor for chronic obstructive pulmonary disease with a unique mode of action: effects on gene expression in human airway epithelial cells. J Pharmacol Exp Ther 360:324-340.

Källén B (2014) Maternal asthma and use of antiasthmatic drugs in early pregnancy and congenital malformations in the offspring. J Pulm Respir Med 4:166.

Kang J, Kim KT, Lee JH, Kim EK, Kim TH, Yoo KH, Lee JS, Kim WJ, Kim JH, and Oh YM (2017) Predicting treatable traits for long-acting bronchodilators in patients with stable COPD. Int J Chron Obstruct Pulmon Dis 12:3557-3565.

Kern DM, Davis J, Williams SA, Tunceli O, Wu B, Hollis S, Strange C, and Trudo F (2015) Comparative effectiveness of budesonide/formoterol combination and fluticasone/salmeterol combination among chronic obstructive pulmonary disease patients new to controller treatment: a US administrative claims database study. Respir Res 16:52.

Kersten ETG and Koppelman GH (2017) Pharmacogenetics of asthma: toward precision medicine. Curr Opin Pulm Med 23:12-20.

Kerstjens HA, Engel M, Dahl R, Paggiaro P, Beck E, Vandewalker M, Sigmund R, Seibold W, Moroni-Zentgraf P, and Bateman ED (2012) Tiotropium in asthma poorly controlled with standard combination therapy. $N$ Engl J Med 367: 1198-1207.

Kerstjens HA, Moroni-Zentgraf P, Tashkin DP, Dahl R, Paggiaro P, Vandewalker M, Schmidt H, Engel M, and Bateman ED (2016) Tiotropium improves lung function, exacerbation rate, and asthma control, independent of baseline characteristics including age, degree of airway obstruction, and allergic status. Respir Med 117: 198-206.
Kerstjens HA and O'Byrne PM (2016) Tiotropium for the treatment of asthma: a drug safety evaluation. Expert Opin Drug Saf 15:1115-1124.

Kew KM and Dahri K (2016) Long-acting muscarinic antagonists (LAMA) added to combination long-acting beta2-agonists and inhaled corticosteroids (LABA/ICS) versus LABA/ICS for adults with asthma. Cochrane Database Syst Rev (1): CD011721.

Kew KM, Evans DJ, Allison DE, and Boyter AC (2015) Long-acting muscarinic antagonists (LAMA) added to inhaled corticosteroids (ICS) versus addition of longacting beta2-agonists (LABA) for adults with asthma. Cochrane Database Syst Rev (6):CD011438

Kim D, Woo JA, Geffken E, An SS, and Liggett SB (2017) Coupling of airway smooth muscle bitter taste receptors to intracellular signaling and relaxation is via $\mathrm{G}_{\alpha \mathrm{i} 1,2,3}$ Am J Respir Cell Mol Biol 56:762-771.

Kim J, Lee JH, Kim Y, Kim K, Oh YM, Yoo KH, Rhee CK, Yoon HK, Kim YS, Park YB, et al. (2013) Association between chronic obstructive pulmonary disease and gastroesophageal reflux disease: a national cross-sectional cohort study. $B M C$ Pulm Med 13:51.

Kistemaker LE, Bos IS, Menzen MH, Maarsingh H, Meurs H, and Gosens R (2016) Combination therapy of tiotropium and ciclesonide attenuates airway inflammation and remodeling in a guinea pig model of chronic asthma. Respir Res 17:13.

Klein Herenbrink C, Sykes DA, Donthamsetti P, Canals M, Coudrat T, Shonberg J, Scammells PJ, Capuano B, Sexton PM, Charlton SJ, et al. (2016) The role of kinetic context in apparent biased agonism at GPCRs. Nat Commun 7:10842.

Kobayashi M, Nasuhara Y, Betsuyaku T, Shibuya E, Tanino Y, Tanino M, Takamura K, Nagai K, Hosokawa T, and Nishimura M (2004) Effect of low-dose theophylline on airway inflammation in COPD. Respirology 9:249-254.

Kobayashi Y, Mercado N, Miller-Larsson A, Barnes PJ, and Ito K (2012) Increased corticosteroid sensitivity by a long acting $\beta_{2}$ agonist formoterol via $\beta_{2}$ adrenoceptor independent protein phosphatase $2 \mathrm{~A}$ activation. Pulm Pharmacol Ther $\mathbf{2 5}$ 201-207.

Kruse AC, Li J, Hu J, Kobilka BK, and Wess J (2014) Novel insights into M3 muscarinic acetylcholine receptor physiology and structure. $J$ Mol Neurosci 53: $316-323$.

Lagente V, Naline E, Guenon I, Corbel M, Biochot E, Burgaud J-L, Del Soldato P, and Advenier C (2004) A nitric oxide-releasing salbutamol elicits potent relaxant and anti-inflammatory activities. J Pharmacol Exp Ther 310:367-375.

Lam M, Royce SG, Donovan C, Jelinic M, Parry LJ, Samuel CS, and Bourke JE (2016) Serelaxin elicits bronchodilation and enhances $\beta$-adrenoceptor-mediated airway relaxation. Front Pharmacol 7:406.

Lam M, Royce SG, Samuel CS, and Bourke JE (2018) Serelaxin as a novel therapeutic opposing fibrosis and contraction in lung diseases. Pharmacol Ther 187: $61-70$.

Lazzaroni M, Grossi E, and Bianchi Porro G (1990) The effect of intravenous doxofylline or aminophylline on gastric secretion in duodenal ulcer patients. Aliment Pharmacol Ther 4:643-649.

Lebender LF, Prünte L, Rumzhum NN, and Ammit AJ (2018) Selectively targeting prostanoid E (EP) receptor-mediated cell signalling pathways: Implications for lung health and disease. Pulm Pharmacol Ther 49:75-87.

Lee LA, Yang S, Kerwin E, Trivedi R, Edwards LD, and Pascoe S (2015) The effect of fluticasone furoate/umeclidinium in adult patients with asthma: a randomized, dose-ranging study. Respir Med 109:54-62.

Lee SJ, Depoortere I, and Hatt H (2019) Therapeutic potential of ectopic olfactory and taste receptors. Nat Rev Drug Discov 18:116-138.

Leeman M, Lejeune P, Melot C, and Naeije R (1987) Reduction in pulmonary hypertension and in airway resistances by enoximone (MDL 17,043) in decompensated COPD. Chest 91:662-666.

Leung JM and Sin DD (2017) Asthma-COPD overlap syndrome: pathogenesis, clinical features, and therapeutic targets. BMJ 358:j3772

Li L, Wang Z, Liang H, Yang F, Yuan W, Gelaye B, Yu Y, Miao M, Nørgaard M, and Li J (2018) Risk of childhood cerebral palsy following prenatal exposure to B2-adrenergic receptor agonist: a nationwide cohort study. PLoS One 13 e0202078

Lim S, Tomita K, Caramori G, Jatakanon A, Oliver B, Keller A, Adcock I, Chung KF, and Barnes PJ (2001) Low-dose theophylline reduces eosinophilic inflammation but not exhaled nitric oxide in mild asthma. Am J Respir Crit Care Med 164: $273-276$.

Liu H, Hofmann J, Fish I, Schaake B, Eitel K, Bartuschat A, Kaindl J, Rampp H, Banerjee A, Hübner H, et al. (2018) Structure-guided development of selective M3 muscarinic acetylcholine receptor antagonists. Proc Natl Acad Sci USA 115 12046-12050.

Lopez-Campos JL, Calero C, and Quintana-Gallego E (2013) Symptom variability in COPD: a narrative review. Int J Chron Obstruct Pulmon Dis 8:231-238.

Ma YJ, Jiang DQ, Meng JX, Li MX, Zhao HH, Wang Y, and Wang LQ (2016) Theophylline: a review of population pharmacokinetic analyses. J Clin Pharm Ther 41: 594-601.

Mahler D, Ohar J, Barnes C, Moran E, Pendyala S, and Crater G (2018) Efficacy of revefenacin by nebulization and tiotropium by Handihaler in subjects with COPD and suboptimal peak inspiratory flow rates (PIFR). Chest 154:732A-733A

Mahler DA, Waterman LA, Ward J, and Gifford AH (2014) Comparison of dry powder versus nebulized beta-agonist in patients with COPD who have suboptimal peak inspiratory flow rate. J Aerosol Med Pulm Drug Deliv 27:103-109.

Maher SA, Dubuis ED, and Belvisi MG (2011) G-protein coupled receptors regulating cough. Curr Opin Pharmacol 11:248-253.

Maia IS, Pincelli MP, Leite VF, Amadera J, and Buehler AM (2017) Long-acting muscarinic antagonists vs. long-acting $\beta 2$ agonists in COPD exacerbations: a systematic review and meta-analysis. J Bras Pneumol 43:302-312.

Mak ACY, White MJ, Eckalbar WL, Szpiech ZA, Oh SS, Pino-Yanes M, Hu D, Goddard P, Huntsman S, Galanter J, et al.; NHLBI Trans-Omics for Precision Medicine (TOPMed) Consortium (2018) Whole-genome sequencing of pharmacogenetic 
drug response in racially diverse children with asthma. Am J Respir Crit Care Med 197:1552-1564.

Maltais F, Buhl R, Koch A, Amatto VC, Reid J, Grönke L, Bothner U, Voß F, McGarvey L, and Ferguson GT (2018) $\beta$-blockers in COPD: a cohort study from the TONADO research program. Chest 153:1315-1325.

Manoharan A, Short PM, Anderson WJ, and Lipworth BJ (2014) Impact of longacting bronchodilators and exposure to inhaled corticosteroids on mortality in COPD: a real-life retrospective cohort study. Hai 192:649-652.

Markham A and Faulds D (1998) Theophylline. A review of its potential steroid sparing effects in asthma. Drugs 56:1081-1091.

Mastrodicasa MA, Droege CA, Mulhall AM, Ernst NE, Panos RJ, and Zafar MA (2017) Long acting muscarinic antagonists for the treatment of chronic obstructive pulmonary disease: a review of current and developing drugs. Expert Opin Investig Drugs 26:161-174.

Masureel M, Zou Y, Picard LP, van der Westhuizen E, Mahoney JP, Rodrigues JPGLM, Mildorf TJ, Dror RO, Shaw DE, Bouvier M, et al. (2018) Structural insights into binding specificity, efficacy and bias of a $\beta_{2} \mathrm{AR}$ partial agonist [published correction appears in Nat Chem Biol (2019) 15:205]. Nat Chem Biol 14: 1059-1066.

Matera MG, Calzetta L, and Cazzola M (2013) $\beta$-Adrenoceptor modulation in chronic obstructive pulmonary disease: present and future perspectives. Drugs $\mathbf{7 3}$ $1653-1663$.

Matera MG and Cazzola M (2017) Muscarinic receptor antagonists. Handb Exp Pharmacol 237:41-62.

Matera MG, Page C, and Cazzola M (2014a) PDE inhibitors currently in early clinical trials for the treatment of asthma. Expert Opin Investig Drugs 23:1267-1275.

Matera MG, Page C, and Cazzola M (2017a) Doxofylline is not just another theophylline!. Int J Chron Obstruct Pulmon Dis 12:3487-3493.

Matera MG, Page C, and Rinaldi B (2018a) $\beta_{2}$-Adrenoceptor signalling bias in asthma and COPD and the potential impact on the comorbidities associated with these diseases. Curr Opin Pharmacol 40:142-146.

Matera MG, Rinaldi B, Calzetta L, and Cazzola M (2017b) Assessing the viability of long-acting $\beta_{2}$-agonists in paediatric asthma patients: a pharmacokinetic/pharmacodynamic perspective. Expert Opin Drug Metab Toxicol 13:129-136.

Matera MG, Rinaldi B, Calzetta L, and Cazzola M (2017c) Pharmacogenetic and pharmacogenomic considerations of asthma treatment. Expert Opin Drug Metab Toxicol 13:1159-1167.

Matera MG, Rinaldi B, Page C, Rogliani P, and Cazzola M (2018b) Pharmacokinetic considerations concerning the use of bronchodilators in the treatment of chronic obstructive pulmonary disease. Expert Opin Drug Metab Toxicol 14:1101-1111.

Matera MG, Rogliani P, Calzetta L, and Cazzola M (2014b) Phosphodiesterase inhibitors for chronic obstructive pulmonary disease: what does the future hold? Drugs 74:1983-1992.

Matera MG, Rogliani P, Calzetta L, and Cazzola M (2016) Safety considerations with dual bronchodilator therapy in COPD: an update. Drug Saf 39:501-508.

Matera MG, Rogliani P, Zanasi A, and Cazzola M (2017d) Bronchodilator therapy for chronic cough. Pulm Pharmacol Ther 47:88-92.

McGarvey L, Morice AH, Smith JA, Birring SS, Chuecos F, Seoane B, and Jarreta D (2016) Effect of aclidinium bromide on cough and sputum symptoms in moderate-to-severe COPD in three phase III trials. BMJ Open Respir Res 3:e000148.

Meurs H, Dekkers BG, Maarsingh H, Halayko AJ, Zaagsma J, and Gosens R (2013) Muscarinic receptors on airway mesenchymal cells: novel findings for an ancient target. Pulm Pharmacol Ther 26:145-155.

Minasian AG, van den Elshout FJ, Dekhuijzen PN, Vos PJ, Willems FF, van den Bergh PJ, and Heijdra YF (2013) Bronchodilator responsiveness in patients with chronic heart failure. Heart Lung 42:208-214.

Miravitlles M, Soler-Cataluña JJ, Calle M, Molina J, Almagro P, Quintano JA, Trigueros JA, Cosío BG, Casanova C, Antonio Riesco J, et al. (2017) Spanish guidelines for management of chronic obstructive pulmonary disease (GesEPOC) 2017. Pharmacological treatment of stable phase. Arch Bronconeumol 53:324-335.

Mokry J and Mokra D (2013) Immunological aspects of phosphodiesterase inhibition in the respiratory system. Respir Physiol Neurobiol 187:11-17.

Morice AH, Faruqi S, Wright CE, Thompson R, and Bland JM (2011) Cough hypersensitivity syndrome: a distinct clinical entity. Lung 189:73-79.

Morris I, Lyttle MD, O'Sullivan R, Sargant N, Doull IJ, and Powell CV; PERUKI network (2015) Which intravenous bronchodilators are being administered to children presenting with acute severe wheeze in the UK and Ireland? Thorax $\mathbf{7 0}$ 88-91.

Mungan Z and Pınarbaș Simsek B (2017) Which drugs are risk factors for the development of gastroesophageal reflux disease? Turk J Gastroenterol 28 (Suppl 1): S38-S43

Muppidi A, Lee SJ, Hsu CH, Zou H, Lee C, Pflimlin E, Mahankali M, Yang P, Chao E, Ahmad I, et al. (2019) Design and synthesis of potent, long-acting lipidated relaxin2 analogs. Bioconjug Chem 30:83-89.

Mutolo D, Cinelli E, Iovino L, Pantaleo T, and Bongianni F (2016) Downregulation of the cough reflex by aclidinium and tiotropium in awake and anesthetized rabbits. Pulm Pharmacol Ther 38:1-9.

Naka T, Ide S, Nakako T, Hirata M, Majima Y, Deyama S, Takeda H, Yoshioka M, and Minami M (2013) Activation of $\beta$-adrenoceptors in the bed nucleus of the stria terminalis induces food intake reduction and anxiety-like behaviors. Neuropharmacology 67:326-330.

Namazy JA and Schatz M (2017) Pharmacological difficulties in the treatment of asthma in pregnant women. Expert Rev Clin Pharmacol 10:285-292.

Newton R and Giembycz MA (2016) Understanding how long-acting $\beta_{2}$-adrenoceptor agonists enhance the clinical efficacy of inhaled corticosteroids in asthma - an update. Br J Pharmacol 173:3405-3430.

Nie Z, Jacoby DB, and Fryer AD (2014) Hyperinsulinemia potentiates airway responsiveness to parasympathetic nerve stimulation in obese rats. Am J Respir Cell Mol Biol 51:251-261.
Nielsen AO, Jensen CS, Arredouani MS, Dahl R, and Dahl M (2017) Variants of the $A D R B 2$ gene in COPD: systematic review and meta-analyses of disease risk and treatment response. COPD 14:451-460.

Oba Y, Keeney E, Ghatehorde N, and Dias S (2018) Dual combination therapy versus long-acting bronchodilators alone for chronic obstructive pulmonary disease (COPD): a systematic review and network meta-analysis. Cochrane Database Syst Rev 12:CD012620.

O'Byrne PM, FitzGerald JM, Bateman ED, Barnes PJ, Zhong N, Keen C, Jorup C, Lamarca R, Ivanov S, and Reddel HK (2018) Inhaled combined budesonideformoterol as needed in mild asthma. $N$ Engl J Med 378:1865-1876.

Oliver A, VanBuren S, Allen A, Hamilton M, Tombs L, Kempsford R, and Qaqundah P (2014) Safety, tolerability, pharmacokinetics, and pharmacodynamics of vilanterol, a novel inhaled long-acting $\beta$-agonist, in children aged 5-11 years with persistent asthma: a randomized trial. Clin Pharmacol Drug Dev 3:215-221.

Oppenheimer JJ and Borish L (2018) Asthma yardstick update: practical recommendations for a sustained step-up in asthma therapy for poorly controlled asthma. Ann Allergy Asthma Immunol 121:660-661.

Ortega VE, Hawkins GA, Moore WC, Hastie AT, Ampleford EJ, Busse WW, Castro M, Chardon D, Erzurum SC, Israel E, et al. (2014) Effect of rare variants in ADRB2 on risk of severe exacerbations and symptom control during longacting $\beta$ agonist treatment in a multiethnic asthma population: a genetic study. Lancet Respir Med 2:204-213.

Ortega VE, Meyers DA, and Bleecker ER (2015) Asthma pharmacogenetics and the development of genetic profiles for personalized medicine. Pharm Genomics Pers Med 8:9-22.

Paediatric Formulary Committee (2016) British National Formulary for Children, BMJ Group, Pharmaceutical Press, and RCPCH Publications, London.

Page CP (2010) Doxofylline: a "novofylline". Pulm Pharmacol Ther 23:231-234.

Page C and Cazzola M (2014) Bifunctional drugs for the treatment of asthma and chronic obstructive pulmonary disease. Eur Respir $J$ 44:475-482.

Page C and Cazzola M (2017) Bifunctional drugs for the treatment of respiratory diseases. Handb Exp Pharmacol 237:197-212.

Pan H, Li Q, Pan L, Liu X, Pan L, Zhang X, Bai H, Cheng M, and Zhang Y (2014) Stereoselective activity of 2-(4-amino-3-chloro-5- trifluomethyl-phenyl)-2-tertbutylamino-ethanol hydrochloride to improve the pulmonary function in asthma. Biomed Rep 2:539-544

Panettieri RA, Pera T, Liggett SB, Benovic JL, and Penn RB (2018) Pepducins as a potential treatment strategy for asthma and COPD. Curr Opin Pharmacol 40: 120-125.

Papapetropoulos A, Simoes DC, Xanthou G, Roussos C, and Gratziou C (2006) Soluble guanylyl cyclase expression is reduced in allergic asthma. Am J Physiol Lung Cell Mol Physiol 290:L179-L184.

Papi A, Canonica GW, Maestrelli P, Paggiaro P, Olivieri D, Pozzi E, Crimi N, Vignola AM, Morelli P, Nicolini G, et al.; BEST Study Group (2007) Rescue use of beclomethasone and albuterol in a single inhaler for mild asthma. N Engl J Med 356: 2040-2052.

Pappová L, Jošková M, Kazimierová I, Šutovská M, and Fraňová S (2016) Combination therapy with budesonide and salmeterol in experimental allergic inflammation. Adv Exp Med Biol 935:25-34.

Pearlman DS, Eckerwall G, McLaren J, Lamarca R, Puu M, Gilbert I, Jorup C, Sandin K, and Lanz MJ (2017) Efficacy and safety of budesonide/formoterol pMDI vs budesonide pMDI in asthmatic children (6- $<12$ years). Ann Allergy Asthma Immunol 118:489-499.e1.

Pelaia G, Muzzio CC, Vatrella A, Maselli R, Magnoni MS, and Rizzi A (2015) Pharmacological basis and scientific rationale underlying the targeted use of inhaled corticosteroid/long-acting $\beta_{2}$-adrenergic agonist combinations in chronic obstructive pulmonary disease treatment. Expert Opin Pharmacother 16:2009-2021.

Penn RB (2015) Physiology. Calcilytics for asthma relief. Science 348:398-399.

Philipson LH (2002) $\beta$-Agonists and metabolism. J Allergy Clin Immunol 110 (Suppl):S313-S317.

Phillips G and Salmon M (2012) Bifunctional compounds for the treatment of COPD. Annu Rep Med Chem 47:209-222.

Plaza Moral V, Alonso Mostaza S, Alvarez Rodríguez C, Gomez-Outes A, Gómez Ruiz F, López Vina A, Molina París J, Pellegrini Belinchón FJ, Plaza Zamora J, Quintano Jiménez JA, et al. (2016) Spanish guideline on the management of asthma. $J$ Investig Allergol Clin Immunol 26 (Suppl 1):1-92.

Prakash YS (2016) Emerging concepts in smooth muscle contributions to airway structure and function: implications for health and disease. Am J Physiol Lung Cell Mol Physiol 311:L1113-L1140.

Price D, Lee AJ, Sims EJ, Kemp L, Hillyer EV, Chisholm A, von Ziegenweidt J, and Williams A (2013) Characteristics of patients preferring once-daily controller therapy for asthma and COPD: a retrospective cohort study. Prim Care Respir 22 161-168.

Provins L, Christophe B, Danhaive P, Dulieu J, Gillard M, Quéré L, and Stebbins K (2007) Dual M3 antagonists-PDE4 inhibitors. Part 2: synthesis and SAR of 3substituted azetidinyl derivatives. Bioorg Med Chem Lett 17:3077-3080.

Pulido-Rios MT, McNamara A, Obedencio GP, Ji Y, Jaw-Tsai S, Martin WJ and Hegde SS (2013) In vivo pharmacological characterization of TD-4208, a nove lung-selective inhaled muscarinic antagonist with sustained bronchoprotective effect in experimental animal models. J Pharmacol Exp Ther 346:241-250.

Qaseem A, Wilt TJ, Weinberger SE, Hanania NA, Criner G, van der Molen T, Marciniuk DD, Denberg T, Schünemann H, Wedzicha W, et al.; American College of Physicians; American College of Chest Physicians; American Thoracic Society; European Respiratory Society (2011) Diagnosis and management of stable chronic obstructive pulmonary disease: a clinical practice guideline update from the American College of Physicians, American College of Chest Physicians, American Thoracic Society, and European Respiratory Society. Ann Intern Med 155:179-191.

Qian CJ, Coulombe J, Suissa S, and Ernst P (2017) Pneumonia risk in asthma patients using inhaled corticosteroids: a quasi-cohort study. Br J Clin Pharmacol 83:2077-2086. 
Qin F, Wang Y, Wang L, Zhao L, Pan L, Cheng M, and Li F (2015) Determination of trantinterol enantiomers in human plasma by high-performance liquid chromatography - tandem mass spectrometry using vancomycin chiral stationary phase and solid phase extraction and stereoselective pharmacokinetic application. Chirality 27:327-331.

Quinn D, Barnes CN, Yates W, Bourdet DL, Moran EJ, Potgieter P, Nicholls A Haumann B, and Singh D (2018) Pharmacodynamics, pharmacokinetics and safety of revefenacin (TD-4208), a long-acting muscarinic antagonist, in patients with chronic obstructive pulmonary disease (COPD): results of two randomized, doubleblind, phase 2 studies. Pulm Pharmacol Ther 48:71-79.

Rabe KF, Fabbri LM, Israel $\mathrm{E}$, Kögler $\mathrm{H}$, Riemann $\mathrm{K}$, Schmidt $\mathrm{H}$, Glaab $\mathrm{T}$, and Vogelmeier CF (2014) Effect of ADRB2 polymorphisms on the efficacy of salmeterol and tiotropium in preventing COPD exacerbations: a prespecified substudy of the POET-COPD trial. Lancet Respir Med 2:44-53.

Ray R, Tombs L, Asmus MJ, Boucot I, Lipson DA, Compton C, and Naya I (2018) Efficacy of umeclidinium/vilanterol in elderly patients with COPD: a pooled analysis of randomized controlled trials. Drugs Aging 35:637-647.

Rider CF, Altonsy MO, Mostafa MM, Shah SV, Sasse S, Manson ML, Yan D, Kärrman-Mårdh C, Miller-Larsson A, Gerber AN, et al. (2018) Long-acting $\beta_{2}$-adrenoceptor agonists enhance glucocorticoid receptor (GR)-mediated transcription by gene-specific mechanisms rather than generic effects via GR. Mol Pharmacol 94: 1031-1046.

Riffo-Vasquez Y, Man F, and Page CP (2014) Doxofylline, a novofylline inhibits lung inflammation induced by lipopolysaccharide in the mouse. Pulm Pharmacol Ther 27:170-178.

Riffo-Vasquez Y, Venkatasamy R, and Page CP (2018) Steroid sparing effects of doxofylline. Pulm Pharmacol Ther 48:1-4.

Rinaldi B, Donniacuo M, Sodano L, Gritti G, Martuscelli E, Orlandi A, Rafaniello C Rossi F, Calzetta L, Capuano A, et al. (2015) Effects of chronic treatment with the new ultra-long-acting $\beta_{2}$-adrenoceptor agonist indacaterol alone or in combination with the $\beta_{1}$-adrenoceptor blocker metoprolol on cardiac remodelling. $\mathrm{Br}$ J Pharmacol 172:3627-3637.

Rocco PR, Momesso DP, Figueira RC, Ferreira HC, Cadete RA, Légora-Machado A, Koatz VL, Lima LM, Barreiro EJ, and Zin WA (2003) Therapeutic potential of a new phosphodiesterase inhibitor in acute lung injury. Eur Respir $J$ 22:20-27.

Rodrigo GJ, Moral VP, Marcos LG, and Castro-Rodriguez JA (2009) Safety of regular use of long-acting beta agonists as monotherapy or added to inhaled corticosteroids in asthma. A systematic review. Pulm Pharmacol Ther 22:9-19.

Rogliani P, Calzetta L, Braido F, Cazzola M, Clini E, Pelaia G, Rossi A, Scichilone N, and Di Marco F (2018a) LABA/LAMA fixed-dose combinations in patients with COPD: a systematic review. Int J Chron Obstruct Pulmon Dis 13:3115-3130.

Rogliani P, Calzetta L, and Cazzola M (2018d) Is ICS-LAMA an alternative option to treat patients with COPD? Lancet Respir Med 6:316-317.

Rogliani P, Calzetta L, Segreti A, Barrile A, and Cazzola M (2014a) Diabetes mellitus among outpatients with COPD attending a university hospital. Acta Diabetol 51 933-940.

Rogliani P, Matera MG, Ritondo BL, De Guido I, Puxeddu E, Cazzola M, and Calzetta L (2019) Efficacy and cardiovascular safety profile of dual bronchodilation therapy in chronic obstructive pulmonary disease: a bidimensional comparative analysis across fixed-dose combinations. Pulm Pharmacol Ther 59:101841.

Rogliani P, Ora J, Ciaprini C, Senis L, Stirpe E, and Cazzola M (2014b) Effect of indacaterol on arterial blood gases in patients suffering from acute exacerbation of COPD. Respir Med 108:307-313.

Rogliani P, Ora J, Matera MG, Cazzola M, and Calzetta L (2018b) The safety of dual bronchodilation on cardiovascular serious adverse events in COPD. Expert Opin Drug Saf 17:589-596.

Rogliani P, Ora J, Puxeddu E, Calzetta L, Cavalli F, Matera MG, and Cazzola M (2018c) Effect of adding roflumilast or ciclesonide to glycopyrronium on lung volumes and exercise tolerance in patients with severe COPD: a pilot study. Pulm Pharmacol Ther 49:20-26.

Rogliani P, Ora J, Puxeddu E, and Cazzola M (2016) Airflow obstruction: is it asthma or is it COPD? Int J Chron Obstruct Pulmon Dis 11:3007-3013.

Rosethorne EM, Bradley ME, Gherbi K, Sykes DA, Sattikar A, Wright JD, Renard E, Trifilieff A, Fairhurst RA, and Charlton SJ (2016) Long receptor residence time of C26 contributes to super agonist activity at the human $\beta_{2}$ adrenoceptor. $\mathrm{Mol}$ Pharmacol 89:467-475.

Rossios C, To Y, Osoata G, Ito M, Barnes PJ, and Ito K (2012) Corticosteroid insensitivity is reversed by formoterol via phosphoinositide-3-kinase inhibition. $\mathrm{Br}$ J Pharmacol 167:775-786.

Roversi S, Fabbri LM, Sin DD, Hawkins NM, and Agustí A (2016) Chronic obstructive pulmonary disease and cardiac diseases. an urgent need for integrated care. Am J Respir Crit Care Med 194:1319-1336.

Rydell-Törmänen K, Risse PA, Kanabar V, Bagchi R, Czubryt MP, and Johnson JR (2013) Smooth muscle in tissue remodeling and hyper-reactivity: airways and arteries. Pulm Pharmacol Ther 26:13-23.

Saint GL, Semple MG, Sinha I, and Hawcutt DB (2018) Optimizing the dosing of intravenous theophylline in acute severe asthma in children. Paediatr Drugs 20 209-214.

Sandhu MS, Dimov V, Romero T, Wichman T, and Casale TB (2010) Effects of rosiglitazone on airway hyperresponsiveness and obstruction in asthma (Abstract). $J$ Allergy Clin Immunol 125:AB66.

Santus P, Radovanovic D, Henchi S, Di Marco F, Centanni S, D'Angelo E, and Pecchiari M (2014) Assessment of acute bronchodilator effects from specific airway resistance changes in stable COPD patients. Respir Physiol Neurobiol 197: $36-45$

Schrage R, De Min A, Hochheiser K, Kostenis E, and Mohr K (2016) Superagonism at G protein-coupled receptors and beyond. Br J Pharmacol 173:3018-3027.

Segreti A, Fiori E, Calzetta L, Sabatini M, Segreti V, Rogliani P, and Cazzola M (2013) The effect of indacaterol during an acute exacerbation of COPD. Pulm Pharmacol Ther 26:630-634.
Selroos O (2008) Effect of disease duration on dose-response of inhaled budesonide in asthma. Respir Med 102:1065-1072.

Seymour SM, Lim R, Xia C, Andraca-Carrera E, and Chowdhury BA (2018) Inhaled corticosteroids and LABAs - removal of the FDA's boxed warning. $N$ Engl J Med 378:2461-2463.

Shimizu Y, Dobashi K, Kusano M, and Mori M (2012) Different gastoroesophagea reflux symptoms of middle-aged to elderly asthma and chronic obstructive pulmonary disease (COPD) patients. J Clin Biochem Nutr 50:169-175.

Shrimanker R, Choo XN, and Pavord ID (2017) A new approach to the classification and management of airways diseases: identification of treatable traits. Clin Sci (Lond) 131:1027-1043.

Singh D, Abbott-Banner K, Bengtsson T, and Newman K (2018) The short-term bronchodilator effects of the dual phosphodiesterase 3 and 4 inhibitor RPL554 in COPD. Eur Respir J 52:1801074.

Singh D, Astbury C, Jimenez L, Seoane B, Villarroel C, Balaguer V, Lei A and Aggarwal A (2017) A randomized placebo and active controlled trial of AZD8871 a novel dual acting bronchodilator in COPD patients. Eur Respir $J \mathbf{5 0}$ (Suppl 61):PA1798

Siu AL, Bibbins-Domingo K, Grossman DC, Davidson KW, Epling JW Jr, García FA Gillman M, Kemper AR, Krist AH, Kurth AE, et al. US Preventive Services Task Force (USPSTF) (2016) Screening for chronic obstructive pulmonary disease: US Preventive Services Task Force recommendation statement. JAMA 315: 1372-1377.

Slob EMA, Vijverberg SJH, Palmer CNA, Zazuli Z, Farzan N, Oliveri NMB, Pijnenburg MW, Koppelman GH and Maitland-van der Zee AH (2018) Pharmacogenetics of inhaled long-acting beta2-agonists in asthma: a systematic review. Pediatr Allergy Immunol 29:705-714

Sobieraj DM, Baker WL, Nguyen E, Weeda ER, Coleman CI, White CM, Lazarus SC, Blake KV, and Lang JE (2018a) Association of inhaled corticosteroids and long-acting muscarinic antagonists with asthma control in patients with uncontrolled, persistent asthma: a systematic review and meta-analysis. JAMA 319:1473-1484.

Sobieraj DM, Weeda ER, Nguyen E, Coleman CI, White CM, Lazarus SC, Blake KV, Lang JE, and Baker WL (2018b) Association of inhaled corticosteroids and longacting $\beta$-agonists as controller and quick relief therapy with exacerbations and symptom control in persistent asthma: a systematic review and meta-analysis. JAMA 319:1485-1496.

Song P, Milanese M, Crimi E, Bruzzone S, Zocchi E, Rehder K, and Brusasco V (2000) $\mathrm{G}(\mathrm{s})$ protein dysfunction in allergen-challenged human isolated passively sensitized bronchi. Am J Physiol Lung Cell Mol Physiol 279:L209-L215.

Spannella F, Giulietti F, Cesari V, Francioso A, Cocci G, Landi L, Lombardi FE, Borioni E, Bernardi B, Rosettani G, et al. (2018) Combination therapy of inhaled indacaterol/glycopyrronium for chronic obstructive pulmonary disease in the very elderly: is it safe? An electrocardiographic evaluation. Respiration 95 (Suppl 1): $22-29$

Spina D and Page CP (2017) Xanthines and Phosphodiesterase Inhibitors. Handb Exp Pharmacol 237:63-91.

Stempel DA, Szefler SJ, Pedersen S, Zeiger RS, Yeakey AM, Lee LA, Liu AH, Mitchell H, Kral KM, Raphiou IH, et al.; VESTRI Investigators (2016) Safety of adding salmeterol to fluticasone propionate in children with asthma. $N$ Engl J Med 375:840-849.

Stuehr D, Ghosh A, Koziol-White C, Asosingh K, Aronica M, Panettieri RA and Erzurum S (2017) Soluble guanylate cyclase as an alternative target for bronchodilator therapy in asthma (Abstract). Am J Respir Crit Care Med 195: A3162.

Su VY, Hu LY, Yeh CM, Chiang HL, Shen CC, Chou KT, Chen TJ, Lu T, Tzeng CH, and Liu CJ (2017) Chronic obstructive pulmonary disease associated with increased risk of bipolar disorder. Chron Respir Dis 14:151-160.

Suissa S, Blais L, and Ernst P (1994) Patterns of increasing beta-agonist use and the risk of fatal or near-fatal asthma. Eur Respir $J$ 7:1602-1609.

Suissa S, Dell'Aniello S, and Ernst P (2018) Comparative effectiveness of LABA-ICS versus LAMA as initial treatment in COPD targeted by blood eosinophils: a population-based cohort study. Lancet Respir Med 6:855-862.

Sullivan P, Bekir S, Jaffar Z, Page C, Jeffery P, and Costello J (1994) Antiinflammatory effects of low-dose oral theophylline in atopic asthma. Lancet 343: $1006-1008$

Sutrisna E (2016) The impact of CYP1A2 and CYP2E1 genes polymorphism on theophylline response. J Clin Diagn Res 10:FE01-FE03.

Tannheimer SL, Sorensen EA, Cui ZH, Kim M, Patel L, Baker WR, Phillips GB Wright CD, and Salmon M (2014) The in vitro pharmacology of GS-5759, a novel bifunctional phosphodiesterase 4 inhibitor and long acting $\beta 2$-adrenoceptor agonist. J Pharmacol Exp Ther 349:85-93.

Tannu SA, Renzetti LM, Tare N, Ventre JD, Lavelle D, Lin TA, Morschauser A, Paciorek J, Bolin DR, Michel H, et al. (2010) Dual bronchodilatory and pulmonary anti-inflammatory activity of RO5024118, a novel agonist at vasoactive intestinal peptide VPAC2 receptors. Br J Pharmacol 161:1329-1342.

Teneggi V, Sivakumar N, Chen D, and Matter A (2018) Drugs' development in acute heart failure: what went wrong? Heart Fail Rev 23:667-691.

Thomas M and Pavord I (2012) Single inhaler maintenance and reliever therapy (SMART) in general practice asthma management: where are we? Prim Care Respir $J$ 21:8-10.

Turner D, Ferrari N, Ford WR, Kidd EJ, Nevin B, Paquet L, Renzi P, and Broadley KJ (2012) Bronchoprotection in conscious guinea pigs by budesonide and the NOdonating analogue, TPI 1020, alone and combined with tiotropium or formoterol. Br J Pharmacol 167:515-526.

Turner S, Francis B, Vijverberg S, Pino-Yanes M, Maitland-van der Zee AH, Basu K, Bignell L, Mukhopadhyay S, Tavendale R, Palmer C, et al.; Pharmacogenomics in Childhood Asthma Consortium (2016) Childhood asthma exacerbations and the Arg16 $\beta_{2}$-receptor polymorphism: a meta-analysis stratified by treatment. $J \mathrm{Al}$ lergy Clin Immunol 138:107-113.e5. 
Van Ly D and Oliver BG (2015) Do we really need to keep redesigning $\beta_{2}$-agonists for the management of asthma? Curr Drug Deliv 12:9-15.

van Mastbergen J, Jolas T, Allegra L, and Page CP (2012) The mechanism of action of doxofylline is unrelated to HDAC inhibition, PDE inhibition or adenosine receptor antagonism. Pulm Pharmacol Ther 25:55-61.

Vrijlandt EJLE, El Azzi G, Vandewalker M, Rupp N, Harper T, Graham L, Szefler SJ, Moroni-Zentgraf P, Sharma A, Vulcu SD, et al. (2018) Safety and efficacy of tiotropium in children aged 1-5 years with persistent asthmatic symptoms: a randomised, double-blind, placebo-controlled trial. Lancet Respir Med 6:127-137.

Xiang Z, Liu J, Sun H, and Wen X (2017) Discovery of novel potent muscarinic $\mathrm{M}_{3}$ receptor antagonists with proper plasma stability by structural recombination of marketed $\mathrm{M}_{3}$ antagonists. ChemMedChem 12:1173-1182.

Xing G, Pan L, Yi C, Li X, Ge X, Zhao Y, Liu Y, Li J, Woo A, Lin B, et al. (2019) Design, synthesis and biological evaluation of 5-(2-amino-1-hydroxyethyl)-8hydroxyquinolin-2 $(1 \mathrm{H})$-one derivatives as potent $\beta_{2}$-adrenoceptor agonists. Bioorg Med Chem 27:2306-2314.

Xiong $\mathrm{S}$ and $\mathrm{Li} \mathrm{L}$ (2018) The effect of CYP1A2 gene polymorphism on the metabolism of theophylline. Exp Ther Med 15:109-114.

Wallin M, Tagami T, Chen L, Yang M, and Chan HK (2018) Pulmonary drug delivery to older people. Adv Drug Deliv Rev 135:50-61.

Wang K, Milojevic N, Sheinman B, and Usmani OS (2017) Cough management in primary, secondary and tertiary settings. Pulm Pharmacol Ther 47:93-98.

Wang L, Zhou R, and Xie X (2019) Tiotropium added to low- to medium-dose inhaled corticosteroids (ICS) versus low- to medium-dose ICS alone for adults with mild to moderate uncontrolled persistent asthma: a systematic review and meta-analysis. J Asthma 56:69-78.

Wang MT, Liou JT, Lin CW, Tsai CL, Wang YH, Hsu YJ, and Lai JH (2018) Association of cardiovascular risk with inhaled long-acting bronchodilators in patients with chronic obstructive pulmonary disease: a nested case-control study. JAMA Intern Med 178:229-238.

Welte T, Vogelmeier C, and Papi A (2015) COPD: early diagnosis and treatment to slow disease progression. Int J Clin Pract 69:336-349.

White J, Paton JY, Niven R, and Pinnock H (2018) Guidelines for the diagnosis and management of asthma: a look at the key differences between BTS/ SIGN and NICE. Thorax 73:293-297.

Wielders PL, Ludwig-Sengpiel A, Locantore N, Baggen S, Chan R, and Riley JH (2013) A new class of bronchodilator improves lung function in COPD: a trial with GSK961081. Eur Respir J 42:972-981.

Wilairat P, Kengkla K, Thayawiwat C, Phlaisaithong P, Somboonmee S, and Saokaew S (2019) Clinical outcomes of theophylline use as add-on therapy in patients with chronic obstructive pulmonary disease: a propensity score matching analysis. Chron Respir Dis 16:1479973118815694.
Yan D, Ayer L, and Giembycz M (2014) EP4-receptor agonism as a novel therapeutic approach for the treatment of chronic inflammatory lung disease. Am J Respir Crit Care Med 189:A4902.

Yarova PL, Stewart AL, Sathish V, Britt RD Jr, Thompson MA, P Lowe AP, Freeman M, Aravamudan B, Kita H, Brennan SC, et al. (2015) Calcium-sensing receptor antagonists abrogate airway hyperresponsiveness and inflammation in allergic asthma. Sci Transl Med 7:284ra60.

Yim EY, Kang HR, Jung JW, Sohn SW, and Cho SH (2013) CYP1A2 polymorphism and theophylline clearance in Korean non-smoking asthmatics. Asia Pac Allergy 3 231-240.

Yohannes AM, Kaplan A, and Hanania NA (2018) Anxiety and depression in chronic obstructive pulmonary disease: recognition and management. Cleve Clin J Med $\mathbf{8 5}$ (Suppl 1):S11-S18

Yoo EJ, Cao G, Koziol-White CJ, Ojiaku CA, Sunder K, Jude JA, Michael JV, Lam H, Pushkarsky I, Damoiseaux R, et al. (2017) G $\alpha 12$ facilitates shortening in human airway smooth muscle by modulating phosphoinositide 3-kinase-mediated activation in a RhoA-dependent manner. Br J Pharmacol 174:4383-4395.

Yun JH, Jeong HS, Kim KJ, Han MH, Lee EH, Lee K, and Cho CH (2018) $\beta$-Adrenergic receptor agonists attenuate pericyte loss in diabetic retinas through Akt activation. FASEB $J$ 32:2324-2338.

Zanasi A, Lecchi M, Del Forno M, Fabbri E, Mastroroberto M, Mazzolini M, Pisani L, Pandolfi P, Nava S, and Morselli-Labate AM (2014) A randomized, placebocontrolled, double-blind trial on the management of post-infective cough by inhaled ipratropium and salbutamol administered in combination. Pulm Pharmacol Ther 29:224-232.

Zhang Y, Zeng K, Wang J, Gao H, Nan Y, and Zheng X (2016) Identifying the antiasthmatic target of doxofylline using immobilized $\beta_{2}$-adrenoceptor based highperformance affinity chromatography and site-directed molecular docking. $\mathrm{J} \mathrm{Mol}$ Recognit 29:492-498.

Zhou Y, Zhong NS, Li X, Chen S, Zheng J, Zhao D, Yao W, Zhi R, Wei L, He B, et al. (2017) Tiotropium in early-stage chronic obstructive pulmonary disease. $N$ Engl J Med 377:923-935.

Zhu B, Haghi M, Goud M, Young PM, and Traini D (2015a) The formulation of a pressurized metered dose inhaler containing theophylline for inhalation. Eur J Pharm Sci 76:68-72.

Zhu B, Haghi M, Nguyen A, Goud M, Yeung S, Young PM, and Traini D (2015b) Delivery of theophylline as dry powder for inhalation. Asian J Pharm Sci 10: $520-527$.

Zuurhout MJ, Vijverberg SJ, Raaijmakers JA, Koenderman L, Postma DS, Koppelman GH, and Maitland-van der Zee AH (2013) Arg16 ADRB2 genotype increases the risk of asthma exacerbation in children with a reported use of long-acting $\beta_{2^{-}}$ agonists: results of the PACMAN cohort. Pharmacogenomics 14:1965-1971. 